\title{
MEASUREMENTS OF TROPICAL BAMBOO WATER USE
}

The Dissertation Submitted in Partial Fulfillments for the Academic Degree of "Doctor of Philosophy" of the Faculty of Forest Sciences and Forest Ecology of the Georg-August-Universität Göttingen

submitted by

Ting-Ting Mei

from Zhejiang, China

Göttingen, 2017 
$\underline{\text { Reviewers }}$

Prof. Dr. Dirk Hölscher

Prof. Dr. Christoph Leuschner

Date of the oral examination: 21 March 2017 


\begin{abstract}
Bamboos are grasses (Poaceae) that are widespread in tropical and subtropical regions. As monocots, woody bamboos have thin-wall hollow culms with abundant parenchyma and the culms are connected by rhizomes. These properties may imply that bamboos have specific water use characteristics. For example, the abundant parenchyma in culms provides a water reservoir for internal water storage, which may influence the response of water use to environmental factors; the connected rhizome provides passages for water transfer between bamboo culms. However, only a few water-use related studies have been conducted with thermal dissipation probe (TDP) and deuterium $\left(\mathrm{D}_{2} \mathrm{O}\right)$ tracing method until now. Therefore, in the present study, we aimed at exploring water use characteristics of four tropical bamboo species (Bambusa vulgaris, Dendrocalamus asper, Gigantochloa atroviolacea and Gigantochloa apus) with TDP and deuterium tracing method. At the meantime, to accurately measure bamboo water use, we also tested and calibrated TDP on the studied bamboo species, and assessed the influence of bamboo water content on TDP. Additionally, as a less used water use measurement method, potential error sources of deuterium tracing method were explored when applying it on bamboos to explore water use, storage and transfer.

As the first step, the TDP method was calibrated with the stem heat balance method (SHB) and gravimetric readings in B. vulgaris culms in a pot experiment. In this experiment, it was confirmed that the stem heat balance method is well suited for bamboos but that thermal dissipation probes need to be calibrated. In situ, TDP was further calibrated with SHB for the four bamboo species and species-specific parameters for such calibration formulas were derived. With the calibrated TDP, we monitored sap flux density $\left(J_{\mathrm{s}}\right)$ of the four bamboo species along with three tropical tree species (Gmelina arborea, Shorea leprosula and Hevea brasiliensis) during a dry and a wet period. During field monitoring, we found that some bamboo species reached high maximal $J_{\mathrm{s}}$. Across bamboo species, maximal $J_{\mathrm{s}}$ increased with decreasing culm diameter. In the diurnal course, $J_{\mathrm{s}}$ in bamboos peaked much earlier than radiation and
\end{abstract}


vapor pressure deficit (VPD), and also much earlier than $J_{\mathrm{s}}$ in trees. There was a pronounced hysteresis between $J_{\mathrm{S}}$ and VPD in bamboos, which was less pronounced in trees. Three of the four bamboo species showed reduced $J_{\mathrm{S}}$ at high VPD values during the dry period, which was associated with a decrease in soil moisture content. Possible roles of internal water storage, root pressure and stomatal sensitivity are discussed.

Bamboos and other plants may substantially rely on stem water storage for transpiration. Fluctuations in wood water content $\left(\theta_{\text {wood }}\right)$ may lead to errors when estimating transpiration based on $J_{\mathrm{S}}$ measurements with the widely used TDP method. To test the effects of $\theta_{\text {wood }}$ on $J_{s}$, we conducted a culm dehydration experiment, monitored bamboos with TDP, and implemented a steady-state thermal model. Central to the calculation of $J_{\mathrm{s}}$, and thus a major potential source of error, is the maximal temperature difference between probes $\left(\Delta \mathrm{T}_{\max }\right)$ which are usually assumed to happen under "zero sap flow" condition. In the culm dehydration experiment, $\theta_{\text {wood }}$ was found to be highly negatively correlated with $\Delta \mathrm{T}_{\max }$. In the long-term field monitoring, soil moisture content was also negatively correlated with daily $\Delta \mathrm{T}_{\max }$, indicating changes in $\theta_{\text {wood }}$ and a seasonal decrease in stem water storage. The steady-state model reproduced the $\theta_{\text {wood }}$ to $\Delta \mathrm{T}_{\max }$ relationship of the dehydration experiment and underlined a considerable sensitivity of $J_{\mathrm{S}}$ estimates to $\theta_{\text {wood }}$. Fluctuations in $\theta_{\text {wood }}$ may lead to substantial underestimation of $J_{\mathrm{s}}$, and subsequently of transpiration, in commonly applied estimation schemes. However, our model results suggest that such underestimation can be quantified and subsequently corrected when key wood properties are known. Our study gives insights into the relationship between $\theta_{\text {wood }}$ and TDP-derived $J_{\mathrm{s}}$ and examines potential estimation biases.

Deuterium tracing method was also applied on bamboos to explore water use, storage and transfer, and its potential error sources were explored. The deuterium-derived sap velocities correlated with the TDP-derived velocities in two of the three species. In all species, the deuterium residence time in bamboo culms was little influenced by the contribution of the culm water storage to transpiration as estimated by TDPs at different culm heights. Potential reasons include a small water storage volume in the culms, a low estimated contribution of the storage to transpiration and high sap flux densities. Daily culm water use rates estimated by the deuterium and the TDP approaches correlated linearly $\left(R^{2}=0.9\right)$ but were by $70 \%$ in the deuterium estimates. After the experiment, culms were cut down and analyzed for residual deuterium, but concentrations were low which indicates that retention did not play a 
major role in causing errors of the deuterium tracing approach. In culms neighboring the deuterium labeled culms of B. vulgaris and G. apus, elevated deuterium concentrations were detected indicating water transfer between culms. Based on the differences in daily water use on labeled culms and the enhanced deuterium concentrations in neighboring culms of these two species, we inferred that five neighboring culms might receive water from the labeled culms. On contrast, in culms neighboring labeled $D$. asper culms, only slightly elevated deuterium concentrations were observed which implies a limited role by water transfer. However, incomplete mixing as indicated by high variation among three TDP sensors at a given height may be of particular importance for deuterium tracing in $D$. asper. In conclusion, species-specific differences among big clumpy bamboos are indicated and the deuterium tracing points to water transfer among culms. 



\section{Table of contents}

1 Introduction 1

1.1 The distribution and usage of bamboos . . . . . . . . . . . 1

1.2 The growing and anatomical characteristics of bamboos . . . . 2

1.3 Water use characteristics of bamboos . . . . . . . . . . 2

1.3.1 Water use . . . . . . . . . . . . . . . 3

1.3.2 Sap flow pattern and stem water content . . . . . . . 4

1.3.3 Water transfer among bamboo culms ....... . 5

1.4 Aims of the study . . . . . . . . . . . . . . 6

1.5 Author contribution . . . . . . . . . . . . . 6

2 Water use patterns of four tropical bamboo species assessed with sap flux measurements 9

2.1 Introduction . . . . . . . . . . . . . . . . . 10

2.2 Materials and methods . . . . . . . . . . . . . 12

2.2.1 Study sites and species selection . . . . . . . . . 12

2.2.2 TDP construction and installation . . . . . . . . 13

2.2.3 Calibration of the TDP method . . . . . . . . . 13

2.2 .4 Field study . . . . . . . . . . . . . . . . . 17

2.3 Results . . . . . . . . . . . . . . . . . 18

2.3.1 Calibration of the TDP method for bamboos . . . . . 18

2.3.2 Field calibration experiment: TDP \& SHB . . . . . 19

2.3 .3 Field study . . . . . . . . . . . . . 21

2.4 Discussion . . . . . . . . . . . . . . . 25

2.4.1 Calibration experiments .......... 25

2.4.2 Water use patterns of bamboos and trees . . . . . . 27

2.5 Conclusion . . . . . . . . . . . . . . . . 30

3 The influence of bamboo culm water content on sap flux measurements by thermal dissipation probes: observations and modeling 31 
3.1 Introduction . . . . . . . . . . . . . . . 32

3.2 Methods ...................... 34

3.2.1 Culm $\theta_{\text {wood }}$ and $\theta_{\text {soil }}$ and $\Delta \mathrm{T}_{\max } \ldots \ldots \ldots 34$

3.2.2 The influence of $\theta_{\text {wood }}$ on $J_{\mathrm{s}} \ldots \ldots \ldots$. . . . . . 38

3.3 Results . . . . . . . . . . . . . . . . . . . . 39

3.3.1 $\Delta \mathrm{T}_{\max }$ and $\theta_{\text {wood }} / \theta_{\text {soil }} \ldots \ldots \ldots \ldots$

3.3.2 The influence of $\theta_{\text {wood }}$ on $J_{\mathrm{s}} \ldots \ldots \ldots$. . . . . 41

3.4 Discussion . . . . . . . . . . . . . . . . . . . 44

3.4.1 $\Delta \mathrm{T}_{\max }$ and $\theta_{\text {wood }} / \theta_{\text {soil }} \ldots \ldots \ldots \ldots 44$

3.4.2 The influence of $\theta_{\text {wood }}$ on $J_{\mathrm{s}} \ldots \ldots \ldots$. . . . . 46

3.5 Conclusions . . . . . . . . . . . . . . . . 48

4 Deuterium tracing for assessing water circulation in bamboos 49

4.1 Introduction . . . . . . . . . . . . . . 50

4.2 Materials and methods . . . . . . . . . . . . . 53

4.2.1 Study site and species . . . . . . . . . . . . 53

4.2.2 Deuterium tracing . . . . . . . . . . . . 53

4.2.3 Deuterium analysis in the lab . . . . . . . . . 55

4.2.4 Deuterium arrival time, velocity and residence time . . 56

4.2.5 Sap flow measurement and water use estimation by TDP method . . . . . . . . . . . . . 56

4.2.6 Data analysis and statistics . . . . . . . . . . 58

4.3 Results . . . . . . . . . . . . . . . . 58

4.3.1 Tracer movement and sap velocity . . . . . . . . . 58

4.3.2 Residence time and stem water storage . . . . . . . 59

4.3 .3 Water use . . . . . . . . . . . . . . . . . 61

4.3.4 $\mathrm{D}_{2} \mathrm{O}$ retention, transfer, incomplete mixing and their influence on deuterium derived water use rate . . . . 61

4.4 Discussion . . . . . . . . . . . . . . . . . 63

4.4.1 Sap velocity . . . . . . . . . . . . . 63

4.4.2 $\mathrm{D}_{2} \mathrm{O}$ residence time and water storage . . . . . . 65

4.4.3 Water use derived with deuterium tracing method . . . 66

4.4.4 Deuterium retention and its influence on $\mathrm{WU}_{\mathrm{D}_{2} \mathrm{O}} \ldots 66$

4.4.5 $\mathrm{D}_{2} \mathrm{O}$ transfer between culms and its influence on $\mathrm{WU}_{\mathrm{D}_{2} \mathrm{O}} 67$

4.4.6 Variability of sap flux and incomplete mixing of $\mathrm{D}_{2} \mathrm{O}$. 69

4.5 Conclusions . . . . . . . . . . . . . . . . . . 69 
5 Synthesis $\quad 71$

5.1 Bamboo water use and methods testing . . . . . . . 71

5.2 Outlook ....................... 75

$\begin{array}{ll}\text { Bibliography } & 77\end{array}$

$\begin{array}{ll}\text { List of figures } & 87\end{array}$

$\begin{array}{ll}\text { List of tables } & 93\end{array}$

$\begin{array}{ll}\text { Appendix } & 95\end{array}$

$\begin{array}{ll}\text { Curriculum vitae } & 105\end{array}$ 



\section{Chapter 1}

\section{Introduction}

\subsection{The distribution and usage of bamboos}

Bamboo is a generic term of Bambusoideae (Mathew, 1998), which is a subfamily of Poaceae (Liese and Köhl, 2015). The bamboos comprise more than 1400 species, and distribute over temperate and tropical regions (BPG, 2012). Until 2010, bamboos covered 31.5 million hectares in 31 countries mostly in South America and Asia (FAO, 2010). These areas are mainly characterized by relatively high air temperature and humidity levels, as such conditions promote the shoot emergence and the culm elongating of the newly sprouted bamboos during the culm elongating period (Liese and Köhl, 2015; Numata, 1987).

The bamboos provide important resources for people with many usages. Traditionally, the bamboos are used as food (bamboo shoot; e.g. Dendrocalamus asper, Gigantochloa apus), and for producing wine, medicine, tee, etc.; the harvested bamboos can be used for building, furniture and engineered bamboo products (Liese and Köhl, 2015). With the development of technologies, bamboos were frequently introduced into new areas, such as biofuel (Kremer et al., 2015), clean energy (Feng et al., 2015) etc. Some species (e.g. Bambusa vulgaris) can be even used for building high-quality "bamboo bicycle" (Liese and Köhl, 2015). At last, Bamboos are considered as valuable non-timber resources contributing to forest conservation and carbon bio-sequestration due to their great growth rate and potentially high yield (Parr et al., 2010; Song et al., 2013; Zhuang et al., 2015). For example, Moso bamboo (Phyllostachys pubescens) accounts for about $5 \%$ of total forest area in China and is an important carbon stock (35-85 $\mathrm{Mg} \mathrm{ha}^{-1}$ ) in subtropical regions (Wang et al., 2013). 


\subsection{The growing and anatomical characteristics of bamboos}

Most of bamboos are woody bamboos, which have tree-like habits but differ from trees in many respects (BPG, 2012). One distinctive characteristic of the bamboos is their fast-growing property. Within one growth season, a newly sprouted bamboo culm can reach its full height with a growth rate of $10-80 \mathrm{~cm}$ per day (Liese and Köhl, 2015). For some species (e.g. D. asper), under favorable conditions daily growth can reach $120 \mathrm{~cm}$ (Durst et al., 1994). Secondly, as monocots, bamboos only have axial growth while without radial growth, which means the diameters of bamboos keep unchanged after the culms emerge from soil. Correspondingly, bamboo culms lack the radial transport of water across the culms (Liese and Köhl, 2015). Third, the bamboo culms (stems) are segmented by solid nodes and hollow internodes. Lacking secondary growth and the hollow culms require bamboos to keep the vascular bundles in the culms conducting over the whole life. Keeping conducting tissues working and avoiding embolism may probably rely on the powerful root pressure (Cao et al., 2012; Yang et al., 2015). Further, bamboos develop underground connections with rhizomes that have similar anatomical structure as culms (Ito et al., 2015), which was assumed as passage for water and nutrients transfer between mature and new sprouted culms (Song et al., 2016). The connected rhizomes make the culms relying to each other, losing one culm may influence the others (Liese and Köhl, 2015).

\subsection{Water use characteristics of bamboos}

The specific anatomy of bamboo may lead to special water use characteristics, while only a few studies focus on such topics thus far (Cao et al., 2012; Dierick et al., 2010; Ichihashi et al., 2015; Komatsu et al., 2010; Kume et al., 2010; Yang et al., 2015; Zhao et al., 2016). In these studies, except one study focusing on the role of root pressure (Cao et al., 2012), all of the others applied sap flow measurement to study the daily or seasonal dynamics of bamboo water use while had different emphasis. 


\subsubsection{Water use}

One concerned question is whether the bamboos consume different water volumes than neighboring trees, on stand or individual scales. On stand scale, compared with the neighboring trees, the non-clump Moso bamboos in Japan transpired more water in both low- (Ichihashi et al., 2015) and high-density stands (Komatsu et al., 2010). On the individual scale, the maximal sap flux density $\left(J_{\mathrm{s}_{-} \max }\right)$ of Moso bamboos in low- and high-density stands was ca. fourand two-fold of that in the compared cedar trees (Ichihashi et al., 2015). The $J_{\text {S_max }}$ of Moso bamboos in another study was about $20 \mathrm{~g} \mathrm{~cm}^{-2} \mathrm{~h}^{-1}$ (Kume et al., 2010), which was close to the values (22.6 and $20 \mathrm{~g} \mathrm{~cm}^{-2} \mathrm{~h}^{-1}$ in dry and wet seasons, respectively) of a clump species - Bambusa vulgaris in China (Yang et al., 2015). Similar results (on average $21 \mathrm{~g} \mathrm{~cm}^{-2} \mathrm{~h}^{-1}$ ) were also earlier found on another clump species - Bambusa blumeana in the Philippines (Dierick et al., 2010), and such values lay in the range of that from the co-occurring trees in the Philippines (17.7-28.9 $\mathrm{g} \mathrm{cm}^{-2} \mathrm{~h}^{-1}$; Dierick and Hölscher, 2009).

The three bamboo species have similar sap flux densities measured with the widely used thermal dissipation probe method (TDP, Granier, 1985), but the TDP was installed at different positions with different sensor types ( 1 or $2.5 \mathrm{~cm}$ length) and calibrated with different methods. These factors may cause the results of the three studies incomparable. To avoid regular TDP sensor $(2 / 2.5 \mathrm{~cm}$ length) from penetrating the thin culm-wall, TDP was installed at the base (0.35 $\mathrm{m}$ above ground) of the culm (Dierick et al., 2010) or at the breast height with self-made sensor with $1 \mathrm{~cm}$ length (Kume et al., 2010; Yang et al., 2015). However, as the different culm wall cross-section area along the culm may lead to large variation of sap flux density $\left(J_{\mathrm{S}}\right), J_{\mathrm{S}}$ at the base of the culm was lower than that at the higher position (Dierick et al., 2010). Additionally, as Granier's formula was derived with empirical relationship (Granier, 1985) rather than based on the physical properties of the wood (Wullschleger et al., 2011), TDP was recommended calibrating on studied species (Lu et al., 2004; Vandegehuchte and Steppe, 2013; Wullschleger et al., 2011). On Moso bamboos, Kume et al. (2010) found TDP underestimate water use by $35 \%$ compared with gravimetric method, and on B. blumeana Dierick et al. (2010) found 13\% underestimation with TDP compared with stem heat balance method (SHB, Sakuratani, 1981). However, Kume et al. (2010) calibrated TDP on cut down bamboo culms which may differ from standing culms on water physiology while Dierick et al. (2010) calibrated on standing 
Introduction

bamboos with SHB which was not further verified. Therefore, to accurately measure bamboo water use with TDP, calibrating TDP with reference method on standing bamboos of more bamboo species should be conducted.

\subsubsection{Sap flow pattern and stem water content}

In general, transpiration is driven by micrometeorological factors and limited by soil water availability (Bovard et al., 2005; Kume et al., 2007; O'Brien et al., 2004). When soil water availability cannot fulfill the high transpiration demand (e.g. at midday in the sunny day), transpiration can be maintained temporally by stem water storage (Carrasco et al., 2015; Goldstein et al., 1998; Waring and Running, 1978). For bamboos, the role of stem water storage may be influenced by two anatomical properties: relative small volume of culm (hollow center and thin culm-wall) and high percentage of parenchyma in the culm (50\%, Liese and Köhl, 2015). The relative small volume of bamboo culm provides limited room for water storage, while the abundant parenchyma may offset the limitation. On B. blumeana, the sap flow at the base of the culms reached its maximal value before midday but the maximal value didn't last as long as that of trees (Dierick et al., 2010). Similar sap flow pattern was observed at the breast height on B. vulgaris (Yang et al., 2015). This was assumed due to limited soil water and low water storage in the part of the bamboo under the installed sensor. However, the near $J_{\mathrm{S} \_ \text {max }}$ at near the top of the culm persisted much longer than that at the breast height on $B$. vulgaris (Yang et al., 2015) which implied that the culm water storage may play an important role for bamboos. The depleted stored water may be refilled during night by root pressure (Cao et al., 2012).

The depletion and refilling of water storage causes fluctuation of wood water content ( $\theta_{\text {wood }}$, Nadler et al., 2008; Yang et al., 2015). On trees, with the daily fluctuation on transpiration, $\theta_{\text {wood }}$ showed a reverse fluctuation pattern. $\theta_{\text {wood }}$ reached to peak values during night when $J_{\mathrm{s}}$ was zero or minimal, and dropped to minimum during daytime (Hao et al., 2013; Sperling et al., 2015). On a bamboo species (B. vulgaris), similar pattern of bamboo culm circumference was observed (Yang et al., 2015). Although it's not the direct measurement on $\theta_{\text {wood }}$, the daily dynamic of culm circumference should reflect at least part of change on $\theta_{\text {wood }}$ as assumed on trees (Köcher et al., 2013; Scholz et al., 2008). 
The daily fluctuation of $\theta_{\text {wood }}$ may influence the wood thermal conductivity $\left(K_{\text {wood }}\right)$ and thus influence estimating $J_{\mathrm{s}}$ with TDP method. According to a theoretical analysis based on a temperature- $\theta_{\text {wood }}$ function (Carslaw and Jaeger, 1959) and a dehydration experiment on tree stem segments in the lab, it was demonstrated that $\theta_{\text {wood }}$ influenced the $K_{\text {wood }}$ around TDP probes and caused underestimation of daytime $J_{\mathrm{s}}$ (Vergeynst et al., 2014). Additionally, the influence of $\theta_{\text {wood }}$ on $J_{\mathrm{s}}$ may differ with soil water conditions. Previous studies found that $\theta_{\text {soil }}$ can strongly regulate the $\theta_{\text {wood }}$ in trees and palm (Constantz and Murphy, 1990; Holbrook et al., 1992; Wullschleger et al., 1996). During a long-term period (monthly or seasonally), the $\theta_{\text {wood }}$ in tree stems was found fluctuating with $\theta_{\text {soil }}$. In rainy days, $\theta_{\text {wood }}$ in stems of trees or palms was significantly increased and subsequently decreased in the following sunny days (Hao et al., 2013; Holbrook et al., 1992; Wullschleger et al., 1996). Such dynamic $\theta_{\text {wood }}$ in stem may further influence the $K_{\text {wood }}$ around TDP probes. If ignoring these influences, the patterns or values of TDP-derived $J_{\mathrm{s}}$ may be misinterpreted as eco-physiological phenomenon. Vergeynst et al. (2014) quantified the influence of $\theta_{\text {wood }}$ on $J_{\mathrm{s}}$ by setting possible temperature change that was assumed to relate to $\theta_{\text {wood }}$. However, the direct relationship between $\theta_{\text {wood }}$ and errors on $J_{\mathrm{s}}$ remained unclear.

\subsubsection{Water transfer among bamboo culms}

Bamboo culms are connected with each other through underground rhizomes (Ito et al., 2015), which was assumed to provide passage for carbon, water and nutrients transfer between culms (Liese and Köhl, 2015; Song et al., 2016). Water transfer among bamboo culms was implied on B. blumeana by observing elevated deuterium concentrations in neighbor culms which closed to the deuterium labelled culms (Dierick et al., 2010). In a rhizome-cutting experiment on Moso bamboos, Zhao et al. (2016) cut the rhizome between juvenile culms and mature culms and found that the rhizome-cut juvenile culms transpired approx. 20\% less of water compared with other still connected juvenile culms. The result thus implied water transfer among bamboo culms. The above two studies were conducted on mature or 1-year-old juvenile culms, which may rely less on the other culms than the freshly sprouted culms. These freshly sprouted culms may rely more on water transfer through rhizome due to less developed leaves and roots. The deuterium tracing method seems promising to trace the water transfer. 
Deuterium tracing method was typically used to estimate tree daily water use, with injecting deuterated water at the base of the stem, tracing in water transpired from leaves over time and calculating water use with "total count" method (Calder et al., 1986). However, the method may produce errors when tracer was lost or unevenly mixed (Schwendenmann et al., 2010). On bamboos, the tracer loss may occur due to the existence of water transfer. However, if the tracer loss can be quantified, it will improve the application of deuterium tracing on estimating daily water use and probably also help to better understand the transfer dynamics.

\subsection{Aims of the study}

The study aims were:

(1) calibrating TDP on potted bamboos with gravimetric and SHB method and in situ on standing bamboos with SHB method;

(2) with the calibrated TDP, monitoring sap flux densities of bamboos and exploring their patterns and relationships with environmental factors;

(3) exploring the effects of wood water content on sap flux densities derived with TDP by conducting a culm dehydration experiment, monitoring bamboos with TDPs in situ, and implementing a steady-state thermal model; and

(4) detecting water transfer between bamboo culms with the deuterium tracing method, and exploring error sources of deuterium tracing method on bamboo water circulation.

\subsection{Author contribution}

The dissertation is substantiated by three manuscripts (Chapter 2-4) at various stages of the publication process (i.e. 'Advanced draft', 'Published'). The status as well as the contributions to each manuscript by the author of this dissertation (in the following simply refer to as 'the author') is indicated for each manuscript. Chapter 1 and 5 were solely compiled by the author.

Chapter 2: Water use patterns of four tropical bamboo species assessed with sap flux measurements 
Ting-Ting $\mathrm{Mei}^{1 * \dagger}$, Dong-Ming Fang ${ }^{1 \dagger}$, Alexander Röll ${ }^{1}$, Fu-Rong Niu ${ }^{1}$, Hendrayanto $^{2}$, Dirk Hölscher ${ }^{1}$

Manuscript status: Published in Frontiers in Plant Science (2016). DOI: 10.3389/fpls.2015.01202

The concept and research priorities for this bamboo and tree study in Bogor, Indonesia were developed by Dirk Hölscher. The author contributed to experimental design, field installation, maintenance of the installations, data collection, writing and revision for the manuscript, in close cooperation and coordination particularly with Dong-Ming Fang and Dirk Hölscher. Dong-Ming Fang worked through the field work and data analysis. Alexander Röll contributed to field installations and manuscript revisions. Fu-Rong Niu contributed to part of the field installations and plotting for the manuscript. Hendrayanto close cooperated in the project.

Chapter 3: Assessing the influence of stem water content on TDP sap flux measurements by experimental, monitoring and modeling approaches Ting-Ting Mei ${ }^{1 * \dagger}$, Dong-Ming Fang ${ }^{1 \dagger}$, Alexander Röll ${ }^{1}$, Dirk Hölscher ${ }^{1}$ Manuscript status: Under review by Trees.

The concept and research priorities for this stem water content study in Bogor, Indonesia were developed by Dirk Hölscher. The author contributed to experimental design, field installation, maintenance of the installations, data collection, writing, plotting and revision for the manuscript, in close cooperation and coordination particularly with Dong-Ming Fang and Dirk Hölscher. Dong-Ming Fang contributed to model developing and data analysis. Alexander Röll contributed to the manuscript revisions.

\section{Chapter 4: Deuterium tracing on tropical bamboo water use}

Dong-Ming Fang ${ }^{1 * \dagger}$, Ting-Ting $\mathrm{Mei}^{1 \dagger}$, Alexander Röll ${ }^{1}$, Hendrayanto ${ }^{2}$, Dirk Hölscher ${ }^{1}$

\section{Manuscript status: Advanced draft.}

The concept and research priorities for this deuterium tracing study in Bogor, Indonesia were developed by Dirk Hölscher. The author contributed to field installations, sample collections, plotting and revision for the manuscript, in close cooperation and coordination particularly with Dong-Ming Fang and Dirk Hölscher. Dong-Ming Fang contributed to the field installations, sample collections, data analysis and writing and revision for the manuscript. Alexander Röll contributed to the manuscript revisions. 
${ }^{1}$ Tropical Silviculture and Forest Ecology, Georg-August-Universität Göttingen, Germany. ${ }^{2}$ Department of Forest Management, Institut Pertanian Bogor, Indonesia

$\dagger$ The authors contributed equally to this work.

* The corresponding author 


\section{Chapter 2}

\section{Water use patterns of four tropical bamboo species assessed with sap flux measurements}

Ting-Ting Mei ${ }^{1 \dagger *}$, Dong-Ming Fang ${ }^{1 \dagger}$, Alexander Röll ${ }^{1}$, Fu-Rong Niu ${ }^{1}$, Hendrayanto $^{2}$, Dirk Hölscher ${ }^{1}$

${ }^{1}$ Tropical Silviculture and Forest Ecology, Georg-August-Universität Göttingen, Germany. ${ }^{2}$ Department of Forest Management, Institut Pertanian Bogor, Indonesia

$\dagger^{\dagger}$ The authors contributed equally to this work.

* Correspondence: Tingting Mei, Tropical Silviculture and Forest Ecology, Georg-August-Universität Göttingen, Büsgenweg 1, Göttingen, 37077, Germany. Email: tmei@gwdg.de

Running title: bamboo water use

Published in Frontiers in Plant Science (2016). DOI: 10.3389/fpls.2015.01202 
Water use patterns of four tropical bamboo species assessed with sap flux 10

measurements

\section{Abstract}

Bamboos are grasses (Poaceae) that are widespread in tropical and subtropical regions. We aimed at exploring water use patterns of four tropical bamboo species (Bambusa vulgaris, Dendrocalamus asper, Gigantochloa atroviolacea and Gigantochloa apus) with sap flux measurement techniques. Our approach included three experimental steps: (1) a pot experiment with a comparison of thermal dissipation probes, the stem heat balance method and gravimetric readings using potted $B$. vulgaris culms, (2) an in situ calibration of thermal dissipation probes with the stem heat balance method for the four bamboo species, and (3) field monitoring of sap flux of the four bamboo species along with three tropical tree species (Gmelina arborea, Shorea leprosula and Hevea brasiliensis) during a dry and a wet period. In the pot experiment, it was confirmed that the stem heat balance method is well suited for bamboos but that thermal dissipation probes need to be calibrated. In situ, species-specific parameters for such calibration formulas were derived. During field monitoring we found that some bamboo species reached high maximum sap flux densities. Across bamboo species, maximal sap flux density increased with decreasing culm diameter. In the diurnal course, sap flux densities in bamboos peaked much earlier than radiation and vapor pressure deficit (VPD), and also much earlier than sap flux densities in trees. There was a pronounced hysteresis between sap flux density and VPD in bamboos, which was less pronounced in trees. Three of the four bamboo species showed reduced sap flux densities at high VPD values during the dry period, which was associated with a decrease in soil moisture content. Possible roles of internal water storage, root pressure and stomatal sensitivity are discussed.

Keywords: calibration, environmental drivers, hysteresis, stem heat balance, thermal dissipation probes, trees, bamboos

\subsection{Introduction}

Bamboos (Poaceae, Bambuseae) are abundant in the natural vegetation of tropical and subtropical regions. They have been used by people for millennia and are still used as food and construction materials. In addition, a large variety of bamboo usages have been developed in recent decades, for example for pulp, paper or clothing production (INBAR, 2014). The increasing economic 
exploitation of bamboos goes along with a considerable expansion of bamboo plantations in some regions (Chen et al., 2009; FAO, 2010), which may lead to changes in ecological processes such as water use patterns (Komatsu et al., 2010; Uchimura, 1994). Some bamboo stands were reported to evaporate more water than tree-dominated forests (Ichihashi et al., 2015; Komatsu et al., 2010), but studies focusing on water use patterns of bamboos are still rare thus far (Dierick et al., 2010; Ichihashi et al., 2015; Komatsu et al., 2010; Kume et al., 2010; Pereira and Hosegood, 1962).

Water use patterns of bamboos and trees differ in several aspects. In contrast to trees, bamboos are monocotyledonous species and lack secondary growth (Zimmermann and Tomlinson, 1972). Therefore, vascular conduits of bamboo xylem have to remain functional throughout the ontogeny of a bamboo culm. Bamboos consequently have great ability to avoid cavitation (Cao et al., 2012; Cochard et al., 1994; Petit et al., 2014); root pressure mechanisms may contribute to repairing embolized conduits at night (Cao et al., 2012). Such features and structural traits of bamboos may also lead to particular water use patterns.

In general, plant water use is driven by micrometeorological factors and can be limited by soil water availability (Bovard et al., 2005; Kume et al., 2007; O'Brien et al., 2004); it is regulated by stomata opening and closing (Jarvis, 1989) and can be influenced by internal water storage mechanisms (Carrasco et al., 2015; Goldstein et al., 1998; Waring and Running, 1978). Xylem sap flux reflects these multiple factors. For some tree species, for example, hysteresis in the diurnal sap flux response to radiation and vapor pressure deficit (VPD) of the air have been reported (Goldstein et al., 1998; O'Brien et al., 2004). Sap flux measurements thus appear suitable to study the water use patterns of bamboos as well as their controlling environmental factors.

Thermal dissipation probes (TDP) are widely used to measure sap flux density $\left(J_{\mathrm{s}}\right)$ in trees (Granier, 1985). Several studies suggest calibrating the method before studying new species (Lu et al., 2004; Vandegehuchte and Steppe, 2013; Wullschleger et al., 2011). To our knowledge, only two studies have applied the TDP method on bamboos so far. Both reported an underestimation of bamboo sap flux compared to stem heat balance (SHB) and reference gravimetric measurements (GM) when the TDP method was not calibrated (Dierick et al., 2010; Kume et al., 2010). In contrast, the SHB method (Sakuratani, 1981) was suggested to be well suited for sap flux measurements on bamboos (Dierick et al., 2010). Bamboo culms are hollow; hence heat loss in the form of heat 
Water use patterns of four tropical bamboo species assessed with sap flux measurements

storage inside culms is marginal, so that steady thermal conditions as a main assumption of the method are met (Baker and Bavel, 1987).

The aim of this study was to analyze water use patterns of tropical bamboo species and particularly the response of $J_{\mathrm{S}}$ to the principal environmental drivers. First, we calibrated the SHB and the TDP method with reference GM in an experiment on potted culms of Bambusa vulgaris. We then measured $J_{\mathrm{S}}$ in the field in four bamboo species including $B$. vulgaris with both the TDP and SHB method, and calibrated the TDP method with the SHB method. Herein, three factors which may influence the quality of the calibration were tested: time step of the data, formula specificity and calibration formula type. After calibration of the TDP method, we applied it to monitor $J_{\mathrm{S}}$ in four bamboo and three tree species in a common garden in Bogor, Indonesia. Differences in the response of $J_{\mathrm{s}}$ to fluctuations in environmental conditions were assessed. The study intends to contribute to expanding the yet limited knowledge on the eco-hydrological functioning of bamboos.

\subsection{Materials and methods}

\subsubsection{Study sites and species selection}

The pot calibration experiment was conducted in Guangzhou, China $\left(23^{\circ} 26^{\prime} 13^{\prime \prime}\right.$ $\mathrm{N}, 113^{\circ} 12^{\prime} 33^{\prime \prime} \mathrm{E}, 13 \mathrm{~m}$ asl). The field calibration experiment and monitoring campaign were carried out in a common garden in Bogor, Indonesia (6 $6^{\circ} 33^{\prime} 40^{\prime \prime}$ $\mathrm{S}, 106^{\circ} 43^{\prime} 27^{\prime \prime} \mathrm{E}, 182 \mathrm{~m}$ asl). Average annual temperature in Bogor is $25.6^{\circ} \mathrm{C}$ and annual precipitation is $3978 \mathrm{~mm}$.

Relatively dry conditions with consecutive rainless days can occur between June and September. During this dry period, monthly precipitation is on average $40 \%$ lower than during the wet period (230 vs. $383 \mathrm{~mm}$ ), and the number of consecutive dry days (rainfall $<1 \mathrm{~mm}$ ) is twice that of the wet period ( 8 vs. 4 days, 1989-2008, Van Den Besselaar et al., 2015). During our study period (July 2012 to January 2013), differences between dry and wet period were more pronounced, i.e. 155 vs. $489 \mathrm{~mm}$ monthly precipitation, 14 vs. 2 consecutive dry days, and 0.29 vs. $0.39 \mathrm{~m}^{-3} \mathrm{~m}^{-3}$ daily soil water content. In Bogor, four bamboo species (Bambusa vulgaris, Dendrocalamus asper, Gigantochloa atroviolacea, Gigantochloa apus) with five culms per species and three tree species (Gmelina arborea, Shorea leprosula and Hevea brasiliensis, Table 2.1) with five stems per species were selected and their $J_{\mathrm{s}}$ 
were monitored with the TDP method for seven months.

\subsubsection{TDP construction and installation}

To measure $J_{\mathrm{s}}$ in trees and bamboos, we used self-made TDP $(1 \mathrm{~cm}$ and $2 \mathrm{~cm}$ length, respectively). In sensor design and construction, we followed Wang et al. (2012). Each TDP sensor was comprised of a heating (downstream) and a reference (upstream) probe made of steel hypodermic needles. The probes were placed $10 \mathrm{~cm}$ apart (vertically). For bamboos and trees, TDP installation depths in culms and stems were 1 and $2 \mathrm{~cm}$, respectively. After installation, each TDP was supplied with a constant current of $120 \mathrm{~mA}$; the respective power outputs of $1 \mathrm{~cm}$ and $2 \mathrm{~cm}$ length TDP were 0.1 and $0.2 \mathrm{~W}$. TDP signals were sampled every $30 \mathrm{~s}$ and stored as 10 -min averages for the pot calibration experiment and as 1-min averages for all other experiments by data loggers and multiplexers (CR1000, AM16/32, Campbell Scientific Inc., USA).

\subsubsection{Calibration of the TDP method}

\section{Pot calibration experiment: TDP, SHB \& GM}

Five culms of $B$. vulgaris (diameter 5.3-7.3 cm, height 2.2-3.2 m) with trimmed canopies were transplanted into plastic bags (diameter $30 \mathrm{~cm}$, height $25 \mathrm{~cm}$ ) six months before the calibration experiment. One day before the experiment, the five bamboos were transplanted into bigger plastic pots (diameter $50 \mathrm{~cm}$, height $65 \mathrm{~cm}$ ). The pots were filled with cobblestones and water and were then fully sealed with plastic cover and aluminum foil to prevent evaporation of water from the pots (Figure 2.1.A). A scaled syringe tube was attached to each pot and connected into the pot through a U-type tube. At the beginning of the experiment, the water was added into the pot through the syringe tube to a fixed level ( $5 \mathrm{~cm}$ below the pot cover). Subsequently, water was added manually every $30 \mathrm{~min}$ to reach the pre-defined level. The weight of the added water was determined gravimetrically $(\mathrm{GM})$. To measure $J_{\mathrm{s}}$, each bamboo culm was equipped with 3 pairs of $1 \mathrm{~cm}$ length TDP which were evenly installed circumferentially, about $15 \mathrm{~cm}$ above the plastic cover. To minimize potential measurement errors induced by circumferential variations of $J_{\mathrm{s}}$, the thermocouple wires of the three TDP were connected in paralFlel to get an average voltage signal for each bamboo culm (Lu et al., 2004). For a second $J_{\text {s }}$ 
Water use patterns of four tropical bamboo species assessed with sap flux 14 measurements

Table 2.1 Structural characteristics of the studied bamboo and tree species ( $\mathrm{n}=5$ per species; mean $\pm \mathrm{SD}$ ).

\begin{tabular}{ccccc}
\hline & Species & DBH $(\mathrm{cm})$ & BCWT $(\mathrm{cm})$ & Height $(\mathrm{m})$ \\
\hline Bamboo & B. vulgaris & $7.0 \pm 0.3$ & $1.3 \pm 0.1$ & $17.9 \pm 0.8$ \\
& G. apus & $8.6 \pm 0.4$ & $1.2 \pm 0.2$ & $16.2 \pm 2.7$ \\
& D. asper & $11.9 \pm 1.9$ & $2.4 \pm 0.2$ & $21.1 \pm 0.9$ \\
\multirow{4}{*}{ Tree } & G. atroviolacea & $8.9 \pm 0.6$ & $1.6 \pm 0.1$ & $17.0 \pm 1.0$ \\
& H. brasiliensis & $27.4 \pm 2.3$ & - & $25.2 \pm 3.0$ \\
& G. arborea & $26.3 \pm 7.7$ & - & $26.5 \pm 2.3$ \\
& S. leprosula & $20.7 \pm 4.8$ & - & $19.2 \pm 2.5$ \\
\hline
\end{tabular}

Note: DBH (Diamter at Breast Height); BCWT (Bamboo Culm Wall Thickness)

estimate, a SHB gauge (SGB50 or SGA70, Dynagage Inc., USA) was installed about $1.5 \mathrm{~m}$ above the TDP. Both sensor types were protected by foil and the sensor signals were subsequently recorded as described in Section 2.2. For the comparison to reference gravimetric measurements (GM), 10-min TDP and SHB derived values were aggregated to half-hourly values.

To assess the performance of TDP and SHB in the pot experiments, $J_{\mathrm{S}}$ derived from TDP and SHB ( $J_{\mathrm{S}_{-} \mathrm{TDP}}$ and $J_{\mathrm{S}_{-} \mathrm{SHB}}$, respectively) on daily and 30-min scales were compared to GM derived $J_{\mathrm{S}}\left(J_{\mathrm{S}_{-} \mathrm{GM}}\right)$ with paired t-tests. Additionally, the slopes of the respective linear fits between $J_{\mathrm{S}_{-} \mathrm{TDP}}, J_{\mathrm{S} \_\mathrm{SHB}}$

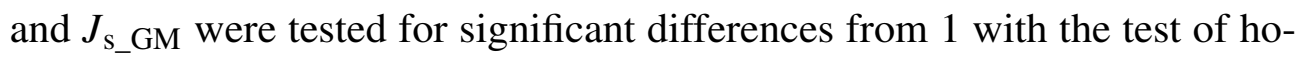
mogeneity of slopes. The same statistical analyses were applied again later when testing for significant differences between $J_{\mathrm{S}_{-} \mathrm{TDP}}$ and $J_{\mathrm{S}_{-} \mathrm{SHB}}$ in the field calibration experiments.

\section{Field calibration experiment: TDP \& SHB}

Five culms per bamboo species (B. vulgaris, D. asper, G. atroviolacea, G. apus) were selected for TDP measurements (Table 2.1), three to four of which were additionally measured with SHB for a field calibration of the TDP method. TDP sensors were installed at $1.3 \mathrm{~m}$ height, and SHB gauges (SGB50, SGA70, Dynagage Inc., USA) were installed about $2.5 \mathrm{~m}$ above the TDP. Simultaneous TDP-SHB measurements were conducted for a minimum of five days per culm (Figure 2.1.B). Heat storage inside bamboo culms is assumed to be negligible, which was confirmed by installing thermocouple wires inside the measured segments of the respective bamboo culms to detect fluctuations in culm temper- 

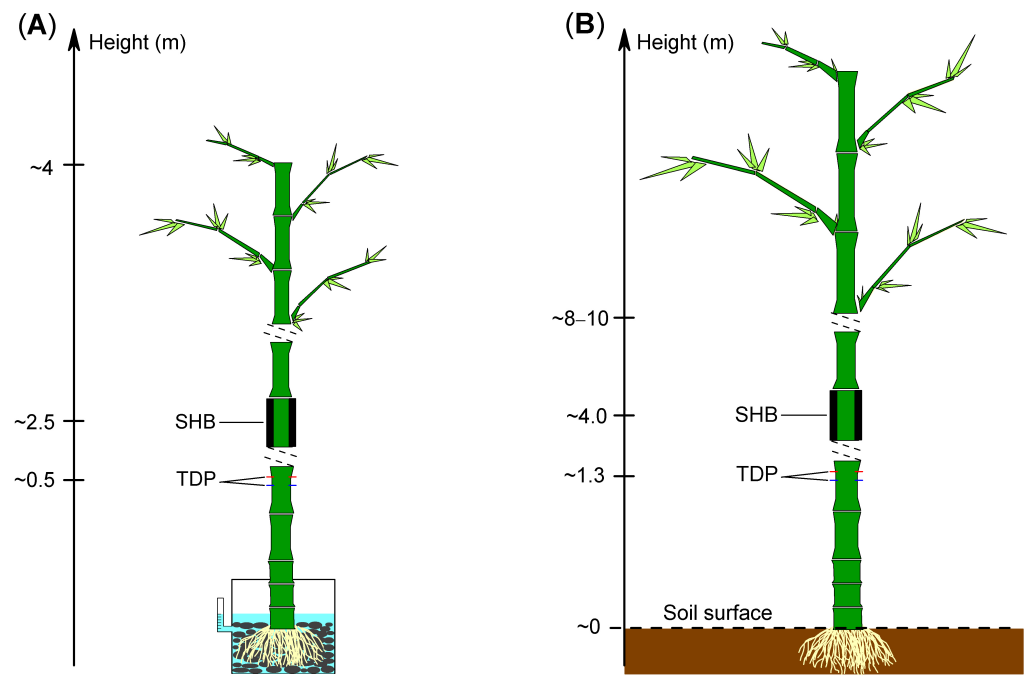

Fig. 2.1 Installation of thermal dissipation probe (TDP) and stem heat balance (SHB) sensors on bamboo culms for the calibration experiments on potted plants (A) and for field calibration (B).

ature (Dierick et al., 2010). The observed fluctuations were marginal, which meant stable thermal conditions as a requirement of the SHB method were met.

\section{Parametrization for TDP calibration}

We derived cross-sectional water conductive areas (A_TDP) from the culm wall thickness at the location of TDP sensor installation. In the pot calibration experiment, reference $J_{\mathrm{s}}$ were calculated by dividing water flow rates $\left(\mathrm{g} \mathrm{h}^{-1}\right.$, GM-derived) by A_TDP. In the field calibration experiment, reference $J_{\mathrm{s}}$ were taken from the SHB measurements. The reference $J_{\mathrm{S}}$ could subsequently be used to calibrate $J_{S_{-}}$TDP. Nighttime sap flux values were excluded in both calibration experiments.

In the field calibration, three factors were considered for obtaining a TDP calibration formula from reference (SHB) measurements: time step of the data, formula specificity and calibration formula type. To examine effects of varying time steps, the formulas were built and tested on data at varying intervals (1-, 10-, 30-, and 60-minute averages, respectively). The effects of formula specificity were examined by using common (i.e. all bamboo species pooled), species-specific and culm-specific formulas, respectively. Regarding the calibration formula type, two formulas were compared: one was nonlinear $\left(J_{\mathrm{s}}=a K^{b}\right)$ and generated by deriving new $a$ and $b$ parameters for the original 
Water use patterns of four tropical bamboo species assessed with sap flux 16 measurements

Granier formula (1985). The second was a linear formula $\left(J_{\mathrm{S}_{-} \mathrm{SHB}}=c \times J_{\mathrm{S}_{-} \mathrm{TDP}}\right)$ which was calculated from the linear relationship between $J_{\mathrm{S}_{-} \mathrm{TDP}}$ and $J_{\mathrm{S} \_\mathrm{SHB}}$.

To obtain stable calibration formulas, pooled data sets were randomly split in half for calibration and independent validation, respectively (Niu et al., 2015). First, for each time step (1-, 10-, 30-, and 60-minute, respectively), a data pool was built. Three culms of each bamboo species were randomly chosen, and for each, three days of data were randomly chosen from an initial common dataset. With these data pools, formula specificity was examined. For the common calibration, culms of all four species were selected for calibration. For species-specific and culm-specific calibration, only the data of the respective species or culms was selected. Next, the selected data was randomly split in half, for building the calibration formula and testing it, respectively. When testing the formula, the differences between $J_{\mathrm{S} \_\mathrm{SHB}}$ and calibrated $J_{\mathrm{S}-\mathrm{TDP}}$ $\left(J_{S_{-} T D P}\right.$ cali , abnormal distribution, $P>0.05$ ) were examined with the Wilcoxon Signed-Rank Test (no significant differences at $P>0.05$ ). The process of randomly building and testing the formula was iterated 10,000 times. Final calibration formula parameters were derived by averaging the parameters of those iterations which passed the Wilcoxon Signed-Rank Test $(P>0.05)$.

For an evaluation of the performance of the different formulas and the influence of the three factors (time scale, formula specificity and calibration formula type), differences in normalized Root-Mean-Square Errors (nRMSE) were assessed for each culm, species and formula factor, respectively. First, the RMSE for each day was derived with the $J_{\mathrm{S}_{-} S H B}$ and $J_{\mathrm{S}_{-} \text {TDP_cali values, }}$ and the nRMSE was calculated by normalizing the RMSE with the observed daily range of $J_{\mathrm{S}_{-} \mathrm{SHB}}$ (difference between maximum and minimum $J_{\mathrm{S}_{-} \mathrm{SHB}}$ ). Then, the nRMSE were analyzed regarding the three formula factors (data time scale, formula specificity and calibration formula type) by ANOVA (Analysis of variance). Additionally, for each day, $J_{S_{-}}$TDP_cali with each formula type was tested for significant differences from $J_{\mathrm{S}_{-} \mathrm{SHB}}$ with the Wilcoxon Signed-Rank Test. The rates of passing the Wilcoxon Signed-Rank Test $(P>0.05$ when no significant difference between TDP and SHB derived values) were assessed for each formula. 


\subsubsection{Field study}

\section{Monitoring bamboo and tree sap flux}

Four calibrated bamboo species as well as three tree species (G. arborea, $S$. leprosula and $H$. brasiliensis) were monitored with the TDP method for seven months (July, 2012 to January, 2013). Five bamboo culms and five tree trunks per species were selected for the measurements. On bamboos, three pairs of TDP (10 mm in length) were installed evenly around each culm at $1.3 \mathrm{~m}$ height and connected in parallel (see Section 2.2 for details). On trees, two pairs of $20 \mathrm{~mm}$ TDP were installed in the trunk $1.3 \mathrm{~m}$ above the ground, in the North and South, respectively. $J_{\mathrm{s}}$ for the two sensors were separately derived with the original calibration formula (Granier, 1985) and subsequently averaged to obtain values for each tree. For bamboos, $J_{\mathrm{s}}$ derived with the original formula were calibrated with species-specific calibration parameters (from reference SHB field measurements) to obtain final $J_{\mathrm{s}}$ values.

\section{Environmental measurements and analyses}

A micrometeorological station was set up in an open area. It was about 100 and $600 \mathrm{~m}$ away from the closer measurement sites (D. asper, G. arborea, G. atroviolacea, G. apus, S. leprosula) and farthest sites (B. vulgaris, H. brasiliensis), respectively. Air temperature $\left(T_{\mathrm{a}},{ }^{\circ} \mathrm{C}\right)$ and air relative humidity $(\mathrm{RH}, \%)$ were measured with a temperature and relative humidity probe (CS215, Campbell) installed in a radiation shield. VPD $(\mathrm{kPa})$ was calculated from Ta and RH. Radiation ( $\mathrm{J} \mathrm{m}^{-2} \mathrm{~s}^{-1}$ ) was measured with a pyranometer (CS300, Campbell). Data were recorded with the previously described data loggers every minute.

In addition to the mentioned micrometeorological variables, soil moisture ( $\mathrm{SM}, \mathrm{m}^{-3} \mathrm{~m}^{-3}$ ) was measured with time domain reflectrometry sensors (TDR, CS616, Campbell) at 0-20 cm depth. As the clump of D. asper and the stand of G. arborea were next to each other, one TDR was positioned between them to measure soil moisture. Likewise, one sensor was used for measurements of $G$. atroviolacea and G. apus. One TDR each were used for the remaining species (S. leprosula, B. vulgaris, H. brasiliensis). TDR measurements ran in parallel to the sap flux field campaign and data were recorded with the described data loggers every minute.

For the day-to-day analysis of influences of fluctuations in environmental conditions (VPD, radiation, SM) on $J_{\mathrm{S}}$ in the studied bamboo and tree species, 
Water use patterns of four tropical bamboo species assessed with sap flux measurements

daily accumulated $J_{\mathrm{s}}\left(\mathrm{kg} \mathrm{cm}^{-2} \mathrm{~d}^{-1}\right)$ were normalized by setting the highest daily observation of each species to 1 and the lowest to 0 . For a more isolated analysis of potentially limiting influences of soil moisture on $J_{\mathrm{S}}$, we focused on 'dry period conditions' with consecutive rainless days, which occurred between June and September in the study area. During this period, monthly precipitation was only $32 \%$ of monthly wet period precipitation (155 vs. 489 $\mathrm{mm}$ ), and the number of consecutive dry days (rainfall $<1 \mathrm{~mm}$ ) was 7 times higher than during the wet period (14 vs. 2 days). Dry period conditions are also characterized by higher VPD (average daily VPD $>0.74 \mathrm{kPa}$ on $92 \%$ of the days). $0.74 \mathrm{kPa}$ was chosen as the threshold to distinguish between dry and wet period because it constituted the mean maximum ('turning point') in the fitted $J_{\mathrm{s}}$ response functions to VPD in three of the four studied bamboo species (except D. asper, see Figure 2.4.B).

For the diurnal analysis of influences of fluctuations in environmental conditions on $J_{\mathrm{S}}$, time lags between $J_{\mathrm{S}}$ and micrometeorological drivers (radiation and VPD) were calculated as the time difference between the respective occurrences of maximal $J_{\mathrm{S}}\left(J_{\mathrm{S} \_\max }\right)$ and maximal radiation and VPD. T-tests were used to test time lags for significant differences from 0 min. 30-min $J_{\mathrm{s}}$ values (average values of three selected sunny days) of each species were plotted against radiation and VPD to examine occurrences of hysteresis. The respective areas of hysteresis were compared between bamboos and trees with t-tests.

All data analyses were performed with SAS 9.3 (SAS Institute Inc., 2013).

\subsection{Results}

\subsubsection{Calibration of the TDP method for bamboos}

\section{Pot calibration experiment: TDP, SHB \& GM}

In the pot calibration experiment with $B$. vulgaris, SHB yielded similar absolute values of $J_{\mathrm{S}}$ as GM on daily and 30-min scales $(P>0.05)$. The slope of the linear fit between SHB and GM on the 30-min scale was $0.98\left(R^{2}=0.93\right.$, $P<0.01)$. It did not significantly differ from 1 ( $P>0.05$, Figure 2.2 .A). In contrast to this, TDP estimates, with the original parameters of the calibration formula (Granier, 1985), differed substantially from GM values at both the daily $\left(60 \%\right.$ underestimation of accumulated $\left.J_{\mathrm{s}}, P<0.01\right)$ and 30 -min scale 

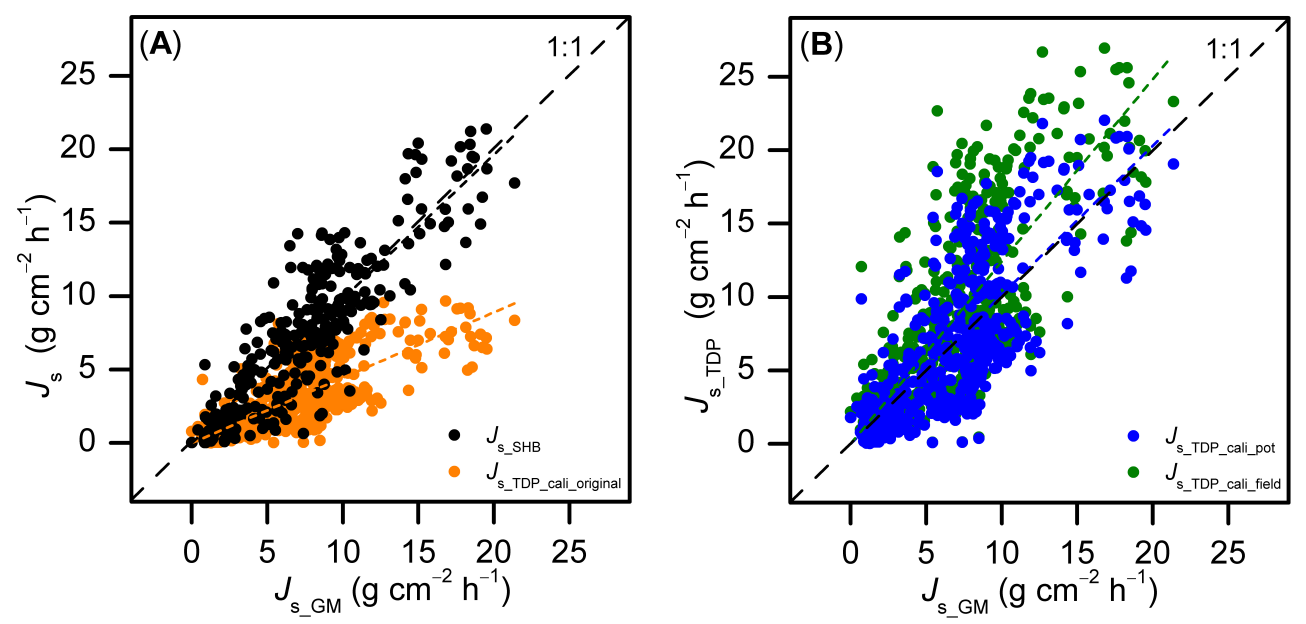

Fig. 2.2 Half-hourly sap flux density $\left(J_{\mathrm{S}}\right)$ measured with thermal dissipation probes (TDP) and stem heat balance (SHB) sensors on five potted Bambusa vulgaris culms plotted against GMderived reference sap flux densities $\left(J_{\mathrm{S}_{-} \mathrm{GM}}\right)$ before $\left(\mathrm{A} ; J_{\mathrm{S} \_\mathrm{TDP}}\right.$ cali_original $: Y=0.44 X, R^{2}=0.84, P<0.01 ; J_{\mathrm{S} \_\mathrm{SHB}}: Y=$

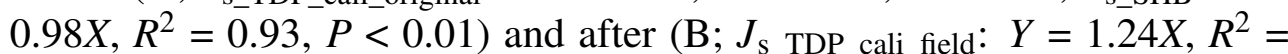
$\left.0.84, P<0.01 ; J_{\text {s_TDP_cali_pot }}: Y=1.01 X, R^{2}=0.84, P<0.01\right)$ species-specific calibration and field calibrations of the TDP method. Pooled data from 2 to 5 days of simultaneous TDP, SHB, and gravimetric measurements (GM).

(56\% underestimation, $P<0.01$ ). The slope of the linear fit between TDP and GM on the 30 -min scale was $0.44\left(R^{2}=0.84, P<0.01\right)$. It was significantly different from 1 ( $P<0.01$, Figure 2.2.A).

After applying the TDP calibration parameter for $B$. vulgaris derived from the pot experiment ( $c=2.28$ ), the 30 -min $J_{\mathrm{S}_{-} \mathrm{TDP}}$ were in line with those from GM. The slope was not significantly different from 1 ( $P>0.05$, Figure 2.2.B). When applying the calibration parameters derived for $B$. vulgaris from the SHB field calibration experiment $(c=2.79), J_{\mathrm{S}_{-} \mathrm{TDP}}$ was $19 \%$ higher than $J_{\mathrm{S}_{-} \mathrm{GM}}(P$ $<0.01$, Figure 2.2.B).

\subsubsection{Field calibration experiment: TDP \& SHB}

Formula type and data time step had no significant influence on the performance of the calibration formula, but it mattered whether culm- or speciesspecific or a common calibration formula was used (Appendix Table 1; Appendix Table 2). Based on the nRMSE and the passing rate of the Wilcoxon test $(P>0.05)$ between calibrated $J_{\mathrm{S}_{-} \mathrm{TDP}}$ and $J_{\mathrm{S}_{-} \mathrm{SHB}}$, culm-specific formulas performed better than species-specific and common formulas. In our study, there was no statistically significant difference between the species-specific 
Water use patterns of four tropical bamboo species assessed with sap flux 20 measurements

Table 2.2 Values of the parameter c of different bamboo calibrations (speciesspecific/common) for TDP sap flux estimates.

\begin{tabular}{cccccc}
\hline & & & \multicolumn{3}{c}{ Formula nRMSE } \\
\cline { 3 - 6 } Formula & Species & $c$ & $\begin{array}{c}\text { Species- } \\
\text { specific }\end{array}$ & common & $P$ \\
\hline Specificity & & & & \\
& B. vulgaris & $2.79 \pm 0.13^{a}$ & 0.10 & 0.11 & 0.07 \\
& G. apus & $3.32 \pm 0.08^{b}$ & 0.10 & 0.12 & 0.06 \\
& D. asper & $2.42 \pm 0.06^{c}$ & 0.18 & 0.18 & 0.97 \\
Common & G. atroviolacea & $2.53 \pm 0.11^{d}$ & 0.12 & 0.13 & 0.81 \\
\hline
\end{tabular}

Note: Significant differences between species-specific and common c estimates (Turkey's test, $P<0.01$ ) are indicated by superscripted letters. $P<0.05$ indicate significant differences between Normalized Root-Mean-Square Errors (nRMSE) of species-specific and common formula.

and the common calibration parameters (Table 2.2, $P>0.05$ ). For two of the four studied bamboo species (G. apus and B. vulgaris), however, using species-specific formulas slightly improved the quality of predictions as compared to applying the common formula ( $P=0.06$ and 0.07 , respectively, Table 2.2). These two bamboo species had lower nRMSE and higher passing rates than D. asper and G. atroviolacea (Appendix Table 2). The linear calibration parameters of the four bamboo species were significantly different from each other $(P<0.01)$. The linear calibration parameters, the slopes of $J_{\mathrm{S}_{-} \mathrm{TDP}} \mathrm{vs}$. $J_{\mathrm{S} \_\mathrm{SHB}}$, were examined with the test of homogeneity of slopes and were found to differ significantly from each other $(\mathrm{t}>0.01)$.

Before calibration, $J_{\mathrm{S}_{-} \mathrm{TDP}}$ was on average $66 \%$ and $63 \%$ lower than SHBderived reference values on the daily and 30-min scales, respectively $(P<$ $0.01)$. This deviation was reduced to $10 \%$ and $8 \%$ underestimations $(P<0.01)$ when using species-specific calibration parameters (Table 2.2). On average, for $77 \pm 6 \%$ of the days that were included in the analysis, the species-specific post-calibration 30-min $J_{\mathrm{S}_{-} \text {TDP }}$ values were not significantly different from the respective reference $J_{\mathrm{S}_{-} \mathrm{SHB}}$ (Wilcoxon Signed-Rank test, $P>0.05$ ). 


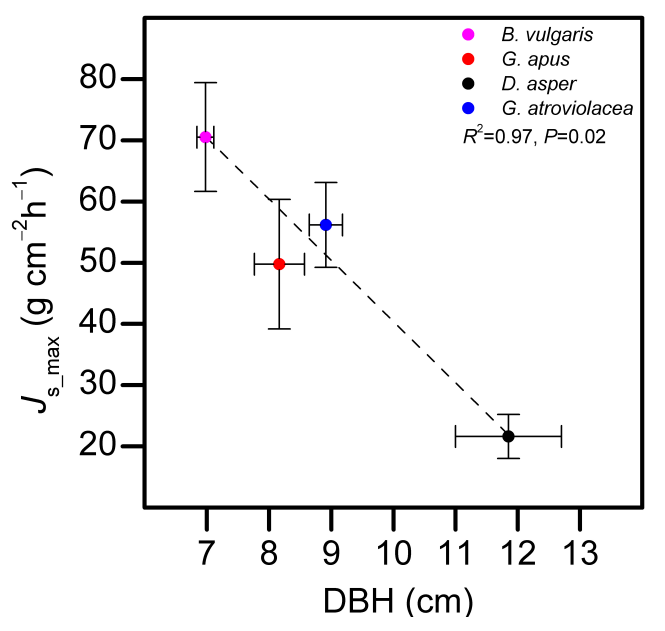

Fig. 2.3 Relationship between diameter at breast height (DBH) of bamboo culms and maximum observed sap flux density $\left(J_{S_{-} \max }\right)$ in four bamboo species. Horizontal error bars indicate DBH standard errors, vertical bars standard errors of $J_{\mathrm{s} \_ \text {max }}$. Data of five culms pooled per species, average of the highest $10 \%$ of daily $J_{S_{-} \text {max }}$ values of each culm used for the analysis.

\subsubsection{Field study}

\section{Monitoring bamboo and tree sap flux}

$J_{\text {S_max }}$ in the studied bamboo species (averages from five individuals per species) were 70.5, 21.6, 49.7 and $56.2 \mathrm{~g} \mathrm{~cm}^{-2} \mathrm{~h}^{-1}$ for B. vulgaris, D. asper, G. apus and G. atroviolacea, respectively. In trees, corresponding values were 17.7, 10.5 and $23.3 \mathrm{~g} \mathrm{~cm}^{-2} \mathrm{~h}^{-1}$ for H. brasiliensis, G. arborea and S. leprosula, respectively. Across bamboo species, $J_{\text {s_max }}$ decreased with increasing culm diameter $\left(R^{2}=0.97, P=0.02\right.$, Figure 2.3).

\section{Environmental measurements and analyses}

The normalized daily accumulated $J_{\mathrm{s}}$ of all studied species increased with increasing daily integrated radiation. This relationship did not fully hold up for accumulated $J_{\mathrm{S}}$ and average daily VPD. In several species, daily $J_{\mathrm{S}}$ increased with increasing VPD only to a certain VPD threshold (approx. 0.74 $\mathrm{kPa}$, Figure 2.4); after this threshold, accumulated $J_{\mathrm{s}}$ decreased with further increasing VPD. Such conditions of high VPD were characteristic of the dry period. For days with VPD $>0.74 \mathrm{kPa}$, daily accumulated $J_{\mathrm{s}}$ of most studied species (except in $D$. asper and G. arborea) declined with decreasing soil moisture content $\left(R^{2}=0.39,0.44,0.4,0.52\right.$ and 0.55 for B. vulgaris, $G$. 
Water use patterns of four tropical bamboo species assessed with sap flux

(A)
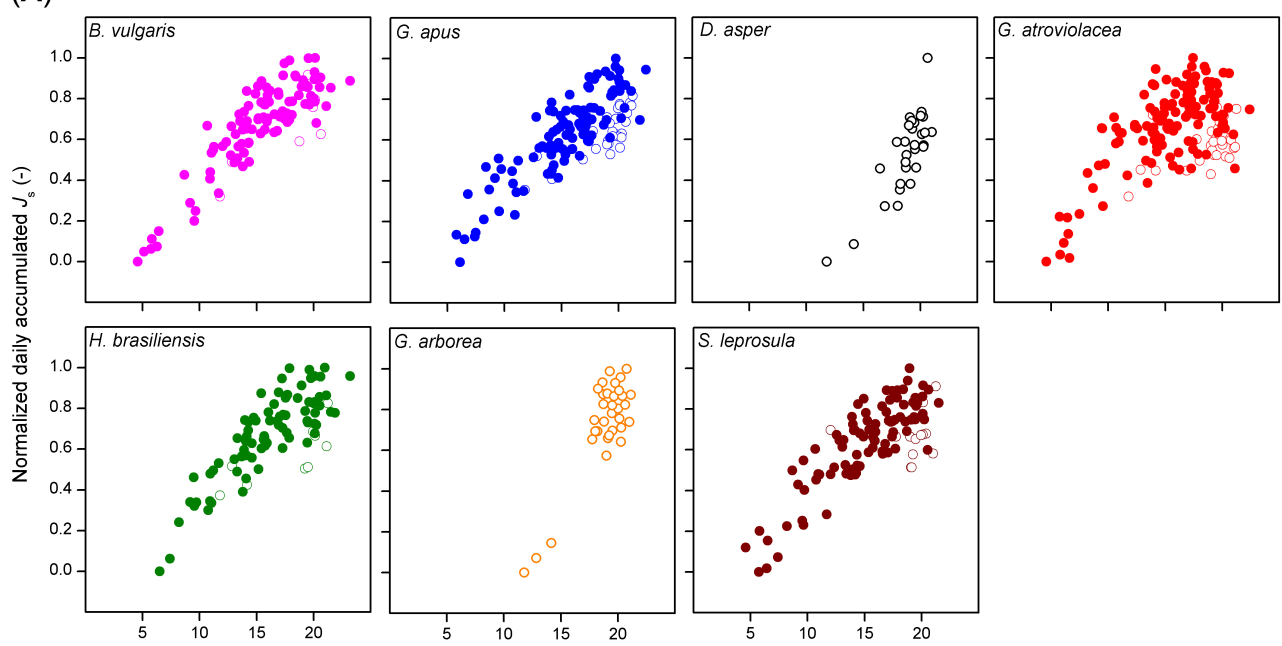

(B)
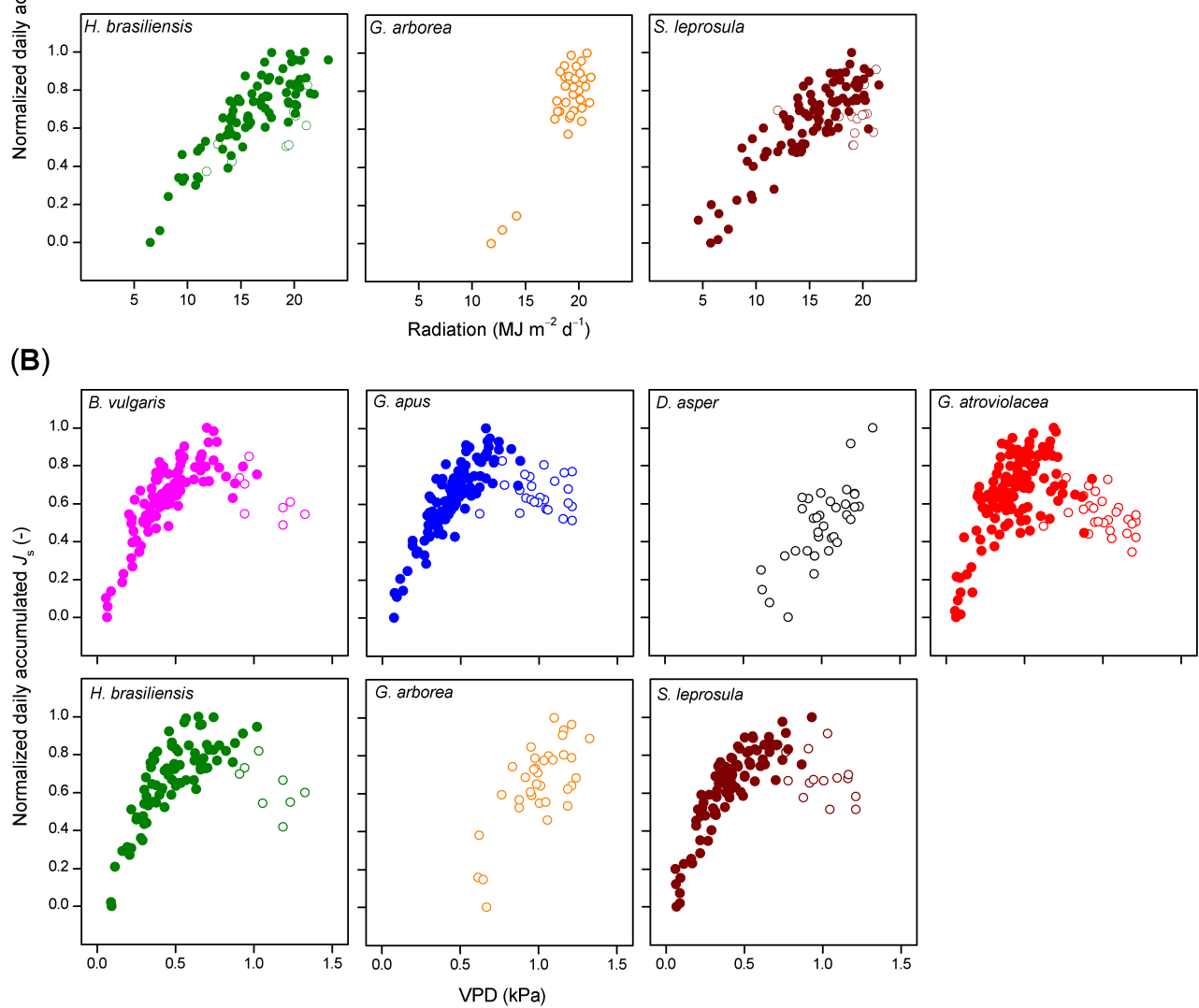

Fig. 2.4 Normallized daily accumulated sap flux density $\left(J_{\mathrm{S}}\right)$ plotted against absolute values of (A) intergrated daily radiation and (B) average daily vapor pressure deficit (VPD). Daily values of four bamboo (upper row) and three tree species (lower row); data from 7 months of measurements (July 2012-January 2013) encompassing both wet (filled circles) and dry (open circles) periods (except for Dendrocalamus asper and Gmelina arborea, mainly dry period). Daily averages derived from measurements of five culms per species. 

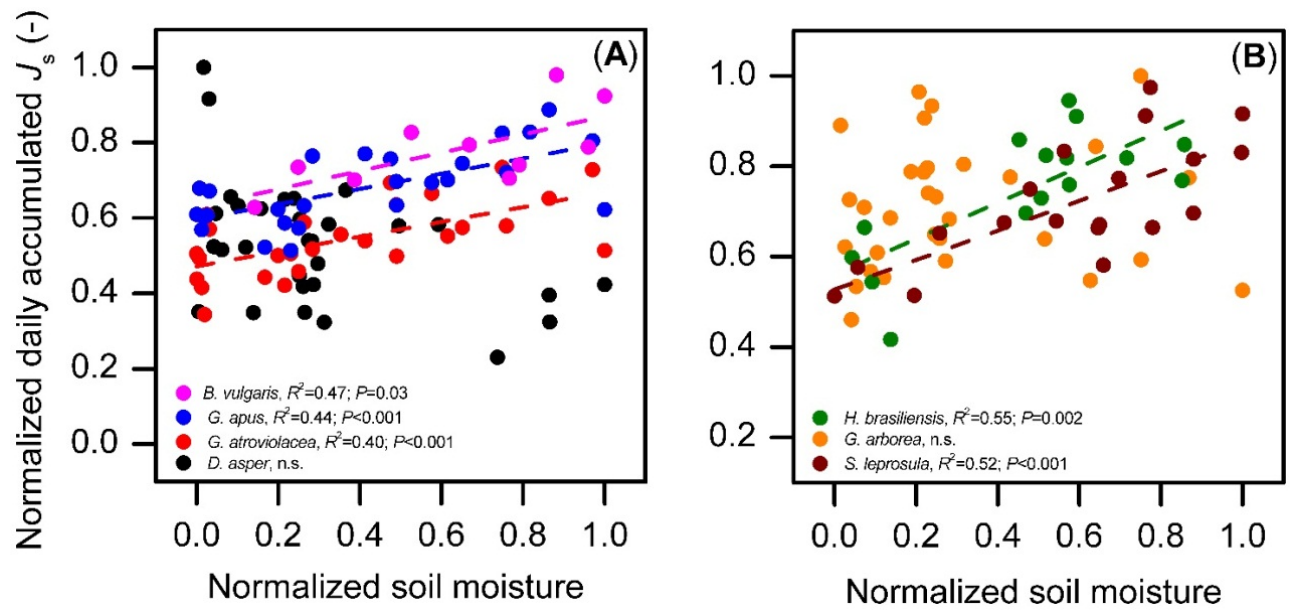

Fig. 2.5 Normalized daily accumulated sap flux density $\left(J_{\mathrm{s}}\right)$ of four bamboo species (A) and three tree species (B) in the 'dry period' (characterized with mean daily VPD $>0.74 \mathrm{kPa}$ ) plotted against normalized mean daily soil moisture content (SM). There was a significant linear relationship between $J_{\mathrm{s}}$ and SM $(P<0.05)$ for all species except $D$. asper and $G$. arborea. Normalized values do not reach 1.0 for all species in the figure as the normalization was performed by setting the maximum value of the full measurement period of each species (including wet period) to one, while the figure displays only values in dry period. Daily averages derived from measurements on five culms per species, data of at least 10 dry period days per species.

apus, G. atroviolacea, S. leprosula and $H$. brasiliensis respectively; $P<0.05$, Figure 2.5.A and 2.5.B).

Diurnal peaks in $J_{\mathrm{s}}$ in the studied bamboo species occurred relatively early (on average at about $11 \mathrm{am}$ ), which was significantly earlier than the peaks of radiation and VPD (20-82 $\mathrm{min}$ and 131-206 min, respectively). In the studied tree species, maximal hourly $J_{\mathrm{s}}$ values were observed after the peak of radiation (3-97 $\mathrm{min}$ ), but still before (51-108 $\mathrm{min}$ ) VPD peaked. All time lags were significantly different from zero minutes $(P<0.01$; Table 2.3$)$, except for the time lag to radiation for the tree species $S$. leprosula $(P>0.05)$.

Diurnally, some of the studied species showed pronounced hysteresis of hourly $J_{\mathrm{s}}$ to radiation and VPD. Direction of rotation (i.e. order of observations) was counter-clockwise for radiation (Figure 2.6.A) and clockwise for VPD (Figure 2.6.B). The area of the hysteresis to VPD was on average 32\% larger in bamboos than in trees, while the area of hysteresis to radiation was on average $50 \%$ smaller in bamboos $(P<0.01)$. 
Water use patterns of four tropical bamboo species assessed with sap flux

(A)
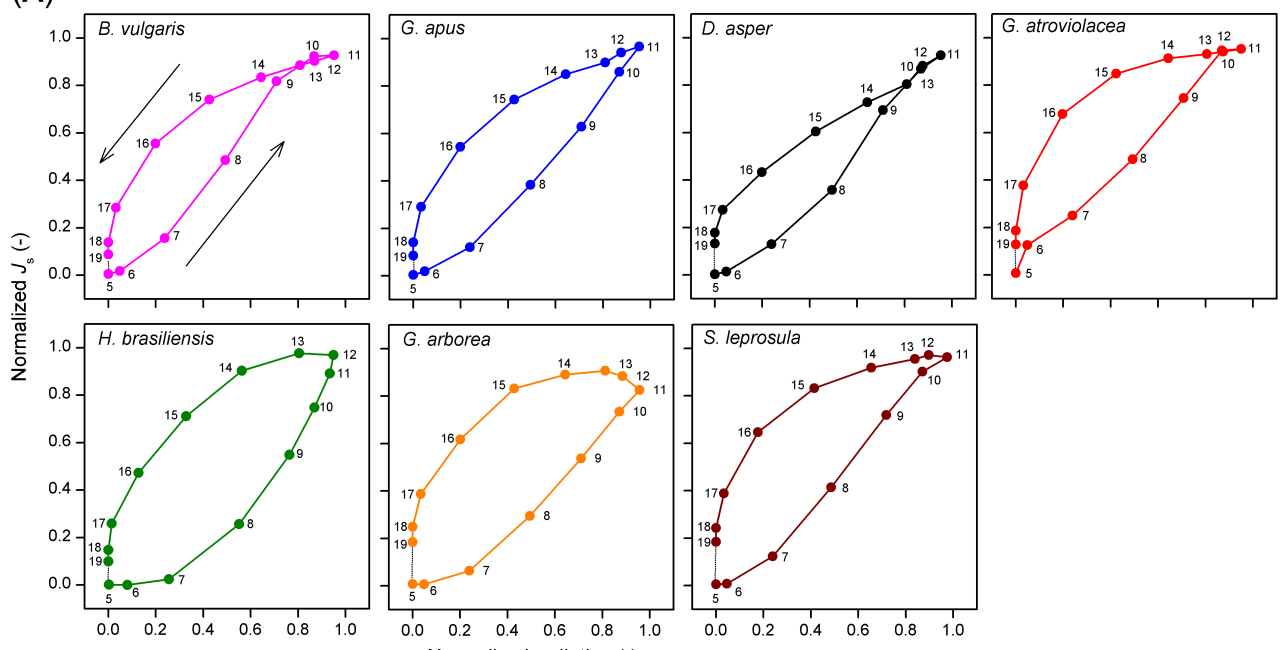

(B)
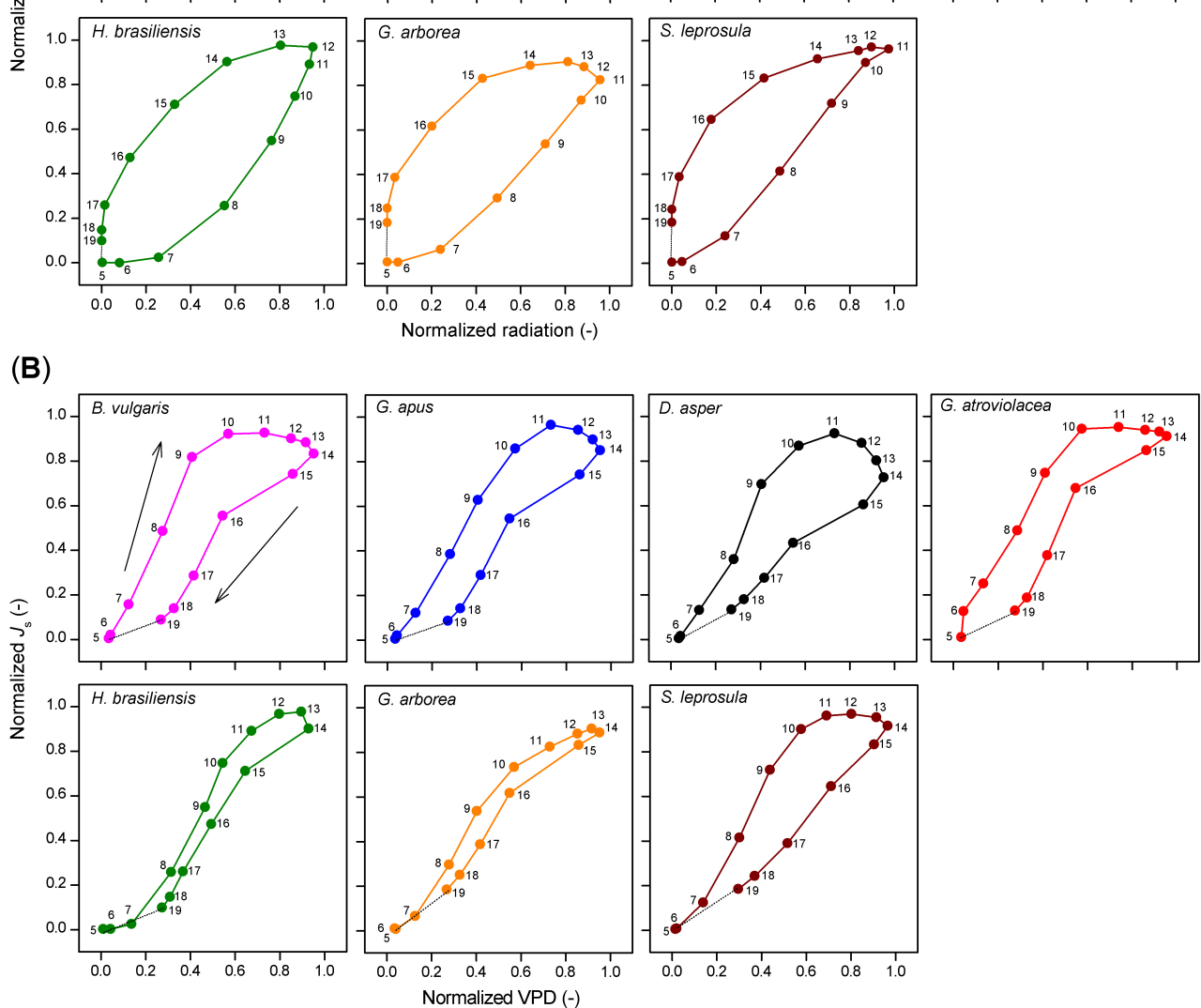

Fig. 2.6 Normalized hourly sap flux density $\left(J_{\mathrm{S}}\right)$ plotted against $(\mathrm{A})$ normalized hourly radiation and (B) VPD. Data of four bamboo (upper row) and three tree species (lower row). Hourly averages derived from simultaneous measurements on five culms per species and by averaging the values of three sunny days to minimize influences of weather. The numbers in the sub-figures indicate the respective time of the day. 
Table 2.3 Time lags between diurnal peaks of radiation and VPD and peaks of $J_{\mathrm{S}}$ in studied bamboos and trees.

\begin{tabular}{cccc}
\hline Species & $N$ & $\begin{array}{c}\text { Time lag with radiation } \\
(\mathrm{min})\end{array}$ & Time lag with VPD (min) \\
\hline B. vulgaris & 5 & $82 \pm 62$ & $171 \pm 63$ \\
G. apus & 5 & $41 \pm 57$ & $206 \pm 57$ \\
D. asper & 4 & $20 \pm 61$ & $131 \pm 53$ \\
G. atroviolacea & 5 & $64 \pm 30$ & $170 \pm 35$ \\
Bamboo_mean & 19 & $51^{A}$ & $169^{A}$ \\
H. brasiliensis & 5 & $-37 \pm 12^{a}$ & $51 \pm 9$ \\
G. arborea & 5 & $-97 \pm 87^{b}$ & $67 \pm 87$ \\
S. leprosula & 5 & $-3 \pm 25^{a}$ & $108 \pm 20$ \\
Tree_mean & 15 & $-46^{B}$ & $75^{B}$ \\
\hline
\end{tabular}

Note: Positive values indicate a peak of radiation/VPD after the peak of $J_{\mathrm{s}}$, negative values indicate a peak before $J_{\mathrm{s}} ; N$, culms/trunks per species averaged (mean $\pm \mathrm{SD}$ ). Significant differences in bamboo/tree mean time lags are indicated by different superscripted letters (Turkey's test, $P<0.01$ ). Significant differences between species are indicated by capital letters $(P<$ $0.01)$.

\subsection{Discussion}

\subsubsection{Calibration experiments}

In the pot calibration experiment, SHB yielded similar results as reference GM measurements. Bamboos seem well suited for the SHB method (Dierick et al., 2010) due to their round shape and smooth and barkless surface, which allows for tight contact with the gauges. Additionally, the hollow center and thin culm walls result in relatively low energy losses to heat storage so that the heat balance conditions required for the SHB method are met. "Zero sap flux" conditions to obtain the heat conductivity of the sheath $\left(K_{\mathrm{sh}}\right.$, Sakuratani, 1981) as a further requirement of the SHB method are difficult to determine in situ due to potential root pressure induced night time sap flux in bamboos (Cao et al., 2012); however, using $K_{\text {sh }}$ derived from field conditions of very low night-time sap flux likely introduced only negligible errors into the calculation of daytime sap flux (Grime and Sinclair, 1999). As we observed very low sap flux over several hours during our experiments (e.g. about $1 \mathrm{~g} \mathrm{~cm}^{-2} \mathrm{~h}^{-1}$ during the pot experiment), our obtained $K_{\text {sh }}$ were likely reliable.

In contrast to SHB, the TDP method was found to substantially underestimate $J_{\mathrm{S}}$ of bamboos in the pot and field calibration experiments. Underesti- 
Water use patterns of four tropical bamboo species assessed with sap flux measurements

mations by TDP were also reported in two other bamboo species: respective average underestimations of 13\% for Bambusa blumeana (Dierick et al., 2010) and $31 \%$ for Phyllostachys pubescens (Moso bamboo, Kume et al., 2010) were reported. Reasons for the observed underestimations could lie in the distinct hydraulic and physiological features of bamboos. Diurnal variations of stem water storage, for example, could affect the accuracy of TDP measurements (Vergeynst et al., 2014). Bamboos have approx. 50\% parenchyma in culm walls (Dransfield and Widjaja, 1995), which potentially provides large water reservoirs. The depletion and refilling of the stem during the day and night, respectively, could cause diurnal fluctuations in culm thermal diffusivity. Higher water content during the night could lead to a lower maximum temperature difference $\left(\Delta \mathrm{T}_{\max }\right)$ between heated and reference probe under "zero sap flux" conditions. Likewise, lower water content during the day could lead to higher observed $\Delta \mathrm{T}$ values. As $\Delta \mathrm{T}_{\max } / \Delta \mathrm{T}$ constitutes the basis for calculations of daytime $J_{\mathrm{S}}$, substantial underestimations of $J_{\mathrm{S}}$ could be introduced when using the original calibration parameters (Granier, 1985; Vergeynst et al., 2014). This hypothesis was assessed further by comparing the linear calibration parameters of $B$. vulgaris from the pot and the field calibration experiment ( $c=2.28$ and 2.79 , respectively). In the pot experiment, the bamboos were always supplied with plenty of water, so that the variability of the culm water content was likely smaller than under field conditions. Effects of varying stem water content on $\Delta \mathrm{T}_{\max } / \Delta \mathrm{T}$ are thus likely much smaller in the pot experiment, which may explain why pot and field calibration experiment yield different parameters for the linear calibration of the same species (B. vulgaris). Another potential factor for the divergence could be that the maximum observed $J_{\mathrm{s}}$ in the field (about $70 \mathrm{~g} \mathrm{~cm}^{-2} \mathrm{~h}^{-1}$ ) was much larger than in the pot experiment (about $20 \mathrm{~g} \mathrm{~cm}^{-2} \mathrm{~h}^{-1}$ ). Higher daytime sap flux (and thus transpiration) may cause a quicker depletion of the potential culm water storage, which consequently leads to a higher variability of culm water content between night and day.

We expected the calibration formula type (linear vs. nonlinear) and data time step to have an impact on the performance of TDP predictions. However, both were not as important as the factor formula specificity. Even though species-specific calibration formulas generally did not perform significantly better than the common formula, species-specific formulas tended to show slightly better performance (Table 2.1) for two of the studied species (G. apus and $B$. vulgaris). Also, the calibration parameters were significantly different among the four studied bamboo species (Table 2.2). Confronting this insight 
with results from sap flux studies on other bamboo species (Dierick et al., 2010; Kume et al., 2010), differences among species become even more apparent. We thus used the derived species-specific formulas for further analysis. The observed differences among species may be indicative of highly heterogeneous wood anatomical properties among bamboo species. For example, size and shape of vascular bundles and parenchyma of 15 bamboo species were reported to be highly variable (de Agrasar and Rodríguez, 2003). For two further bamboo species (Chusquea ramosissima and Merostachys claussenii), it was suggested that differences in number of vascular bundles per unit area $\left(1000\right.$ vs. 225 per $\left.\mathrm{cm}^{2}\right)$ and vessel length $(\approx 1 \mathrm{~m} \mathrm{vs.} 20 \mathrm{~cm})$ could lead to differences in xylem hydraulic conductivity (Saha et al., 2009). Differences in wood anatomical properties may also lead to heterogeneous heat conductive properties, which potentially affects applicability and accuracy of sap flux measurements and particularly of the TDP method (Wullschleger et al., 2011).

In our study, culm-specific formulas performed better at predicting $J_{\mathrm{s}}$ than species-specific and common calibration formulas (Appendix Table 1 and 2). This result indicates heterogeneity in conductive properties among culms of the same species. Potential reasons could lie in the age and the ontogeny of individual culms. Even though we carefully selected culms of similar age (approx. two years old), the exact age of individual bamboo culms within a given clump is difficult to assess. As all monocot species, bamboos lack secondary growth (Zimmermann and Tomlinson, 1972), so culm diameters are not related to culm age. Additionally, over the ontogeny of a certain culm, events and processes such as conductive circuit failure (drought- or metabolism-related; Cochard et al., 1994; Liese and Weiner, 1996), lignification (Lin et al., 2002) or increasing hydraulic limitations with height (Cao et al., 2012; Renninger and Phillips, 2010) could result in overall reduced hydraulic conductivity and thus lower sap flux densities with increasing culm age. However, these processes remain difficult to assess from the outside of the culm; further studies linking the age and ontogeny of bamboos to (TDP-derived) sap flux and water use patterns are suggested.

\subsubsection{Water use patterns of bamboos and trees}

Half-hourly $J_{\text {s_max }_{-}}$in the four studied bamboo species ranged from 21.6 to $70.5 \mathrm{~g} \mathrm{~cm}^{-2} \mathrm{~h}^{-1}$ and were (on average) almost two times greater than in the studied tree species. The observed range for both bamboos and trees falls into 
Water use patterns of four tropical bamboo species assessed with sap flux measurements

the range of $J_{S_{-} \max }$ values reported for tropical tree species in a variety of sap flux studies (Meinzer et al., 2001; O'Brien et al., 2004). For D. asper, the $J_{\text {S_max }}\left(21.6 \mathrm{~g} \mathrm{~cm}^{-2} \mathrm{~h}^{-1}\right)$ was similar to values reported for Bambusa blumeana culms (25.7 $\mathrm{g} \mathrm{cm}^{-2} \mathrm{~h}^{-1}$, Dierick et al., 2010) and Moso bamboos (approx. $20 \mathrm{~g}$ $\mathrm{cm}^{-2} \mathrm{~h}^{-1}$, Kume et al., 2010) of similar size. Our four studied bamboo species showed significant differences in $J_{\mathrm{S}_{-} \max }$, which were negatively correlated with species-specific differences in DBH (Figure 2.3). Consistent with this, in a study on 27 tropical tree species, the negative correlation between $J_{\mathrm{S} \_ \text {max }}$ and DBH was also observed (Meinzer et al., 2001). It was assumed to be related to a decline of the leaf area to sapwood area ratio with increasing DBH. This was also observed in a study on Eucalyptus grandis trees (Dye and Olbrich, 1993). In our study, we harvested leaves of three bamboo species (B. vulgaris, D. asper, and G. apus) and found that the leaf weight to sapwood area ratio was positively correlated with $J_{\text {s_max }_{-}}\left(R^{2}=0.45, P<0.05\right)$. However, studies connecting such anatomical and eco-hydrological properties of bamboos are yet scarce (Saha et al., 2009).

On the day-to-day level, accumulated $J_{\mathrm{S}}$ of both the studied bamboo and tree species were significantly correlated with radiation and VPD (Figure 2.4). During the long wet period, accumulated $J_{\mathrm{S}}$ linearly increased with higher integrated radiation and average daily VPD. Likewise, linear relationships in the day-to-day behavior of $J_{\mathrm{s}}$ to micrometeorological drivers have been reported for some tropical bamboo and several dicot tree species (Dierick and Hölscher, 2009; Köhler et al., 2009). During the dry period characterized by higher radiation and VPD (13\% and 100\% higher, respectively) than during the wet period, however, the observed linear relationship to VPD did not hold. Higher average daily VPD ("dry period conditions") led to decreases in accumulated $J_{\mathrm{S}}$ of several studied species (Figure 2.4.B). Similar decreases after a certain peak value have been reported for some previously studied tree species (Jung et al., 2011; Kubota et al., 2005), but in most species studied so far, higher average daily VPD leads to increases in accumulated $J_{\mathrm{s}}$ or water use (Hernández-Santana et al., 2008; Horna et al., 2011; Kume et al., 2007; Peters et al., 2010; Tang et al., 2006; Wullschleger and Norby, 2001). This was also reported for Moso bamboo (Komatsu et al., 2010). The observed decreasing accumulated $J_{\mathrm{S}}$ in bamboos under high VPD in our study were related to a reduction of soil moisture in the dry period (for three of the four bamboo and two of the three studied tree species). During the dry period, VPD was generally much higher than during the wet period. Soil moisture may become a limiting factor after several days without rainfall in the dry period. 
Accumulated $J_{\mathrm{s}}$ decreased strongly and linearly with decreasing soil moisture under "dry period conditions" (i.e. VPD $>0.74 \mathrm{kPa}$ ) for all studied bamboo (except D. asper ) and tree species (except G. arborea, Figure 2.5). Similarly, in a throughfall reduction experiment in Indonesia, declines of monthly $J_{\mathrm{S}}$ of Cacao and Gliricidia sepium were found to linearly correlate with reduced soil moisture (Köhler et al., 2010). Such sensitivity of daily $J_{\mathrm{s}}$ to fluctuating soil moisture may be related to a relatively shallow rooting depth (Kume et al., 2007).

Regarding the diurnal course of $J_{\mathrm{s}}$, the studied bamboo species showed earlier peaks than radiation and VPD, and also earlier than the respective peaks of the studied tree species. In contrast to this, previous studies on tropical trees reported rather small time-lags between peaks of $J_{\mathrm{s}}$ and radiation and VPD, respectively (Dierick and Hölscher, 2009; Horna et al., 2011; Köhler et al., 2009). Pre-noon peaks of $J_{\mathrm{s}}$ have only been described for few species thus far, for example, Acer rubrum (Johnson et al., 2011) and oil palms (Niu et al., 2015). The early diurnal peaks of $J_{\mathrm{S}}$ result in substantial hysteresis of $J_{\mathrm{s}}$ particularly to VPD. For another monocot species, oil palm, it has been suggested that such pre-noon peaks of $J_{\mathrm{S}}$ and the resulting large hysteresis to VPD could be indicative of internal trunk water storage and/or root pressure mechanisms (Niu et al., 2015; Röll et al., 2015). Early peaks of $J_{\mathrm{S}}$ could be due to a pre-noon contribution of internal water storage to bamboo transpiration. Likewise, the decoupling of hourly $J_{\mathrm{S}}$ particularly from VPD in the afternoon, i.e. the drop in bamboo $J_{\mathrm{S}}$ (after an early peak) despite further rising VPD, could be connected to the reduced water availability for leaves after the depletion of internal water storage at a certain time of the day. The depletion of stored stem water may be compensated for during the night by root pressure mechanisms (Cao et al., 2012; Yang et al., 2012). Other potential reasons for the diurnally relatively early decline of bamboo $J_{\mathrm{s}}$ and the consequent decoupling of the sap flux response from micrometeorological drivers could be a decline in leaf hydraulic conductance in the afternoon hours, which could contribute to prevent stem water potential loss and subsequent xylem cavitation (Saha et al., 2009; Yang et al., 2012). 
Water use patterns of four tropical bamboo species assessed with sap flux 30 measurements

\subsection{Conclusion}

Adjusting and applying the TDP method for sap flux measurements on four bamboo species pointed to substantial differences in water use patterns between the studied bamboos and three tree species studied. Bamboos had higher $J_{\mathrm{s}}$, and respective hourly maxima were reached earlier in the day than in tree species. This resulted in strong diurnal hysteresis, particularly to VPD, and in significant time lags between the peaks of $J_{\mathrm{S}}$ in bamboos and the respective peaks of radiation and VPD. Both may point to a strong contribution of internal water storage mechanisms to bamboo transpiration. We found substantial differences in the day-to-day $J_{\mathrm{S}}$ response of most studied bamboo and tree species to fluctuations in environmental conditions between the dry and the wet period. Reduced $J_{\mathrm{s}}$ under conditions of high VPD in the dry period could largely be explained by limiting soil moisture content. The regulation of bamboo water use thus seems to involve mechanisms at the leaf-, culm- and root- level. However, these mechanisms yet remain to be inter-connected convincingly. 


\section{Chapter 3}

\section{The influence of bamboo culm water content on sap flux measurements by thermal dissipation probes: observations and modeling}

Ting-Ting Mei ${ }^{1 \dagger *}$, Dong-Ming Fang ${ }^{1 \dagger}$, Alexander Röll ${ }^{1}$, Dirk Hölscher ${ }^{1}$

${ }^{1}$ Tropical Silviculture and Forest Ecology, Georg-August-Universität Göttingen, Germany

$\dagger$ The authors contributed equally to this work.

* Correspondence:

Ting-Ting Mei, Tropical Silviculture and Forest Ecology, Georg-AugustUniversität Göttingen, Büsgenweg 1, Göttingen, 37077, Germany. Email: tmei@gwdg.de 
The influence of bamboo culm water content on sap flux measurements by 32 thermal dissipation probes: observations and modeling

\section{Abstract}

Bamboos and other plants may substantially rely on stem water storage for transpiration. Fluctuations in wood water content $\left(\theta_{\text {wood }}\right)$ may lead to errors when estimating transpiration based on sap flux $\left(J_{\mathrm{S}}\right)$ measurements with the widely used thermal dissipation probe (TDP) method. To test the effects of $\theta_{\text {wood }}$ on $J_{\mathrm{s}}$, we conducted a culm dehydration experiment, monitored bamboos with TDPs, and implemented a steady-state thermal model. Central to the calculation of $J_{\mathrm{s}}$, and thus a major potential source of error, is the maximal temperature difference between probes $\left(\Delta \mathrm{T}_{\max }\right)$ which is often referred to as "zero sap flow" condition. In the culm dehydration experiment, we observed that $\Delta \mathrm{T}_{\max }$ decreased when $\theta_{\text {wood }}$ increased. In long-term field monitoring, $\Delta \mathrm{T}_{\max }$ decreased when soil moisture content increased, potentially indicating changes in $\theta_{\text {wood }}$ and a seasonal decrease in stem water storage. The steady-state model reproduced the $\theta_{\text {wood }}$ to $\Delta \mathrm{T}_{\max }$ relationship of the dehydration experiment and underlined a considerable sensitivity of $J_{\mathrm{s}}$ estimates to $\theta_{\text {wood }}$. Fluctuations in $\theta_{\text {wood }}$ may lead to substantial underestimation of $J_{\mathrm{s}}$, and subsequently of transpiration, in commonly applied estimation schemes. However, our model results suggest that such underestimation can be quantified and subsequently corrected for when key wood properties are known. Our study gives insights into the relationship between $\theta_{\text {wood }}$ and TDP-derived $J_{\mathrm{s}}$ and examines potential estimation biases.

Keywords: calibration, culm water storage, soil moisture content, steadystate thermal model, transpiration, zero sap flow

\subsection{Introduction}

Plant stems are the pathways of soil water to the leaves for transpiration (Tyree and Sperry, 1988). Measuring sap flow in stems and up-scaling it to plant transpiration can be conducted with several different sap flow methods such as the stem heat balance method, the heat pulse method or the thermal dissipation method (Smith and Allen, 1996). Among these methods, the thermal dissipation probe (TDP) method (Granier, 1985) is most widely used. Its advantages include its relatively low cost as well as relatively easy sensor construction and installation (Lu et al., 2004). The empirical TDP formula for the calculation of sap flux density $\left(J_{\mathrm{s}}, \mathrm{g} \mathrm{m}^{-2} \mathrm{~s}^{-1}\right)$ was first put forward by (Granier, 1985); $J_{\mathrm{s}}$ is 
expressed as a function of the temperature difference $(\Delta \mathrm{T})$ between a heating probe and a reference probe: $J_{\mathrm{S}}=119 \times\left(\Delta \mathrm{T}_{\max } / \Delta \mathrm{T}-1\right)^{1.231}$, where $\Delta \mathrm{T}_{\max }$ is the $\Delta \mathrm{T}$ under zero flow condition, which is commonly substituted by the daily, nighttime maximum $\Delta \mathrm{T}$ (Granier, 1987).

As the Granier's formula was derived from an empirical relationship (Granier, 1985) rather than based on wood physical properties (Wullschleger et al., 2011), the TDP method has been reported to substantially over- or underestimate $J_{\mathrm{s}}$ in various studies (Bush et al., 2010; Clearwater et al., 1999; Steppe et al., 2010). Potential reasons for the observed divergences include non-uniform sap flow along the sensor (Clearwater et al., 1999), lacking compensation for the "wound effect" (Wullschleger et al., 2011) and gradients in temperature along the stem (Do and Rocheteau, 2002). Further, the effects of variations in wood water content $\left(\theta_{\text {wood }}\right)$ of the stem on the accuracy of TDP measurements have been the subject of investigation (Lu et al., 2004; Tatarinov et al., 2005; Vergeynst et al., 2014). Generally, the depletion and recharge of water storage in stems can lead to substantial fluctuations of $\theta_{\text {wood }}$ (Nadler et al., 2008; Yang et al., 2015), which may influence wood thermal conductivity $\left(K_{\text {wood }}\right)$ and subsequently estimates of $J_{\mathrm{s}}$. Based on theoretical analysis of a temperature- $\theta_{\text {wood }}$ function (Carslaw and Jaeger, 1959) and a laboratory dehydration experiment on tree stem segments (Vergeynst et al., 2014), it was demonstrated that $\theta_{\text {wood }}$ influenced $K_{\text {wood }}$ around TDP probes and caused underestimation of daytime $J_{\mathrm{s}}$. The underestimation was attributed to selecting one single $\Delta \mathrm{T}_{\max }$ (usually at night) to calculate hourly $J_{\mathrm{s}}$ for the whole day (Granier, 1987) while ignoring the different $K_{\text {wood }}$ between nighttime and daytime. Additionally, the influence of $\theta_{\text {wood }}$ on $\Delta \mathrm{T}_{\max }$ may differ with soil water conditions, as previous studies found that $\theta_{\text {wood }}$ in trees and palms fluctuates with $\theta_{\text {soil }}$ on the longer (i.e. monthly, seasonal) term (Constantz and Murphy, 1990; Holbrook et al., 1992; Wullschleger et al., 1996). Further, on rainy days, trunk $\theta_{\text {wood }}$ was reported to be significantly increased, and subsequently decreased during the following sunny days (Constantz and Murphy, 1990; Holbrook et al., 1992; Wullschleger et al., 1996), which may further influence $K_{\text {wood }}$ around TDP probes, and thus $\Delta \mathrm{T}_{\max }$. Ignoring these influences could lead to a potential misinterpretation of the patterns or values of TDP-derived $J_{\mathrm{s}}$.

In a previous study on bamboo water use, underestimated $J_{\mathrm{S}}$ by TDP was observed when using the original parameters of the calibration equation (Granier, 1985), while newly calibrated, species-specific equation parameters significantly improved the accuracy of the estimation (Mei et al., 2016). Among the potential reasons for the underestimation by the TDP approach on 
The influence of bamboo culm water content on sap flux measurements by 34 thermal dissipation probes: observations and modeling

bamboos is the thus-far neglected influence of dynamics in $\theta_{\text {wood. }}$ Bamboo culms have a large percentage of parenchyma $(\approx 50 \%$, Liese and Köhl, 2015), which provides a potential "buffering" reservoir for transpiration. With the withdrawal from and refilling of water to this reservoir, $\theta_{\text {wood }}$ may fluctuate accordingly, which can induce changes in culm circumference (Yang et al., 2015). Changes in $\theta_{\text {wood }}$ in bamboo culms may at least partly be responsible for underestimations of $J_{\mathrm{s}}$ by influencing $K_{\text {wood }}$ of the culm and consequently $\Delta \mathrm{T}_{\max }$

However, the mentioned factors are rather difficult to assess under field conditions and are commonly ignored in TDP studies on bamboos and trees, which is mainly due to practical constraints and the difficulty of measuring the dynamics of temperature around the TDP sensors. One promising approach could be series of controlled numerical simulations of $\theta_{\text {wood }}$ encompassing different scenarios. Such numerical simulations have been previously applied successfully to investigate the uncertainty of factors (wood thermal conductivity, non-homogeneity of sap flow radial profiles and of external temperature gradients) on thermal-based methods including the TDP approach (Tatarinov et al., 2005 ) and to analyze the influence of wood and probe properties (Wullschleger et al., 2011) and of heat storage capacity (Hölttä et al., 2015) on the accuracy of TDP estimates.

Partially based on such series of numerical simulations, the objectives of our study were 1) to test on bamboo segments in a laboratory dehydration experiment if $\Delta \mathrm{T}_{\max }$ is affected by decreasing $\theta_{\text {wood }}$, and to explore if $\Delta \mathrm{T}_{\max }$ in bamboos is influenced by changes in $\theta_{\text {soil }}$ under field conditions, and 2) to quantify and if necessary correct for potential deviations of $J_{\mathrm{S}}$ in bamboo culms with a steady-state thermal model. Our study is intended as a methodological baseline study to evaluate and improve the accuracy of TDP measurements on bamboos.

\subsection{Methods}

\subsubsection{Culm $\theta_{\text {wood }}$ and $\theta_{\text {soil }}$ and $\Delta \mathbf{T}_{\max }$}

To test if $\Delta \mathrm{T}_{\max }$ is affected by changes in $\theta_{\text {wood }}$ in bamboos, we applied three different approaches: 1) a dehydration experiment on freshly cut culm segments of Gigantochloa apus, 2) long-term field monitoring of $\theta_{\text {soil }}$ and daily TDP-derived $\Delta \mathrm{T}_{\max }$ on culms of three bamboo species (Bambusa vulgaris, 
Dendrocalamus asper, G. apus), and 3) numerical simulation experiments with a steady-state thermal model based on the geometry and physical characteristics of a segment of B. vulgaris.

\section{Laboratory dehydration experiment}

Similar to previously conducted dehydration experiments on tree segments (Vergeynst et al., 2014), we performed dehydration experiments on freshly cut culm segments of G. apus; our laboratory experiments took place in May 2013. Before the actual experiments, a freshly sprouted culm of G. apus (diameter $7.3 \mathrm{~cm}$ ) was cut before sunrise in the common garden of Bogor Agriculture University, Bogor, Indonesia. From the cut culm, three segments (each $20 \mathrm{~cm}$ in length) were collected and immediately transported to the laboratory inside a sealed plastic bag to prevent water loss. In the laboratory, the segments were soaked in $40 \mathrm{mM} \mathrm{KCl}$ solution for 24 hours to ensure that they reached saturation moisture content. After that, water on the surface of the segments was removed with tissues, while the two ends of each segment were sealed with glue. This ensured that they subsequently only and uniformly dehydrated from the outer culm superficies.

At a first step of the actual dehydration experiment, the fresh weight of each segment ( $w_{\text {fresh }}, \mathrm{g}$ ) was obtained with a balance with $0.01 \mathrm{~g}$ resolution (KB2400-2N, KERN \& SOHN GmbH, Balingen, Germany). Each segment was then laid down horizontally and a pair of $1 \mathrm{~cm}$-long TDP was installed in the culm wall (Mei et al., 2016). The heating and reference probes were placed $10 \mathrm{~cm}$ apart, at $5 \mathrm{~cm}$ distance to each end of the segment.

As a second step, cycles of three-hour probe powering and subsequent two-hour dehydration periods were conducted repeatedly over the duration of five days. During the powering phase, the heating probe of the TDP sensors was continuously powered with $0.1 \mathrm{~W}$ in order to obtain stable $\Delta \mathrm{T}_{\max }$ readings. During this interval, room temperature was kept constant at about $20{ }^{\circ} \mathrm{C}$ and laboratory conditions prevailed (constant light, only a little air circulation); the segments thus dehydrated only marginally during this time. During the following two-hour dehydration period, the power of the heating probe was turned off and the segments were placed under an electric fan to artificially accelerate the dehydration process. The segments were further continuously turned to ensure uniform dehydration. At the end of each two-hour period, TDP sensors were removed and the segments were weighted. By continuously 
The influence of bamboo culm water content on sap flux measurements by 36 thermal dissipation probes: observations and modeling

repeating the powering-dehydration cycles, data pairs of $w_{\text {fresh }}$ vs. $\Delta \mathrm{T}_{\max }$ were produced and recorded.

After the end of the dehydration experiments, the segments were oven dried at $100{ }^{\circ} \mathrm{C}$ for 48 hours to get their dry weight $\left(w_{\text {dry }}, \mathrm{g}\right)$. With the $w_{\text {dry }}$ and $w_{\text {fresh }}$ of each powering-dehydration cycle, the $\theta_{\text {wood }}\left(\mathrm{kg} \mathrm{kg}^{-1}\right)$ was calculated as $\left(w_{\text {fresh }}-w_{\text {dry }}\right) / w_{\text {dry }}$. Subsequently, the relationship between $\theta_{\text {wood }}$ and $\Delta \mathrm{T}_{\max }$ was examined.

\section{Field monitoring of $\theta_{\text {soil }}$ and $\Delta \mathbf{T}_{\max }$}

To explore whether, and if so how, $\Delta \mathrm{T}_{\max }$ in bamboo culms was influenced by the $\theta_{\text {soil }}$ under field conditions, we monitored daily TDP-derived $\Delta \mathrm{T}_{\max }$ on three culms each of D. asper and G. apus and on four culms of B. vulgaris for seven months (July 2012 to April 2013). Simultaneously, $\theta_{\text {soil }}$ at $20 \mathrm{~cm}$ depth was monitored at the respective study sites with time domain reflectometry sensors (TDR, CS616, Campbell). Detailed information of the installations refers to Mei et al. (2016). Subsequently, the relationship between $\Delta \mathrm{T}_{\max }$ and daily mean $\theta_{\text {soil }}$ was examined.

\section{$\theta_{\text {wood }}$ and thermal conductivity}

The thermal conductivity of each sample segment was calculated following Vandegehuchte and Steppe (2012), who introduced a corrected thermal conductivity for axial directions $\left(K_{\mathrm{a}}, \mathrm{W} \mathrm{m}^{-1} \mathrm{~K}^{-1}\right.$; Eq. 1$)$ :

$$
K_{a}=K_{w}\left(\theta_{\text {wood }}-\theta_{\text {wood }-F S P}\right) \frac{\rho_{d r y}}{\rho_{w}}+0.04186 \times\left(21.0-20.0 \times F_{v-F S P}\right)
$$

Where $K_{\mathrm{w}}$ is thermal conductivity of water $\left(0.6 \mathrm{~W} \mathrm{~m}^{-1} \mathrm{~K}^{-1}\right), \theta_{\text {wood-FSP }}$ is $\theta_{\text {wood }}$ at the fiber saturation point $(\%), \rho_{\text {dry }}$ and $\rho_{\mathrm{w}}$ are the respective densities of dry wood and water $\left(1000 \mathrm{~kg} \mathrm{~m}^{-3}\right)$ and $F_{\mathrm{v} \text {-FSP }}$ is the void fraction of wood at the fiber saturation point. $\theta_{\text {wood-FSP }}$ and $F_{\text {v-FSP }}$ were calculated with several different approaches, using $\rho_{\text {dry }}$ and $\rho_{\mathrm{w}}$ (see details in Appendix).

To obtain $\rho_{\text {dry }}$ of bamboo culms, all culms of the three species that were monitored in our study were harvested at 6:00 am on 15, 16 and 28 April 2013. Segments were obtained every two meters on the respective culms. The segments were immediately transported to the laboratory in sealed plastic bags. The fresh volumes $\left(v_{\text {fresh }}, \mathrm{cm}^{3}\right)$ of the segments were derived by measuring 
lengths and inner and outer radiuses of the cylindrical segments; additionally, the $w_{\text {fresh }}$ of each segment was established. After that, the segments were dried in an oven at $100{ }^{\circ} \mathrm{C}$ for 48 hours to get their $w_{\text {dry }}$. Subsequently, $\rho_{\mathrm{d}}$ could be calculated as $w_{\text {dry }} / v_{\text {fresh }}$.

With the mentioned variables ( $\rho_{\mathrm{dry}}, \rho_{\mathrm{w}}, \theta_{\text {wood-FSP }}$ and $\left.F_{\mathrm{v}-\mathrm{FSP}}\right)$, we calculated series of $K_{\mathrm{a}}$ with $\theta_{\text {wood }}$ ranging from 0.1 to $1 \mathrm{~kg} \mathrm{~kg}^{-1}$ (in incremental 0.1 $\mathrm{kg} \mathrm{kg}^{-1}$ steps); the thermal conductivity in the transverse direction $\left(K_{\mathrm{t}}\right)$ was set to half the value of the $K_{\mathrm{a}}$ (Wullschleger et al., 2011). At last, using the same variables as above $\left(\rho_{\mathrm{dry}}, \rho_{\mathrm{w}}, \theta_{\text {wood-FSP }}\right.$ and $\left.F_{\mathrm{v}-\mathrm{FSP}}\right)$ and varying $K_{\mathrm{a}}$ and $K_{\mathrm{t}}$ with varying $\theta_{\text {wood }}$ (Eq. 2 ), we derived a series of temperatures at thermal steady state with zero sap flow. Thus, $\Delta \mathrm{T}_{\max }$ between the heating probe and unheated reference probe was calculated.

\section{Steady-state thermal model}

To test if $\Delta \mathrm{T}_{\max }$ decreased with increasing $\theta_{\text {wood }}$ in bamboos, numerical simulations of temperature distributions were performed with a steady-state thermal model (Academic version, CFX 17.0, ANSYS Inc., Pennsylvania, USA). The simulations were conducted on a 3D anisotropic grid by numerically solving the steady-state energy balance equation (Eq. 2):

$$
-\lambda \nabla^{2} T+c_{w} Q_{w} \nabla T=q
$$

Where $q$ is the heat input of a grid $\left(\mathrm{W} \mathrm{m}^{-3}\right), T$ is the temperature of a grid $(\mathrm{K}), \lambda$ is matrix of thermal conductivity $\left(\mathrm{W}^{-1} \mathrm{~K}^{-1}\right), \nabla$ is vector differential operator, $c_{\mathrm{w}}$ is the specific heat of water $\left(\mathrm{J} \mathrm{kg}^{-1} \mathrm{~K}^{-1}\right)$ and $Q_{\mathrm{W}}$ is the sap flow vector $\left(\mathrm{kg} \mathrm{m}^{-2} \mathrm{~s}^{-1}\right)$. To explore the relationship between $\theta_{\text {wood }}$ and $\Delta \mathrm{T}_{\max }$, $Q_{\mathrm{w}}$ was set to zero sap flow when aiming to simulate $\Delta \mathrm{T}_{\max }$ (See detailed parameters in Table 3.1).

In order to simplify the simulation, the geometry of the model was based on a simplified 3D bamboo segment, i.e. a cuboid with $20 \mathrm{~cm}$ height, 6.65 $\mathrm{cm}$ width, and $1 \mathrm{~cm}$ depth, ignoring the curvature of the stem surface. The heating probe of the TDP sensor was modeled as an aluminum tube with its actual dimensions, i.e. $0.235 \mathrm{~cm}$ in diameter and $1 \mathrm{~cm}$ in length (Mei et al., 2016); it was inserted through into the $1 \mathrm{~cm}$ wide simulated culm wall of the cuboid, in the center of the segment (Wullschleger et al., 2011). Resembling the (actual) field methodology, the unheated reference probe was positioned $10 \mathrm{~cm}$ upstream from the heating probe. Along the axial and radial direction of 
The influence of bamboo culm water content on sap flux measurements by thermal dissipation probes: observations and modeling

Table 3.1 Parameters for the ANSYS numerical simulation

\begin{tabular}{ccc}
\hline Parameters & Values & Reference \\
\hline Specific heat capacity of fresh wood & $1644 \mathrm{~J} \mathrm{~kg}^{-1} \mathrm{~K}^{-1}$ & Measured \\
Dry wood density & $956 \mathrm{~kg} \mathrm{~m}^{-3}$ & Measured \\
Heating probe power & $1444 \mathrm{~W} / \mathrm{m}^{2}$ & Measured \\
Probe length & $1 \mathrm{~cm}$ & Measured \\
Ambient temperature & $300 \mathrm{~K} / 26.85{ }^{\circ} \mathrm{C}$ & Set \\
\hline
\end{tabular}

the heating probe, the temperature was assumed to be fairly uniform (following Wullschleger et al., 2011), and wood physical properties along the probe were also assumed to be uniform. Therefore, the steady state simulations were thus simplified on the front and back surfaces of the segment. Generally, a $2 \mathrm{~mm}$ (quadratic) mesh was used for the thermal steady state model. However, mesh type was set to quad/tri around the heating probe, because the contact area between the heating probe and the surrounding wood was irregular.

The boundary conditions of the segment surfaces included inlet, outlet, probe, symmetric surfaces (front and back) and wall. The inlet surface was located on the upstream side and the water came into the segment from the inlet. The outlet surface was located on the downstream side and the pressure was set to $0 \mathrm{~Pa}$. The heating probe was located in the center of the bamboo segment and was powered with $1444 \mathrm{~W} \mathrm{~m}^{-2}$ (the input power divided by the surface area of the aluminum tube). The front and back surfaces of the wood domain were set as symmetric, which means any plane between the front and back surfaces has same physical and thermal properties. The left and right sides of the bamboo segment were defined as walls with no water flowing out of the segment. The initial temperatures on all segment surfaces and of sap water were set to $300 \mathrm{~K}\left(26.85^{\circ} \mathrm{C}\right)$ by default in the ANSYS model.

\subsubsection{The influence of $\theta_{\text {wood }}$ on $\boldsymbol{J}_{\mathrm{s}}$}

To simulate the influence of varying $\theta_{\text {wood }}$ on TDP-derived $J_{\mathrm{s}}$ in bamboo culms, we simulated the $\Delta \mathrm{T}$ between probes in a series of numerical simulations of $J_{\mathrm{s}}$ and $\theta_{\text {wood. }}$. We incrementally increased $J_{\mathrm{s}}$ from 0 to $30 \mathrm{~g} \mathrm{~cm}^{-2} \mathrm{~h}^{-1}$ in $5 \mathrm{~g}$ $\mathrm{cm}^{-2} \mathrm{~h}^{-1}$ steps, and $\theta_{\text {wood }}$ from 0.1 to $1 \mathrm{~kg} \mathrm{~kg}^{-1}$ in $0.1 \mathrm{~kg} \mathrm{~kg}^{-1}$ steps. The $\Delta \mathrm{T}$ of each possible combination at zero $J_{\mathrm{s}}$ was used as $\Delta \mathrm{T}_{\max }$. The settings of geometry, meshing and change of $K_{\mathrm{a}}$ against $\theta_{\text {wood }}$ followed the previously described model description (see 2.1.3). 
Two scenarios were simulated: 1 ) relative to a fixed nighttime $\theta_{\text {wood }}$ (e.g. $1 \mathrm{~kg} \mathrm{~kg}^{-1}$ ), the daytime $\theta_{\text {wood }}$ was reduced in $0.1 \mathrm{~kg} \mathrm{~kg}^{-1}$ steps (for clarity, some of the figures only show reductions of $0.1,0.3,0.7$ and $0.9 \mathrm{~kg} \mathrm{~kg}^{-1}$ ); 2) based on different nighttime $\theta_{\text {wood }}\left(0.3,0.6\right.$ and $\left.0.9 \mathrm{~kg} \mathrm{~kg}^{-1}\right)$, the daytime $\theta_{\text {wood }}$ was reduced by half compared to nighttime $\theta_{\text {wood }}$. The first scenario was simulated to explore the influence of changes in $\theta_{\text {wood }}$ between daytime and nighttime ( $\left.\Delta \theta_{\text {wood }}\right)$ on daytime $J_{\mathrm{s}}$ in a day. The second scenario compared the varying influence of $\Delta \theta_{\text {wood }}$ on daytime $J_{\mathrm{s}}$ among the days with different nighttime $\theta_{\text {wood, }}$, which likely occurs e.g. between different seasons (dry vs. wet season) or among days with different weather conditions (sunny vs. rainy days).

For a set $\theta_{\text {wood }}$ (e.g. $\theta_{\text {wood }}=1 \mathrm{~kg} \mathrm{~kg}^{-1}$ ), the derived $\Delta \mathrm{T}$ were used to calculate $J_{\mathrm{S}}$ in two ways: (1), $J_{\mathrm{S}}$ was calculated with $\Delta \mathrm{T}_{\max }$ and $\Delta \mathrm{T}$ for the same $\theta_{\text {wood }} ;(2), J_{\text {s-mis }}$ was calculated with $\Delta \mathrm{T}_{\max }$ and $\Delta \mathrm{T}$ for a lower $\theta_{\text {wood }}\left(\right.$ e.g. $\theta_{\text {wood-mis }}=0.9 \mathrm{~kg} \mathrm{~kg}^{-1}$ ). The respective relative changes of $J_{\mathrm{s}}$ and $\Delta \theta_{\text {wood }}$ were calculated as $\left(J_{\mathrm{s}}-J_{\mathrm{s}-\mathrm{mis}}\right) / J_{\mathrm{s}}$ and $\left(\theta_{\text {wood }}-\theta_{\text {wood-mis }}\right) / \theta_{\text {wood }}$. Relative changes of $J_{\mathrm{s}}$ were analyzed with the $\Delta \theta_{\text {wood }}$ between nighttime and daytime. The relationship between the relative changes of $J_{\mathrm{s}}$ and $\Delta \theta_{\text {wood, }}$, respectively, was then applied to the $J_{\mathrm{S}}$ of $B$. vulgaris on a sunny day, to determine the degree of influence on daily water use.

All data analysis and figures were performed with SAS 9.3 (SAS Institute Inc., Cary, NC, USA, 2013).

\subsection{Results}

\subsection{1 $\Delta \mathbf{T}_{\max }$ and $\theta_{\text {wood }} / \theta_{\text {soil }}$}

In the laboratory dehydration experiment, the three freshly sprouted bamboo segments of $G$. apus showed differences in $\theta_{\text {wood }}$ vs. $\Delta \mathrm{T}_{\max }$ patterns. Nonetheless, when pooled, all three segments showed significant negative linear correlations between $\Delta \mathrm{T}_{\max }$ and $\theta_{\text {wood }}\left(R^{2}=0.61, P<0.05\right.$; Fig. 3.1).

In the field monitoring, daily mean $\theta_{\text {soil }}$ was found to have a significant negative linear relationship $(\mathrm{P}<0.05)$ with daily $\Delta \mathrm{T}_{\max }$ on all three bamboo species (D. asper, G. apus, B. vulgaris; Fig. 3.2). The slope of the $\Delta \mathrm{T}_{\max }-\theta_{\text {soil }}$ regression line was larger on $B$. vulgaris $(-3.55)$ than on D. asper (-1.91) and G. apus (-2.14). 
The influence of bamboo culm water content on sap flux measurements by 40 thermal dissipation probes: observations and modeling

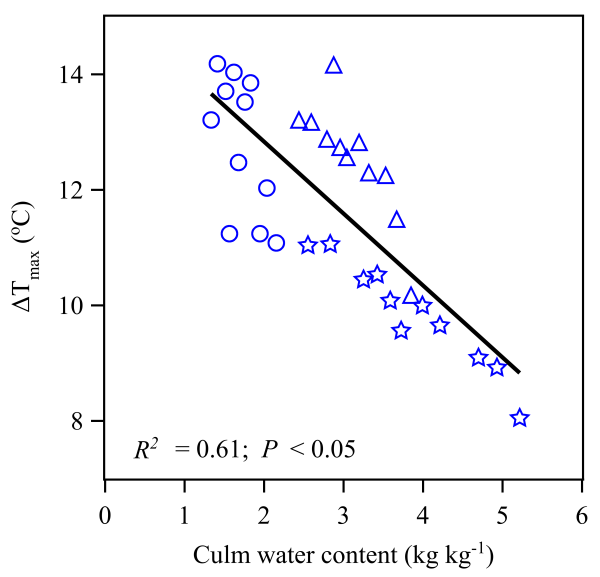

Fig. 3.1 The maximum temperature difference between the probes of TDP $\left(\Delta \mathrm{T}_{\max }\right)$ in relation to the water content in culm segments of freshly sprouted G. apus in a dehydration experiment. Different symbols indicate different segments. The unit of culm water content $\left(\mathrm{kg} \mathrm{kg}^{-1}\right)$ indicates $\mathrm{kg}$ water in the culm per kg dry weight.

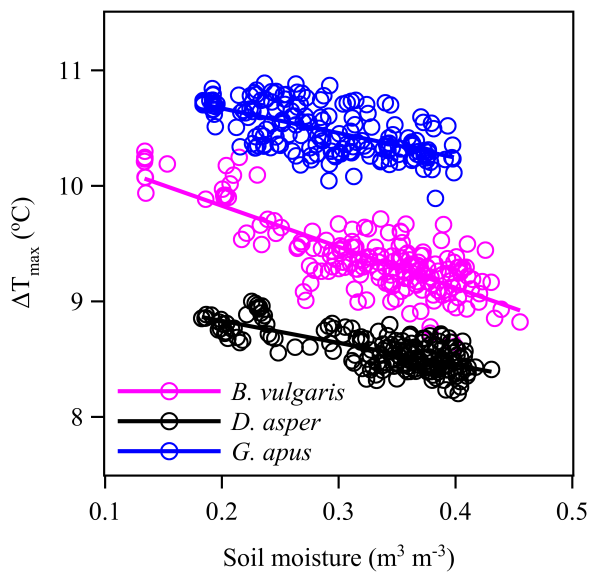

Fig. 3.2 The daily maximum temperature difference between the probes of TDP $\left(\Delta \mathrm{T}_{\max }\right)$ in relation to daily mean soil moisture for three bamboo species $(B$. vulgaris: $Y=-3.55 X+10.54, R^{2}=0.63, P<0.01 ; D$. asper: $Y=-1.91 X+9.21$, $R^{2}=0.54, P<0.01 ; G$. apus: $\left.Y=-2.14 X+11.10, R^{2}=0.37, P<0.01\right)$. 


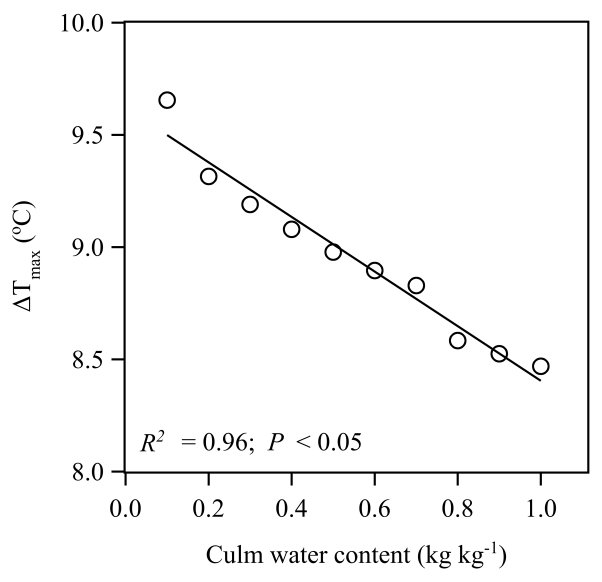

Fig. 3.3 The simulated maximum temperature difference between the probes of TDP $\left(\Delta \mathrm{T}_{\max }\right)$ with the ANSYS model in relation to culm water content. The unit of culm water content $\left(\mathrm{kg} \mathrm{kg}^{-1}\right)$ indicates $\mathrm{kg}$ water in the culm per $\mathrm{kg}$ dry weight.

Using a steady-state thermal model (ANSYS), the heat field around TDP sensors was simulated for different $\theta_{\text {wood }}$ when $J_{\mathrm{S}}$ was zero ("zero sap flow" condition). With increasing $\theta_{\text {wood }}$, the heat field area became smaller, and temperatures became lower (Appendix Fig. 1). A significant negative linear relationship between $\Delta \mathrm{T}_{\max }$ and $\theta_{\text {wood }}$ was found with data provided by the steady-state thermal model $\left(R^{2}=0.97, P<0.05\right.$; Fig. 3.3$)$. This negative correlation could potentially be attributed to changes of culm $K_{\mathrm{a}}$ (Eq. 1) with changing $\theta_{\text {wood }}$ around the heating probe. To test for this, we calculated $K_{\mathrm{a}}$ using the $\rho_{\text {dry }}$ and $\theta_{\text {wood }}$ of 82 segments from a total of 10 culms from the three bamboo species. The normalized ratio of culm $K_{\mathrm{a}}$ to $\rho_{\text {dry }}$ of all segments was significantly linearly correlated to $\theta_{\text {wood }}\left(R^{2}=0.99, P<0.05\right.$; Fig. 3.4).

\subsubsection{The influence of $\theta_{\text {wood }}$ on $J_{s}$}

Keeping other controlling variables constant, large underestimation became apparent 1) for large decreases of $\theta_{\text {wood }}$ from nighttime to daytime, 2) at relatively low $J_{\mathrm{s}}$, and 3 ) for relatively larger nighttime $\theta_{\text {wood }}$ when the ratio of decrease to the daytime (e.g. by half) was kept constant.

Using the ANSYS model for series of numerical simulations of $\theta_{\text {wood }}$ and $J_{\mathrm{S}}$, we found that TDP underestimated daytime $J_{\mathrm{S}}$ calculated with nighttime $\Delta \mathrm{T}_{\max }$ when $\theta_{\text {wood }}$ was lower during the day than during the night. For a given nighttime $\theta_{\text {wood }}$ (e.g. $1 \mathrm{~kg} \mathrm{~kg}^{-1}$ ), lower daytime $\theta_{\text {wood }}$ (e.g. $-0.9 \mathrm{~kg} \mathrm{~kg}^{-1}$ ) led 


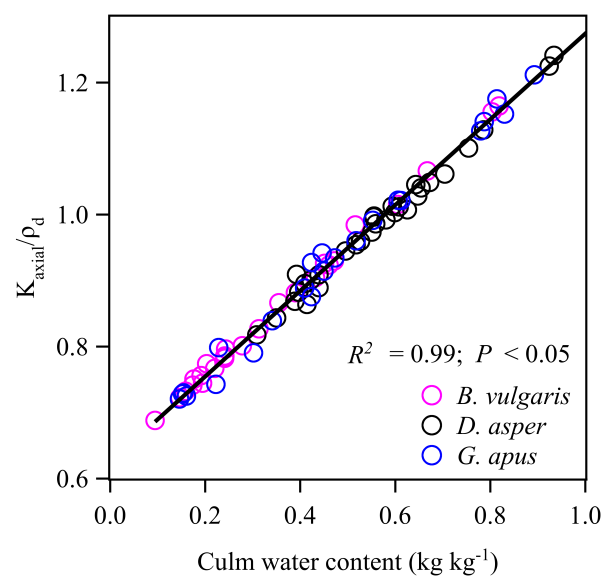

Fig. 3.4 The relationship between the ratio of thermal conductivity in the axial direction to culm dry density and the culm water content.

to larger underestimation of $J_{\mathrm{S}}$ of up to $44 \%$ (Fig. 3.5). Numerical simulations with the ANSYS model for reductions of daytime $\theta_{\text {wood }}$ by $0.1,0.3,0.7$ and $0.9 \mathrm{~kg} \mathrm{~kg}^{-1}$ from a $1 \mathrm{~kg} \mathrm{~kg}^{-1}$ nighttime $\theta_{\text {wood }}$ result in underestimation of daily accumulated $J_{\mathrm{s}}$ by $2 \%, 10 \%, 19 \%$ and $28 \%$, respectively (Fig. 3.6).

The relative error of $J_{\mathrm{s}}(\%)$ was larger at lower $J_{\mathrm{s}}$, and it gradually became smaller and approached to a stable value with increasing $J_{\mathrm{s}}$. For example, the relative error was $18.6 \%$ at $5 \mathrm{~g} \mathrm{~cm}^{-2} \mathrm{~h}^{-1}$ while only $9.4 \%$ at $30 \mathrm{~g} \mathrm{~cm}^{-2}$ $\mathrm{h}^{-1}$ when $\theta_{\text {wood }}$ was decreased by $0.3 \mathrm{~kg} \mathrm{~kg}^{-1}$ in the daytime from $1 \mathrm{~kg} \mathrm{~kg}^{-1}$ in nighttime (Fig. 3.7). Even though relative errors were smaller at higher daytime $J_{\mathrm{s}}$, they were responsible for most of the underestimation of daily water use. For example, the relative errors caused by the sap flux over $30 \mathrm{~g}$ $\mathrm{cm}^{-2} \mathrm{~h}^{-1}$ constituted as much as $64 \%$ of the total underestimation of daily water use when $\theta_{\text {wood }}$ was decreased by $0.3 \mathrm{~kg} \mathrm{~kg}^{-1}$ in the daytime from $1 \mathrm{~kg}$ $\mathrm{kg}^{-1}$ in nighttime (Fig. 3.6).

For hypothetical reductions of nighttime $\theta_{\text {wood }}\left(0.3,0.6,0.9 \mathrm{~kg} \mathrm{~kg}^{-1}\right)$ to half of their respective values in the daytime (i.e. $0.15,0.3$ and $0.45 \mathrm{~kg}$ $\mathrm{kg}^{-1}$ ), the highest (> 25\%) underestimation of daytime $J_{\mathrm{s}}$ were simulated for scenarios with high nighttime $\theta_{\text {wood }}$ (i.e. $0.9 \mathrm{~kg} \mathrm{~kg}^{-1}$ ) under conditions of low sap flux density (e.g. $5 \mathrm{~g} \mathrm{~cm}^{-2} \mathrm{~h}^{-1}$ ). With increasing $J_{\mathrm{s}}$, the underestimation became smaller (e.g. $<15 \%$ at $30 \mathrm{~g} \mathrm{~cm}^{-2} \mathrm{~h}^{-1}$ ), particularly for lower (i.e. 0.3, 0.6) nighttime $\theta_{\text {wood }}\left(<10 \%\right.$ at $30 \mathrm{~g} \mathrm{~cm}^{-2} \mathrm{~h}^{-1}$, Fig. 3.7). 


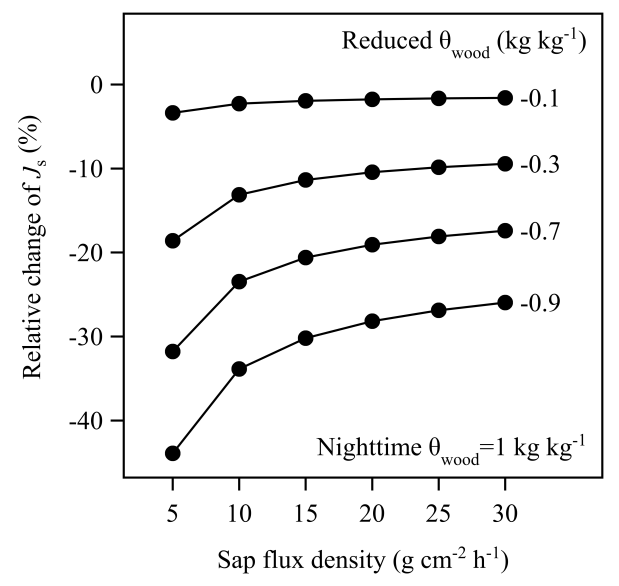

Fig. 3.5 The simulated relative change of daytime sap flux density $\left(J_{\mathrm{s}}\right)$ in percentage (\%) at different absolute $J_{\mathrm{s}}\left(\mathrm{g} \mathrm{cm}^{-2} \mathrm{~h}^{-1}\right)$. Relationships are provided for different reductions of stem water content in daytime $(-0.1,-0.3,-0.7$ and $-0.9 \mathrm{~kg} \mathrm{~kg}^{-1}$ ) from $1 \mathrm{~kg} \mathrm{~kg}^{-1}$ in the nighttime, which results in different degrees of change of stem thermal conductivity. Provided data based on numerical simulations with the ANSYS model.

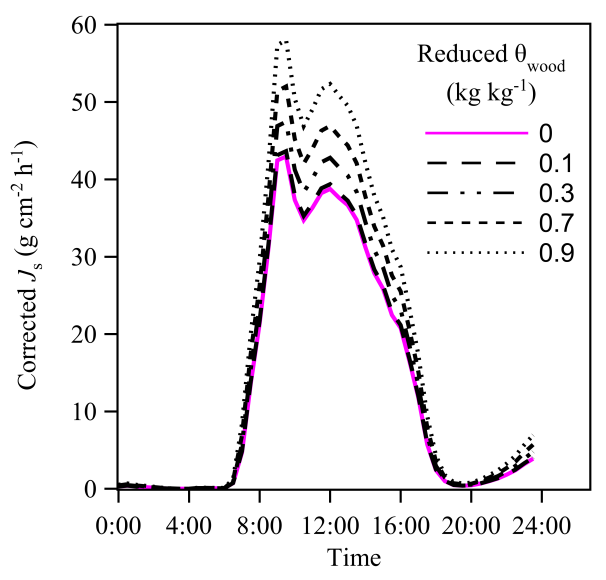

Fig. 3.6 The corrected sap flux density $\left(J_{\mathrm{s}}\right)$ for different levels of $\theta_{\text {wood }}$ reduction (\%) during the daytime. Simulations based on field monitoring data of a B. vulgaris on 17 September 2012. Numerical simulations with the ANSYS model for reductions of daytime $\theta_{\text {wood }}$ by $0.1,0.3,0.7$ and $0.9 \mathrm{~kg} \mathrm{~kg}^{-1}$ from a $1 \mathrm{~kg} \mathrm{~kg}^{-1}$ nighttime $\theta_{\text {wood }}$ result in underestimation of daily accumulated $J_{\mathrm{s}}$ by $2 \%, 10 \%, 19 \%$ and $28 \%$, respectively. 
The influence of bamboo culm water content on sap flux measurements by thermal dissipation probes: observations and modeling

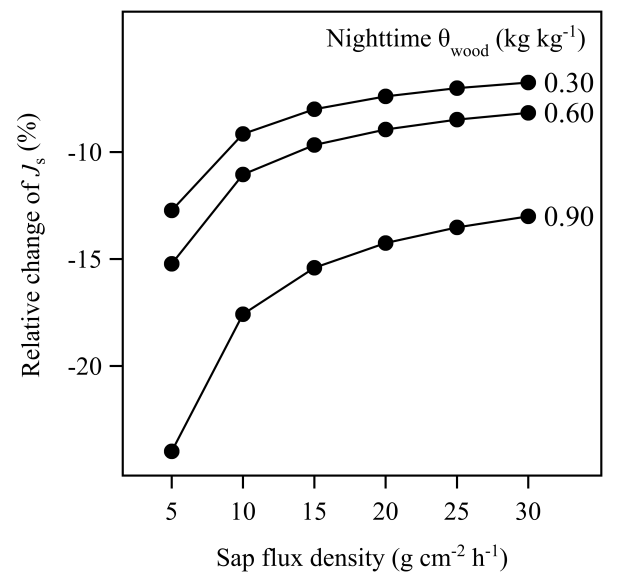

Fig. 3.7 The simulated relative change of daytime sap flux density $\left(J_{\mathrm{s}}\right)$ in $\%$ at different absolute $J_{\mathrm{s}}\left(\mathrm{g} \mathrm{cm}^{-2} \mathrm{~h}^{-1}\right)$. Relationships are provided for different nighttime stem water contents $\left(\theta_{\text {wood }}, 0.3,0.6\right.$ and $\left.0.9 \mathrm{~kg} \mathrm{~kg}^{-1}\right)$, assuming a constant reduction (i.e. by half) in the ratio between nighttime and daytime $\theta_{\text {wood }}$ Provided data based on numerical simulations with the ANSYS model.

\subsection{Discussion}

\subsection{1 $\Delta \mathbf{T}_{\max }$ and $\theta_{\text {wood }} / \theta_{\text {soil }}$}

The Granier's formula is based on one assumption that the wood thermal property keeps constant during the whole day, and this constant wood thermal property corresponds to one daily $\Delta \mathrm{T}_{\max }$ (Granier, 1987). However, $\Delta \mathrm{T}_{\max }$ would change accordingly when the wood thermal property fluctuated during one day, and one common daily $\Delta \mathrm{T}_{\max }$ would not reflect such change and would cause errors if still insisting on calculating $J_{\mathrm{s}}$ with this common daily $\Delta \mathrm{T}_{\max }$ (Vergeynst et al., 2014). In our study, a dehydration experiment was conducted on segments of freshly sprouted bamboo culms. The results showed that decreasing culm $\theta_{\text {wood }}$ led to increasing $\Delta \mathrm{T}_{\max }$ (Fig. 3.1). Similar results were found in a dehydration experiment on tree segments (Vergeynst et al., 2014). In trees, contrasting the daily fluctuation pattern of transpiration, $\theta_{\text {wood }}$ showed an opposite fluctuation pattern. $\theta_{\text {wood }}$ reached peak values during the night, when $J_{\mathrm{s}}$ was zero or marginal, and dropped to a minimum during the daytime (Hao et al., 2013; Sperling et al., 2015). On culms of the bamboo species B. vulgaris, a similar pattern of culm circumference was observed (Yang et al., 2015). Although this study did not include direct measurements of $\theta_{\text {wood, }}$, the daily dynamics of culm circumference can be expected to at least partly reflect changes in $\theta_{\text {wood }}$ (Köcher et al., 2013; Scholz et al., 2008). According 
to our findings, such fluctuations of $\theta_{\text {wood }}$ between nighttime and daytime go along with corresponding fluctuations of $\Delta \mathrm{T}_{\max }$. In the bamboo culms in our study, $\Delta \mathrm{T}_{\max }$ significantly decreased with increasing $\theta_{\text {soil }}$ (Fig. 3.2). This may be attributed to corresponding changes of $\theta_{\text {wood }}$ caused by the dynamics in $\theta_{\text {soil }}$. For trees, close coupling of the $\theta_{\text {wood }}-\theta_{\text {soil }}$ relationship was reported for rainy days and sunny days and for different seasons; on rainy days or after irrigation, $\theta_{\text {wood }}$ was significantly increased and subsequently decreased during following sunny days (Hao et al., 2013; Holbrook et al., 1992; Wullschleger et al., 1996). Similarly to $\theta_{\text {wood }}$ and being an important indicator of $\theta_{\text {wood }}$ stem circumference changed substantially between dry soil conditions and fully watered conditions (Köcher et al., 2013). Over the course of a growing season, variation in $\theta_{\text {wood }}$ was reported to be $39 \%$ in red maple; they were most produced between the dry and the wet season (Wullschleger et al., 1996). It has been put forward that dynamics in $\theta_{\text {wood }}$ may reflect changes in stem water storage (Sperling et al., 2015). Stem water storage mechanisms were shown to alleviate water shortage due to high transpiration demand during the daytime, with the assumption that depleted reservoirs can be fully recharged within one day, i.e. during the nighttime (Čermák et al., 2007; Goldstein et al., 1998; Köcher et al., 2013). However, this assumption may lead to errors in calculating stem water storage when the water storage depleted during the daytime is not fully refilled every day. Such incomplete refilling could be implied by a continuous decrease or increase of $\theta_{\text {wood }}$ on a day-to-day basis (Sperling et al., 2015; Wullschleger et al., 1996), e.g. due to changes in $\theta_{\text {soil }}$. Dynamics in stem water storage may thus be derived by changes in $\theta_{\text {wood }}$ between days, when $\theta_{\text {wood }}$ is derived from the $\Delta \mathrm{T}_{\max }-\theta_{\text {wood }}$ relationship and dry weight or volume of the tree stems or bamboo culms are known.

The model-derived $\Delta \mathrm{T}_{\max }-\theta_{\text {wood }}$ relationship was based on an ideal assumption that the nighttime zero sap flow existed and lasted long enough to establish a one-to-one correspondence between $\Delta \mathrm{T}_{\max }$ and maximum $\theta_{\text {wood. }}$. However, this ideal assumption may not always be met during experiments (Regalado and Ritter, 2007). As such, several studies have reported nighttime sap flow in different species, which was presumably related to atmospheric evaporative demand (Forster, 2014). Further, during dry periods the commonly high daytime transpiration in combination with relatively low soil water availability could potentially lead to more nighttime sap flow in the form of refilling the depleted stem water reservoirs (Wang et al., 2012). In some cases, this might mean that zero flow conditions are not met at all, not even during the night. Even when the stem is fully recharged and reaches its maximum water 
The influence of bamboo culm water content on sap flux measurements by 46 thermal dissipation probes: observations and modeling

content, nighttime sap flow could still occur, e.g. in the form of guttation. In the wet season (approx. April to May), we observed guttation from midnight to approx. 6:00 in the morning on bamboos growing close to a river. During this time, or even in general, zero nighttime sap flux conditions might thus not have been met, which would consequently affect the derived $\Delta \mathrm{T}_{\max }$. In our study, $\Delta \mathrm{T}_{\max }$ thus could have potentially been affected (i.e. lowered) by water fluxes occurring for different reasons. Therefore, both changes in $\theta_{\text {wood }}$ and nighttime sap flow are likely to influence $\Delta \mathrm{T}_{\max }$ in the same direction. As to which proportion they contributed in our study can thus far not be disentangled. This will require further, more in-depths ecophysiological studies.

\subsubsection{The influence of $\theta_{\text {wood }}$ on $J_{s}$}

In our study, we numerically simulated the influence of $\theta_{\text {wood }}$ on TDP-derived $J_{\mathrm{s}}$. The results pointed to a direct and quantifiable relationship between $\theta_{\text {wood }}$ and changes in $J_{\mathrm{s}}$, and thus potential errors in previous studies assuming a static $\theta_{\text {wood }}$ (Vergeynst et al., 2014; Wullschleger et al., 2011). Wullschleger et al. (2011) simulated scenarios examining the impact of wood thermal conductivity on the relationship between $J_{\mathrm{S}}$ and $k\left(=\Delta \mathrm{T}_{\max } / \Delta \mathrm{T}-1\right)$. They found a negative relationship between $\Delta \mathrm{T}$ and thermal conductivity and pointed out that the $J_{\mathrm{s}}-k$ relationship might be influenced by several factors including $\theta_{\text {wood }}$, wood density, and thermal conductivity. Vergeynst et al. (2014) quantified the influence of $\theta_{\text {wood }}$ on $J_{\mathrm{s}}$ by simulating possible temperature changes that were assumed to relate to $\theta_{\text {wood. }}$. However, they did not find a direct relationship between $\theta_{\text {wood }}$ and errors in $J_{\mathrm{s}}$. Our results supplement previous TDP error analyses and point to a direct and quantifiable relationship between $\theta_{\text {wood }}$ and errors on $J_{\mathrm{S}}$, which could potentially be corrected for e.g. with the mentioned model.

Using numerical simulations, we found increasing underestimation of $J_{\mathrm{s}}$ with the larger decrease of $\theta_{\text {wood }}$ from nighttime to daytime, e.g. due to depleted stem water storage (Fig. 3.5, 3.6). In previous studies on bamboos (Yang et al., 2015) and palms (Sperling et al., 2015), gradual decreases of $\theta_{\text {wood }}$ from sunrise to sunset were reported. $\theta_{\text {wood }}$ in the afternoon and especially at dusk was likely the lowest, which could introduce substantial bias into according estimates of $J_{\mathrm{S}}$ (Fig. 3.5). Our results indicate that the magnitude of the underestimation of $J_{\mathrm{s}}$ substantially differed with varying $J_{\mathrm{s}}$ : the relative error of $J_{\mathrm{s}}(\%)$ was largest at low $J_{\mathrm{s}}$, and gradually became smaller eventually 
approaching a stable value with increasing $J_{\mathrm{S}}$ (Fig. 3.5). TDP-derived $J_{\mathrm{S}}$ is thus influenced more profoundly by changing $\theta_{\text {wood }}$ in plants with generally low $J_{\mathrm{s}}$ or when $J_{\mathrm{s}}$ tends to be low (e.g. early morning, late afternoon). In contrast, for the plants with generally high $J_{\mathrm{s}}$ or at peak times of $J_{\mathrm{S}}$ (e.g. around noon), the influence of changes in $\theta_{\text {wood }}$ would be smaller. Despite the relatively smaller errors at higher daytime $J_{\mathrm{s}}$, they were responsible for causing most of the underestimation of daily water use (Fig. 3.6).

Additional to varying with different $J_{\mathrm{s}}$, the influence of $\theta_{\text {wood }}$ on TDPderived $J_{\mathrm{S}}$ may also differ with different water conditions of the soil due to different weather or management conditions, e.g. between rainy or sunny days or after irrigation. The applied model indicated that, when $\theta_{\text {wood }}$ was reduced by the same ratio (e.g. half) from nighttime to daytime, higher nighttime $\theta_{\text {wood }}$ caused larger underestimation of $J_{\mathrm{s}}$ (Fig. 3.7). High nighttime $\theta_{\text {wood }}$ may occur during the wet season or during the growing period of a plant. This could potentially lead to estimation errors when calibrating the TDP method with other methods in situ. As such, it was reported that even after calibrating the method with a full month of data encompassing parallel measurements of a reference method, the daily $J_{\mathrm{s}}$ of bamboos was still on average $10 \%$ lower when derived by TDP than by the stem heat balance method (Mei et al., 2016). Consequently, calibration approaches conducted over short periods of time may not reflect medium- or long-term dynamics in $\theta_{\text {wood }}$. Similarly, one-time laboratory calibration experiments on tree or bamboo segments may also be prone to error due to potentially varying (or unknown) $\theta_{\text {wood }}$, e.g. as a result of varying soil water conditions. We therefore strongly recommend multiple calibration experiments encompassing different seasons and soil water conditions, particularly if the TDP approach is applied for long-term monitoring; alternatively, the model applied in our study could potentially be used to correct for errors due to changing $\theta_{\text {wood }}$ if some basic wood properties are known.

For TDP and other heat-based methods, influences or biases due to changes in $\theta_{\text {wood }}$ cannot fully be avoided (Vergeynst et al., 2014). Additional to calibration-based approaches to correct for such errors, other possible solutions may include new types of sensors, which already account for dynamic changes of $\theta_{\text {wood }}$ when estimating $J_{\mathrm{s}}$ (Trcala and Čermák, 2016; Vandegehuchte and Steppe, 2013). Decreasing the sensitivity of the heat domain by increasing the power supply (Tatarinov et al., 2005) may be a further option. However, this may lead to possible damages to the wood structure; including dynamic change of $\theta_{\text {wood }}$ into estimating $J_{\mathrm{s}}$ thus seems to be a more promising 
The influence of bamboo culm water content on sap flux measurements by 48 thermal dissipation probes: observations and modeling

approach. The model applied in our study to simulate the influence of changes in $\theta_{\text {wood }}$ on $J_{\mathrm{s}}$ may be a first step to developing such a dynamic solution. In our study, the model was built under steady-state conditions, under which each simulation result was derived from the assumption of constant sap flow. These steady-state conditions may not (always) be met under field conditions, where sap flow is prone to external influences and may thus change frequently and not always predictably. For future studies, the application of the model in situ for simultaneous assessments of $\theta_{\text {wood }}$ and sap flow would be an interesting next step.

\subsection{Conclusions}

In our study encompassing laboratory dehydration experiments, field monitoring and model simulations, $\Delta \mathrm{T}_{\max }$, the core variable in calculating $J_{\mathrm{S}}$ with the TDP method, was found to correlate negatively with both $\theta_{\text {wood }}$ in bamboo culms and with $\theta_{\text {soil }}$. By numerically simulating this negative $\Delta \mathrm{T}_{\max }-\theta_{\text {wood }}$ relationship for different scenarios of daily and seasonal changes in $\theta_{\text {wood }}$, the corresponding underestimation of $J_{\mathrm{S}}$ was quantified. Keeping other controlling variables constant, large underestimation became apparent 1) for large decreases of $\theta_{\text {wood }}$ from nighttime to daytime, 2) at relatively low $J_{\mathrm{s}}$, and 3) for relatively larger nighttime $\theta_{\text {wood }}$ when the ratio of decrease to the daytime (e.g. by half) was kept constant. Our findings indicate that TDP measurements can be profoundly influenced by diurnal changes in $\theta_{\text {wood }}$ particularly in species with low water consumption, in species with large diurnal changes in stem water storage (between nighttime and daytime) and between periods with strongly alternating soil water conditions (e.g. between sunny and rainy days). Our study further suggests that $\Delta \mathrm{T}_{\max }$ derived by TDP could be a proxy for the stem water status and could thus potentially help to further understand the dynamics of stem water storage when coupled with steady-state thermal models. Interesting approaches for future studies include testing the here applied model in situ by simultaneously assessing dynamics in $\theta_{\text {wood }}$ and $J_{\mathrm{s}}$, as well as further improving and developing heat-based methods to include the assumption of non-stable $\theta_{\text {wood }}$ at different temporal scales. 


\section{Chapter 4}

\section{Deuterium tracing for assessing water circulation in bamboos}

Dong-Ming Fang ${ }^{1 \dagger *}$, Ting-Ting Mei $^{1 \dagger}$, Alexander Röll ${ }^{1}$, Hendrayanto ${ }^{2}$, Dirk Hölscher ${ }^{1}$

${ }^{1}$ Tropical Silviculture and Forest Ecology, Georg-August-Universität Göttingen, Germany. ${ }^{2}$ Department of Forest Management, Institut Pertanian Bogor, Indonesia

$\dagger$ The authors contributed equally to this work.

* Correspondence: Dong-Ming Fang, Tropical Silviculture and Forest Ecology, Georg-August-Universität Göttingen, Büsgenweg 1, Göttingen, 37077, Germany. Email: dongmingf@gmail.com 


\section{Abstract}

Bamboos are woody monocots with a hollow culm and connected rhizomes. We assessed bamboo water circulation in three big clumpy bamboo species by deuterium tracing along with formerly calibrated thermal dissipation probes (TDP) in a common garden in Indonesia. The deuterium-derived sap velocities correlated with the TDP-derived velocities in two of three species. In all species, the deuterium residence time in bamboo culms was little influenced by the contribution of the culm water storage to transpiration as estimated by TDPs at different culm heights. Potential reasons include a small water storage volume in the culms, a low estimated contribution of the storage to transpiration and high sap flux densities. Daily culm water use rates estimated by the deuterium and the TDP approaches correlated linearly $\left(R^{2}=0.9\right)$ but were by $70 \%$ in the deuterium estimates. After the experiment, culms were cut down and analyzed for residual deuterium, but concentrations were low which indicates that retention did not play a major role in causing errors of the deuterium tracing approach. In culms neighboring the deuterium labeled culms of Bambusa vulgaris and Gigantochloa apus, elevated deuterium concentrations were detected indicating water transfer between culms. Based on the differences in daily water use on labeled culms and the enhanced deuterium concentrations in neighboring culms of these two species, we inferred that five neighboring culms might receive water from the labeled culms. On contrast, in culms neighboring labeled Dendrocalamus asper culms, only slightly elevated deuterium concentrations were observed which implies a limited role by water transfer. However, incomplete mixing as indicated by high variation among three TDP sensors at a given height may be of particular importance for deuterium tracing in $D$. asper. In conclusion, species-specific differences among big clumpy bamboos are indicated and the deuterium tracing points to water transfer among culms.

Keywords: error analysis, sap velocity, water residence time, water storage, water transfer, water use

\subsection{Introduction}

Unidirectional water transport from the soil through plants to air was thought to be the general framework when studying plant water use (Goldsmith, 2013; 
Philip, 1966). However, this framework has been enlarged gradually by the new findings, such as foliage water uptake from air into leaves (Goldsmith et al., 2013; Studer et al., 2015) and inverse flow from the leaves to soil (Eller et al., 2013; Goldsmith, 2013), soil water translocation by roots (Burgess et al., 2001b; Sakuratani et al., 1999; Smith et al., 1999), and water transfer among interconnected plants through roots or rhizomes (Adonsou et al., 2016; Zhao et al., 2016). Such these water use characteristics, in combination with the frequently studied internal water storage (James et al., 2003; Meinzer et al., 2006; Yang et al., 2015) and the most studied transpiration, seem to constitute a more complicated water circulation within and among the plants. Within the plants, the internal water circulation can be formed by water transport (sap flow) to canopy or soil, and by water exchange between conduits and storage compartments for water storage (James et al., 2003). Between the plants and the environment (air and soil) and among the plants, the outer water circulation can be composed by water uptake from soil or foliage, water translocation, and water transfer. These water circulations were important to stimulate and maintain some physiological processes, e.g. regulating stomatal closure by transporting the root-produced abscisic acid to leaves (Hartung et al., 2002), maintaining high transpiration rates with the temporally stored water in stems (Goldstein et al., 1998; James et al., 2003), or relieving water shortage by water redistribution among interconnected plants (Adonsou et al., 2016; Zhao et al., 2016). Therefore, exploring and monitoring these water circulations would deepen our understanding of plant physiology.

Bamboos, as fast growing monocots, may have unique characteristics of water circulation. Compared with trees, comparable (Dierick et al., 2010; Kume et al., 2010) or higher (Ichihashi et al., 2015; Mei et al., 2016) maximum sap flux densities were found on bamboo species in previous studies. High sap flux densities may be attributed to the large culm hydraulic conductivity and low sapwood capacitance, as sap velocity on trees was found positively correlated with stem hydraulic conductivity and negatively with sapwood capacitance (Meinzer et al., 2006). If such correlations applied to bamboos, it may mean that bamboos had low sapwood capacitance which could be implied by the short residence time of water in the stem (Meinzer et al., 2006). However, longer residence time on one bamboo species (Bambusa blumeana) than on the reference trees was found (Schwendenmann et al., 2010). The contradictory findings may be case-specific or common for bamboos, and therefore, the corresponding investigation needs to be done on more bamboo species. Another distinctive characteristic of water circulation on 
bamboos is the water transfer among culms, due to the rhizomes which possibly provide passages for transporting water among culms (Stapleton, 1998). Water transfer among culms has been implied on B. blumeana by observing elevated deuterium $\left(\mathrm{D}_{2} \mathrm{O}\right)$ concentrations on the leaves of the neighbor culms which were in the same clump of the $\mathrm{D}_{2} \mathrm{O}$ labeled culms (Dierick et al., 2010). Another investigation on Moso bamboo (Phyllostachys pubescens) also implied water transfer by finding $20 \%$ less water use on the rhizome-cut culms than on the regular culms (Zhao et al., 2016). These findings need to be further tested on more species with the directly connected culms and with no destructive operation.

Deuterium tracing method, due to its traceability, has been applied for measuring sap velocity and water residence time in the stems of trees (Gaines et al., 2016; James et al., 2003; Meinzer et al., 2006), and for estimating daily water use rates (Calder, 1991; Dierick et al., 2010; Dye et al., 1992; Schwendenmann et al., 2010). In these studies, the $\mathrm{D}_{2} \mathrm{O}$ was first injected into the base stem of trees/bamboos (this operation is usually called labeling) and then the water transpired from leaves in the labeled trees/bamboos was periodically sampled to trace the $\mathrm{D}_{2} \mathrm{O}$ movement (Calder, 1991). Subsequently, the $\mathrm{D}_{2} \mathrm{O}$ concentration in the samples was used to estimate sap velocity, water residence time and daily water use rates (See details in Calder (1991) or Meinzer et al. (2006)). However, deuterium-derived water use rates were thought to be less reliable when two assumptions proposed by Calder (1991) for estimating the water use rates were violated (Schwendenmann et al., 2010). The two assumptions were: First, all the D2O injected into the base stem is taken up and transpired out from leaves without tracer loss in other forms; Second, the $\mathrm{D}_{2} \mathrm{O}$ is thoroughly mixed in the transpiration stream before water flowed into different regions of the crown (Calder, 1991). Compared with the other methods (e.g. thermal dissipation probe, TDP), both overestimation (Kalma et al., 1998; Marc and Robinson, 2004; Schwendenmann et al., 2010) and underestimation (Dye et al., 1992) on water use rates from deuterium tracing method were observed. On one bamboo species (B. blumeana), water use rates were found eight times higher with deuterium tracing method than with TDP method (Schwendenmann et al., 2010). The discrepancies could be attributed to several potential interference sources which may break the two assumptions, such as tracer loss due to retention of tracer in plants and water transfer among plants (Schwendenmann et al., 2010). Nevertheless, the discrepancies caused by the interference sources can also be estimated to explore the corresponding water circulation characteristics (e.g. water transfer). This process could be 
realized by monitoring tracer dynamics on leaves, stem and the interconnected plants to address the difference in water use rates simultaneously derived with deuterium tracing method and a reference method.

Our objectives were applying $\mathrm{D}_{2} \mathrm{O}$ : (1) to explore the water circulation characteristics of the bamboos, including sap velocities, water residence time, water use rates, and water transfer between culms, (2) and to evaluate the potential interference sources in $\mathrm{D}_{2} \mathrm{O}$-based daily water use estimates with referring to TDP method, such as $\mathrm{D}_{2} \mathrm{O}$ retention and transfer. To achieve the aims, we applied deuterium tracing method simultaneously with measurements of calibrated TDP sensors (Mei et al., 2016) on three tropical clumpy bamboo species in a common garden.

\subsection{Materials and methods}

\subsubsection{Study site and species}

The study was conducted in a common garden in Bogor, Indonesia (6 $6^{\circ} 33^{\prime} 40^{\prime \prime}$ $\mathrm{S}, 106^{\circ} 43^{\prime} 27^{\prime \prime} \mathrm{E}, 182 \mathrm{~m}$ asl). Bogor is a city with moderate temperature (average annual temperature $25.6{ }^{\circ} \mathrm{C}$ ) and plenty of rainfall (annual precipitation $3978 \mathrm{~mm}$ ) but has apparent wet and dry season (Van Den Besselaar et al., 2015). Three bamboo species (Bambusa vulgaris, Gigantochloa apus and Dendrocalamus asper) were selected for $\mathrm{D}_{2} \mathrm{O}$ labeling. For each species, the selected bamboo culms for $\mathrm{D}_{2} \mathrm{O}$ labeling were in one clump and located at the edge of the clump. The clump base areas were 18, 20 and $6 \mathrm{~m}^{2}$, and the canopy areas were 346,427 and $63 \mathrm{~m}^{2}$ for B. vulgaris, G. apus and D. asper.

\subsubsection{Deuterium tracing}

Three to four culms per species were labeled (Table 4.1). The labeled culms were injected with $\mathrm{D}_{2} \mathrm{O}(99.90 \%$ D, euroiso-top, Gif sur Yvette, France) during 6:00-7:00 on $8^{\text {th }}$ March 2013 (Fig. 4.1). The operation of injecting $\mathrm{D}_{2} \mathrm{O}$ into the studied bamboos followed Dierick et al. (2010). First, plastic tubes were fixed with an angle of $45^{\circ}$ to the bamboo culms at the height of $50 \mathrm{~cm}$ above the ground. Four to six tubes (four tubes for B. vulgaris and G. apus; six tubes for $D$. asper) were fixed eventually around each labeled culm. The tubes were then filled with $40 \mathrm{mM} \mathrm{KCl}$ solution and holes were drilled under water. After 


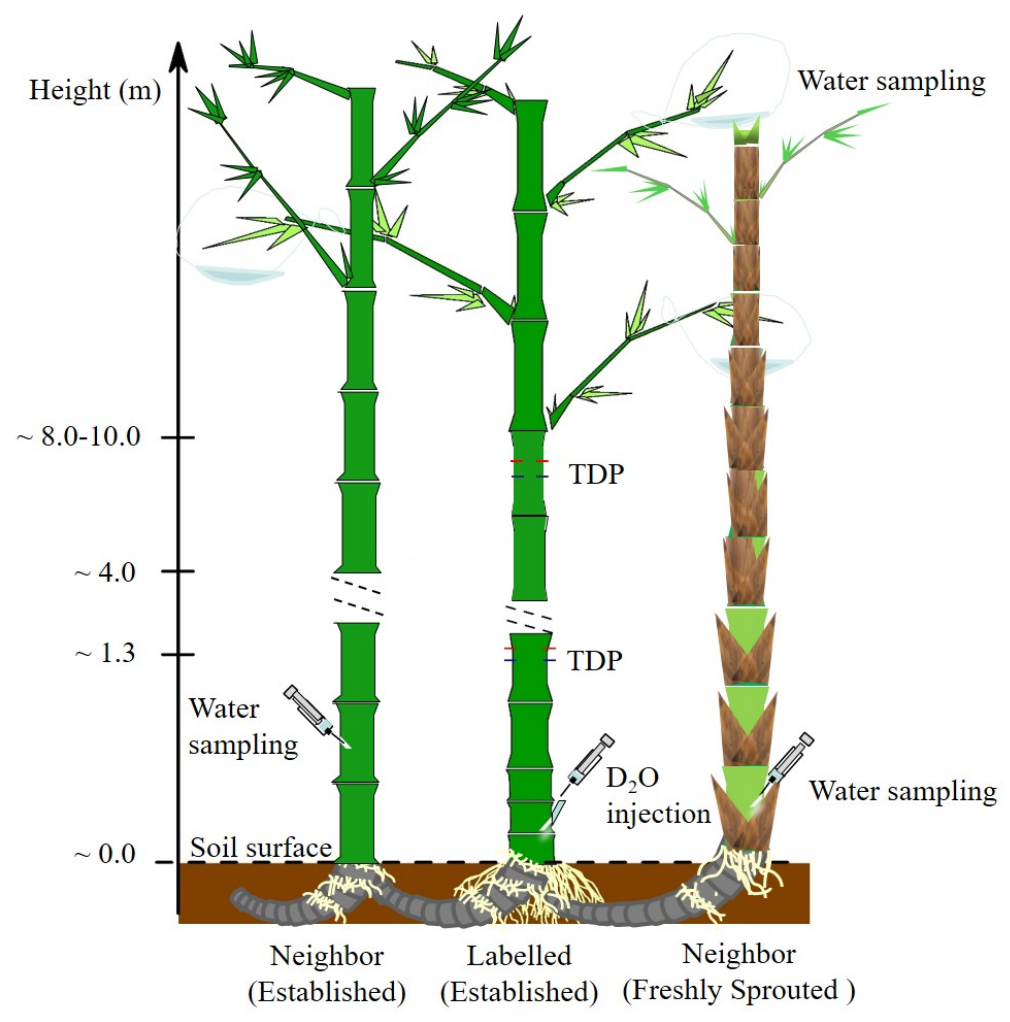

Fig. 4.1 Scheme of applying deuterium tracing and TDP methods.

that, holes were washed by injecting more solution and the remaining solution in the holes were extracted by a syringe and replaced with $1.5-3 \mathrm{~g} \mathrm{D}_{2} \mathrm{O}$ in each hole. The $\mathrm{D}_{2} \mathrm{O}$ was taken up by transpiration stream and $\mathrm{KCl}$ solution was added into holes for several times afterward to make the residual $\mathrm{D}_{2} \mathrm{O}$ in the tubes/holes being taken up as much as possible. After sunset, water remained in the tubes and holes was collected and weighed, and then $1.5 \mathrm{ml}$ of them was stored at $4{ }^{\circ} \mathrm{C}$ in the refrigerator and used for isotope analysis to measure the amount of remained $\mathrm{D}_{2} \mathrm{O}$.

Following the approach of Calder (1991), the $\mathrm{D}_{2} \mathrm{O}$ samples were collected from leaf condensate water by installing transparent bags. On each sampling day between 7:00 and 8:00, ten self-sealing transparent bags were installed on five different sun-exposed regions on each bamboo canopy (sealing 5-6 leaves per bag) and the bags were collected at the same time in the next day. All the ten condensate samples for a culm were totally combined to a mixed sample, and $1.5 \mathrm{ml}$ of the mixed sample was transferred into a glass vial and stored as same as mentioned above. Sampling was conducted every day in the first ten days and 4-6 days' interval in the next three weeks. 
Table 4.1 The information of studied bamboos and trees ( 3 culms per species but 4 culms of $B$. vulgaris used). The adjusted $\mathrm{WU}_{\mathrm{D}_{2} \mathrm{O}}$ was $\mathrm{WU}_{\mathrm{D}_{2} \mathrm{O}}$ adjusted with deuterium transfer on bamboos. The values were represented as the means(SD) which were in parenthesis.

\begin{tabular}{cccccc}
\hline Species & Height $(\mathrm{m})$ & $\mathrm{DBH}(\mathrm{cm})$ & $\mathrm{D}_{2} \mathrm{O}$ injected & $T_{\text {arrival }}$ & $T_{\text {residence }}$ \\
\hline B. vulgaris & $17.9(0.8)$ & $7.0(0.4)$ & $5.8(1.6)$ & $1.5(1.0)$ & $5.5(1.3)$ \\
D. asper & $21.1(0.9)$ & $10.7(0.9)$ & $8.0(1.1)$ & $1.0(0.0)$ & $5.0(1.7)$ \\
G. apus & $16.2(2.7)$ & $7.9(1.1)$ & $5.7(0.1)$ & $1.0(0.0)$ & $6.3(0.6)$ \\
\hline
\end{tabular}

To detect if there was $\mathrm{D}_{2} \mathrm{O}$ retention in the bamboos, on $16^{\text {th }}, 17^{\text {th }}$ or $20^{\text {th }}$ April 2013, all the $\mathrm{D}_{2} \mathrm{O}$ labeled bamboos were harvested in early mornings (from 5:00-7:00). On each culm, three water samples (1.5 ml) were extracted from leaves, branches and rhizomes, and one sample was obtained from each culm segment every $2 \mathrm{~m}$ height. The sampling organs were sealed in the transparent plastic bags and left under the sunshine to make water transpired out, and water samples $(1.5 \mathrm{ml})$ were collected in glass vials. Outside diameter, wall thickness and height of the segment were measured to calculate the fresh volume $\left(v_{\mathrm{f}}, \mathrm{cm}^{3}\right)$. Samples collected from each organ were weighted $\left(w_{\mathrm{f}}, \mathrm{g}\right)$ and dried with $100{ }^{\circ} \mathrm{C}$ in the oven for $24 / 48$ hours ( 24 hours for leaves/branches, 48 hours for rhizomes and culms) to get dry weight $\left(w_{\mathrm{d}}, \mathrm{g}\right)$ in the lab. The water content of each segment was then derived as $\left(w_{\mathrm{f}}-w_{\mathrm{d}}\right) / w_{\mathrm{d}}$.

To test for $\mathrm{D}_{2} \mathrm{O}$ transfer among bamboo culms, three established and three freshly sprouted neighbor culms, which were $30-50 \mathrm{~cm}$ distant to the $\mathrm{D}_{2} \mathrm{O}$ labeled culms, were sampled in 3-5 days' interval. The established culms were similar to the labeled ones. The young culms popped up 4-5 months before the tracer study began and had already reached a height of around $10 \mathrm{~m}$ or higher, but they still hold some brown sheaths attached to the culms and were not fully leafing. In approximately 6:00, small holes were drilled in the bamboo wall at around $1 \mathrm{~m}$ height, and water samples $(1.5 \mathrm{ml})$ were collected directly from the holes (Fig. 4.1).

The $\mathrm{D}_{2} \mathrm{O}$ concentrations in the culm segments of the cut-down labeled culms were used as background values for correcting the $\mathrm{D}_{2} \mathrm{O}$ concentrations in the samples in the labeled and neighboring culms.

\subsubsection{Deuterium analysis in the lab}

The isotope analysis was carried out in the Center for Stable Isotope Research and Analysis (KOSI) at the University of Göttingen, Germany. The samples 
were measured in a Delta V Plus isotope ratio mass spectrometer (ThermoElectron Cooperation, Bremen, Germany) coupled with a high-temperature conversion/elemental analyzer (TC/EA, Thermo Quest Finnigan, Bremen, Germany). The results with $2 \%$ measurement precision are expressed in delta notation in units of per mil $\left(\delta \mathrm{D}, \%_{0}\right)$ as $\mathrm{D} / \mathrm{H}$ of the sample $\left(R_{\text {sample }}\right)$ relative to that of Vienna Standard Mean Ocean Water $\left(R_{\text {VSMOW }}\right)$.

\subsubsection{Deuterium arrival time, velocity and residence time}

Three variables were used to describe the behavior of the $\mathrm{D}_{2} \mathrm{O}$ reflecting the water uptake and storage characteristics (Meinzer et al., 2006; Schwendenmann et al., 2010). First, arrival time ( $T_{\text {arrival }}$, days) was defined as the time of leaf $\mathrm{D}_{2} \mathrm{O}$ concentration passing over $10 \%$ of the maximum $\mathrm{D}_{2} \mathrm{O}$ concentration for the first time. Second, tracer velocity $\left(V_{\mathrm{D}_{2} \mathrm{O}}, \mathrm{m}\right.$ day $\left.{ }^{-1}\right)$ was derived as the distance between sampling and injecting points over the arrival time. At last, tracer residence time ( $T_{\text {residence}}$, days) was estimated as the time course when $\mathrm{D}_{2} \mathrm{O}$ concentration was above $10 \%$ of the maximum $\mathrm{D}_{2} \mathrm{O}$ concentration.

To calculate water use estimated by deuterium tracing method, the notation of $\mathrm{D}_{2} \mathrm{O}(\delta \mathrm{D})$ values were converted to give a mass concentration of the tracer (Calder, 1991). The mean daily water use $\left(\mathrm{WU}_{\mathrm{D}_{2} \mathrm{O}}\right)$ over the experiment was calculated with the equation as below:

$$
W U_{D_{2} O}=\frac{M}{\sum_{i=1}^{T} C_{i} \Delta t_{i}}
$$

Where $C_{\mathrm{i}}$ is the mass concentration $\left(\mathrm{g} \mathrm{kg}^{-1}\right)$ in the $i^{\text {th }}$ time increment, $\Delta_{\mathrm{ti}}$ is the duration of the $i^{\text {th }}$ time increment (days) and $T$ is the last time increment. This function is usually used under two assumed conditions as described in the introduction part (Calder et al., 1992).

\subsubsection{Sap flow measurement and water use estimation by TDP method}

On each labeled bamboo culm (three culms per species but four culms of $B$. vulgaris used), sap flux density $\left(J_{\mathrm{s}}, \mathrm{g} \mathrm{cm}^{-2} \mathrm{~h}^{-1}\right)$ was measured by self-made $1 \mathrm{~cm}$ length TDP. The sensors were inserted into the bamboo culm at breast height (Mei et al., 2016) and below the lowest branches at around $7 \mathrm{~m}$ height. 
Three pairs of $1 \mathrm{~cm}$ length TDP were installed evenly apart from each other. From $8^{\text {th }}$ March to $6^{\text {th }}$ April 2013, the three TDP signal wires were connected in parallel to get an averaged voltage value. From $7^{\text {th }}$ April 2013, to detect the circumferential variation of $J_{\mathrm{s}}$, the three TDP sensors were installed separately to measure $J_{\mathrm{S}}$ in three directions for at least one week. The TDP signals were sampled every 30 seconds and stored as 1-minute averages in data loggers and multiplexers (CR1000, AM16/32, Campbell Scientific Inc., USA). $J_{\mathrm{S}}$ was calculated with species-specific calibrated formulas for these bamboos (Mei et al., 2016).

To compare with tracer velocity $\left(V_{\mathrm{D}_{2} \mathrm{O}}, \mathrm{m}_{\text {day }}{ }^{-1}\right)$, daily accumulated $J_{\mathrm{s}}$ $\left(J_{\mathrm{s}-\mathrm{d}}, \mathrm{kg} \mathrm{cm}^{-2} \mathrm{day}^{-1}\right)$ derived from TDP method was converted into sap velocity $\left(V_{\mathrm{TDP}}, \mathrm{m} \mathrm{day}^{-1}\right)$ by the unit change. Water use $\left(\mathrm{WU}_{\mathrm{TDP}}\right)$ of each bamboo was derived by multiplying $J_{\mathrm{s}}$ with the culm wall cross-sectional area. Because $\mathrm{WU}_{\mathrm{D}_{2} \mathrm{O}}$ was not arithmetic mean of daily water use during the experiment, mean TDP-derived WU and $\mathrm{WU}_{\mathrm{D}_{2} \mathrm{O}}$ cannot be directly compared (Calder, 1991). Therefore, a weighted WU was introduced with the following equation:

$$
W U_{T D P}=\frac{\sum_{1}^{T} W U_{i} C_{i}}{\sum_{1}^{T} C_{i}}
$$

Where $\mathrm{WU}_{\mathrm{i}}$ is the daily water use $\left(\mathrm{kg} \mathrm{d}^{-1}\right)$ in the $i^{\text {th }}$ time period (day) and $C_{\mathrm{i}}$ is the mean mass concentration of $\mathrm{D}_{2} \mathrm{O}$ in condensate water in the $i^{\text {th }}$ time period.

To assess the influence of stem water storage on $\mathrm{WU}_{\mathrm{D}_{2} \mathrm{O}}$, the relative contribution of stem water storage to transpiration $\left(C_{\mathrm{WS}}\right)$ was calculated following the procedure by Goldstein et al. (1998). The underlying assumption is that the daily water use measured at the lower (near breast height) and upper stems (under the crown) were equal in one day. First, adjusted half-hourly water use at the upper stem was derived by multiplying half-hourly water use at the upper stem with the ratio between the daily water use at the lower stem and at the upper stem. Second, the difference between the half-hourly water use at the lower stem and the upper stem was calculated, and the positive difference in one day was integrated as water storage that contributed to daily transpiration. At last, water storage was divided by daily transpiration to get the $C_{\mathrm{Ws}}$. 


\subsubsection{Data analysis and statistics}

Linear regressions were done on exploring relationships between $V_{\mathrm{D}_{2} \mathrm{O}}$ and $V_{\mathrm{TDP}}$, between $T_{\text {residence }}$ and $V_{\mathrm{D}_{2} \mathrm{O}}, V_{\mathrm{TDP}}$ or $C_{\mathrm{WS}}$, and between $\mathrm{WU}_{\mathrm{D}_{2} \mathrm{O}}$ and $\mathrm{WU}_{\mathrm{TDP}}$. The relative differences between $\mathrm{WU}_{\mathrm{D}_{2} \mathrm{O}}$ and $\mathrm{WU}_{\mathrm{TDP}}$ (Dif-WU, \%) was first calculated as the ratio of the difference between $\mathrm{WU}_{\mathrm{D}_{2} \mathrm{O}}$ without considering any $\mathrm{D}_{2} \mathrm{O}$ loss and $\mathrm{WU}_{\mathrm{TDP}}$ to $\mathrm{WU}_{\mathrm{TDP}}$. In the following step, two interference sources relating $\mathrm{D}_{2} \mathrm{O}$ losses for bamboo $\mathrm{WU}_{\mathrm{D}_{2} \mathrm{O}}$ were quantitatively assessed in our study: $\mathrm{D}_{2} \mathrm{O}$ retention in the labeled culms and $\mathrm{D}_{2} \mathrm{O}$ transfer to the neighbor culms. For each interference source (retention or transfer), the corresponding $\mathrm{D}_{2} \mathrm{O}$ losses were included into the Calder's equation (Calder, 1991) for calculating corrected $\mathrm{WU}_{\mathrm{D}_{2} \mathrm{O}}$. Subsequently, the corresponding relative differences between the corrected $\mathrm{WU}_{\mathrm{D}_{2} \mathrm{O}}$ and $\mathrm{WU}_{\mathrm{TDP}}$ were calculated. When assessing the influence of $\mathrm{D}_{2} \mathrm{O}$ transfer, the maximum amount of culms that may receive the transferred $\mathrm{D}_{2} \mathrm{O}$ from each labeled culm $\left(N_{\max }\right)$ was calculated under the assumption that the Dif-wu was caused solely by $\mathrm{D}_{2} \mathrm{O}$ transfer. The distribution of the $N_{\max }$ of all the labeled culms was subsequently plotted with histogram and kernel density distribution, from which a mode was derived. Thereafter, a corrected $\mathrm{WU}_{\mathrm{D}_{2} \mathrm{O}}$ and a corresponding Dif-WU were calculated with assumptions that water was transferred from each labeled culm to neighbor culms and that the amount of the receiving culms equaled to the mode value of the $N_{\max }$ distribution. The newly derived Dif-wU was further plotted with $\mathrm{CV}_{\mathrm{J}_{\mathrm{S}}}$ with linear regression to assess the influence of incomplete mixing on $\mathrm{WU}_{\mathrm{D}_{2} \mathrm{O}}$ estimation. All data analysis and figures were performed with SAS 9.3 (SAS Institute Inc., 2013).

\subsection{Results}

\subsubsection{Tracer movement and sap velocity}

On most of the studied bamboo culms, the $\mathrm{D}_{2} \mathrm{O}$ concentrations showed a two-peak pattern during the experiment, with a drop in the second day after labeling, which was a rainy day (Fig. 4.2). $T_{\text {arrival }}$ from stem base to the crown was one day on most of the labeled bamboos, except 3 days on one culm of B. vulgaris (Table 4.1). The maximal $\mathrm{D}_{2} \mathrm{O}$ concentrations on the labeled culms appeared in 1-3 days and varied between 0.09 and $0.79 \mathrm{~g} \mathrm{~kg}^{-1}$ for the three bamboo species (Fig. 4.2). Sap velocities derived from deuterium tracing 

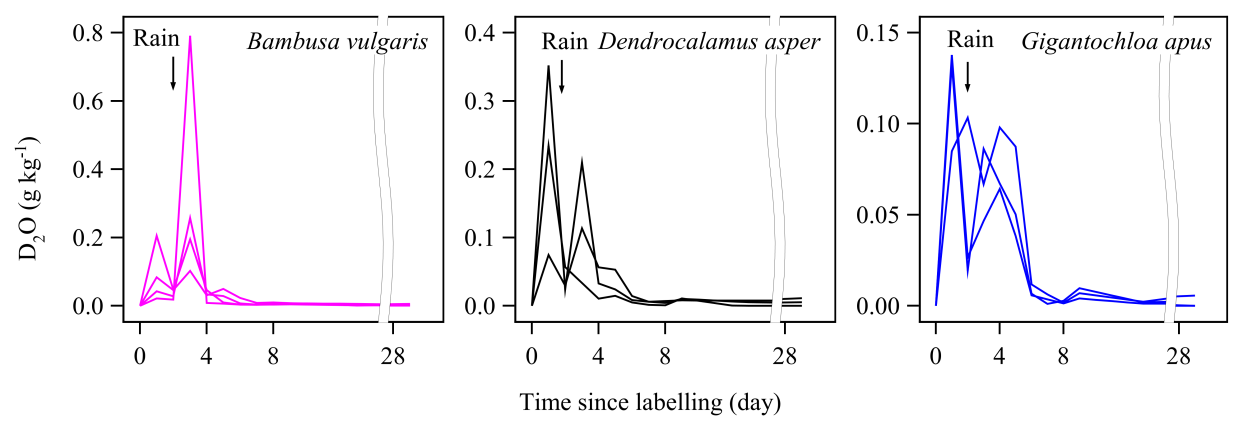

Fig. 4.2 Deuterium concentration $\left(\mathrm{D}_{2} \mathrm{O} \mathrm{g} \mathrm{kg} \mathrm{g}^{-1}\right.$ above background level) in transpired water of B. vulgaris, G. apus and D. asper over the course of the experiment. Day 0 is the day of deuterium injection.

Table 4.2 Deuterium signature $(\delta \mathrm{D}, \%)$ in different bamboo organs (leaf, branch, stem at $0,2,6,10 \mathrm{~m}$ height and rhizome) of the labelled bamboos (4 culms of B. vulgaris and 3 culms of D. asper and G. apus) which was harvested after about 40 days since labelling. The values were represented as the means (standard deviation).

\begin{tabular}{cccccccc}
\hline & & \multicolumn{4}{c}{ Stem } & & \\
\cline { 3 - 4 } Species & Rhizome & $0 \mathrm{~m}$ & $2 \mathrm{~m}$ & $6 \mathrm{~m}$ & $10 \mathrm{~m}$ & Branch & Leaf \\
\hline B. vulgaris & $-32.9(5.6)$ & $-40.9(1.7)$ & $-42.8(1.5)$ & $-43.3(1.7)$ & $-43.7(4.5)$ & $-41.7(2.8)$ & $-33.8(1.5)$ \\
G. apus & $-38.5(0.8)$ & $-42.4(2.5)$ & $-44.3(3.0)$ & $-43.1(2.3)$ & $-41.7(3.0)$ & $-38.4(3.0)$ & $-30.2(1.1)$ \\
D. asper & $-44.9(2.2)$ & $-32.5(25.1)$ & $-38.0(9.0)$ & $-40.9(5.0)$ & $-42.4(3.3)$ & $-39.0(11.6)$ & $-52.3(13.1)$ \\
\hline
\end{tabular}

method $\left(V_{\mathrm{D}_{2} \mathrm{O}}\right)$ were on average 5.6 times higher than from the TDP method ( $V_{\mathrm{TDP}} ; 12.5$ vs. $3.6,13.3$ vs. 3.2 and 16.1 vs. $1.3 \mathrm{~m} \mathrm{day}^{-1}$ on $B$. vulgaris, $G$. apus and $D$. asper, respectively). $V_{\mathrm{D}_{2} \mathrm{O}}$ was significantly correlated with $V_{\mathrm{TDP}}$ among culms of $B$. vulgaris and $D$. asper $\left(R^{2}=0.78 ; P<0.01\right)$ but not in $G$. apus (Fig. 4.3).

\subsubsection{Residence time and stem water storage}

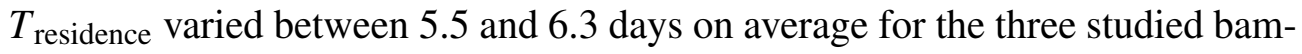
boo species (Table 4.1). $T_{\text {residence }}$ seemed to decrease with increasing $V_{\mathrm{TDP}}$ and did not significantly correlate with culm water storage $\left(C_{\mathrm{WS}}\right.$; Fig. 4.4). During the experiment, $C_{\mathrm{WS}}$ were $15 \%, 9 \%$ and $9 \%$ on average for $B$. vulgaris, G. apus and D. asper, respectively. 


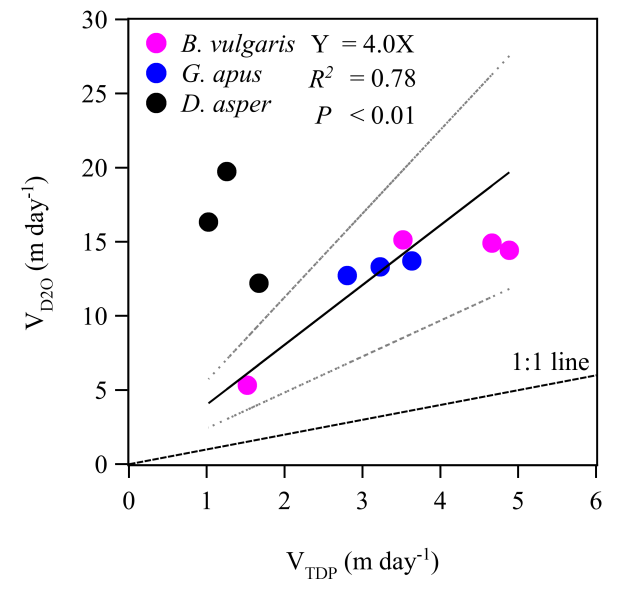

Fig. 4.3 Sap velocities $\left(\mathrm{m} \mathrm{day}^{-1}\right)$ derived from deuterium tracing method $\left(V_{\mathrm{D}_{2} \mathrm{O}}\right)$ in relation to the sap velocities obtained from TDP method ( $\left.V_{\mathrm{TDP}}\right)$. The two grey dot lines represent $95 \%$ confidence limits for the expected values. The black line accounts for a regression line.
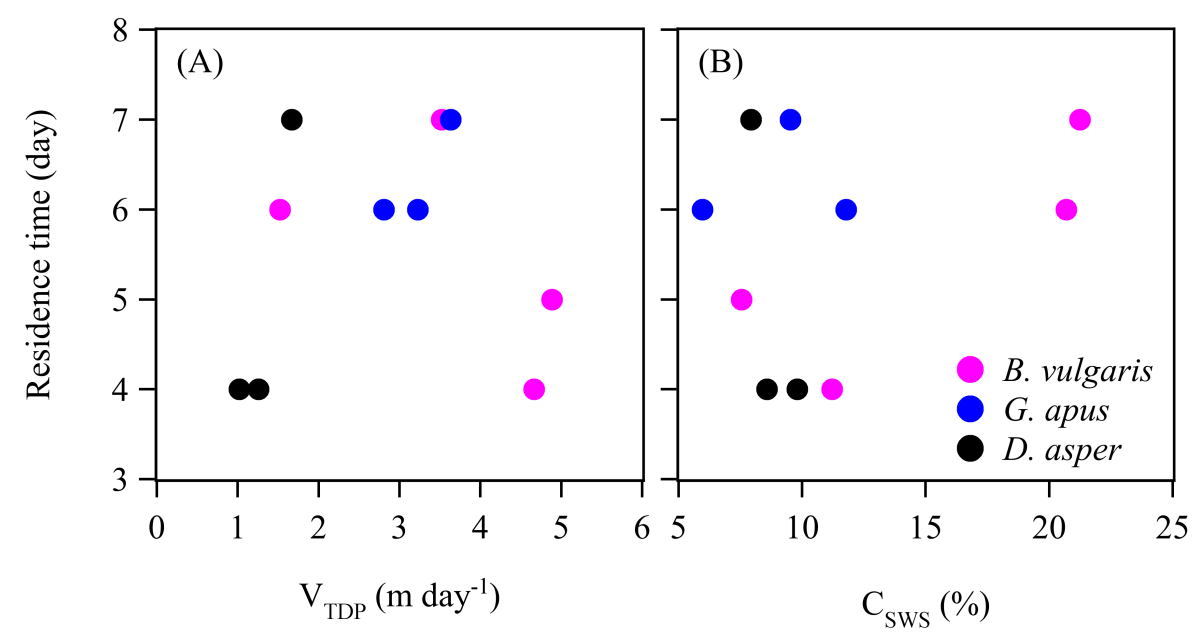

Fig. 4.4 Residence time in relation to (A) the sap velocity derived from thermal dissipation probe $\left(V_{\mathrm{TDP}}, \mathrm{m} \mathrm{day}^{-1}\right)$ and (B) the contribution of culm water storage to daily water use $\left(C_{\mathrm{WS}}, \%\right)$. 


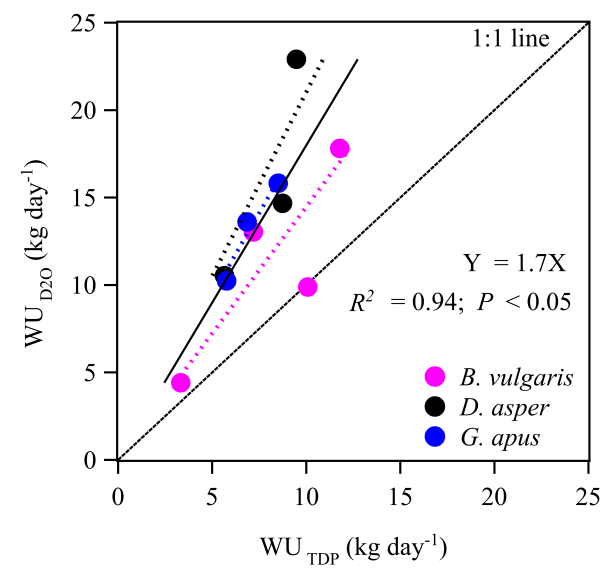

Fig. 4.5 Water use estimated by the TDP method ( $\mathrm{WU}_{\mathrm{TDP}}, \mathrm{kg}_{\mathrm{day}}{ }^{-1}$ ) versus water use determined by deuterium tracing $\left(\mathrm{WU}_{\mathrm{D}_{2} \mathrm{O}}, \mathrm{kg}_{\text {day }}{ }^{-1}\right)$ on bamboos. The solid line represents regression of all values of the three bamboo species. The dash lines represent species-specific regressions: $B$. vulgaris: $Y=1.4 X$, $R^{2}=0.95, P<0.01 ; D$. asper: $Y=2.0 X, R^{2}=0.97, P<0.01 ; G$. apus: $Y=$ $1.9 X, R^{2}=0.99, P<0.01$.

\subsubsection{Water use}

There was a significant correlation between $\mathrm{WU}_{\mathrm{D}_{2} \mathrm{O}}$ and $\mathrm{WU}_{\mathrm{TDP}}$ estimates $\left(R^{2}\right.$ $=0.94, P<0.05$; Fig. 4.5). However, the deuterium tracing method gave $70 \%$ on average higher values than the TDP method. $\mathrm{WU}_{\mathrm{D}_{2} \mathrm{O}}$ and $\mathrm{WU} \mathrm{U}_{\mathrm{TDP}}$ were 11.3 vs. $8.1,13.2$ vs. 7.0 and 16.0 vs. $8.0 \mathrm{~kg} \mathrm{day}^{-1}$ for B. vulgaris, G. apus and $D$. asper, respectively

\subsection{4 $\mathrm{D}_{2} \mathrm{O}$ retention, transfer, incomplete mixing and their influence on deuterium derived water use rate}

In the cut-down bamboo tissues, the $\mathrm{D}_{2} \mathrm{O}$ concentration $\left(\delta \mathrm{D}, \%_{0}\right)$ showed an increasing trend from stem base to leaves and root in B. vulgaris and G. apus, while not in D. asper (Table 4.2). In B. vulgaris and G. apus, the $\delta \mathrm{D}$ values were significantly higher on leaves than on stems $(P<0.05$ with a t-test). The remained $\mathrm{D}_{2} \mathrm{O}$ in each whole bamboo (including leaves, branches, culm and rhizome) varied between 0.005 to $0.075 \mathrm{~g}$, which was negligible to the injected mass (Table 4.1) and produced only $1 \%$ on average higher values on $\mathrm{WU}_{\mathrm{D}_{2} \mathrm{O}}$ referring to $\mathrm{WU}_{\mathrm{TDP}}$. 


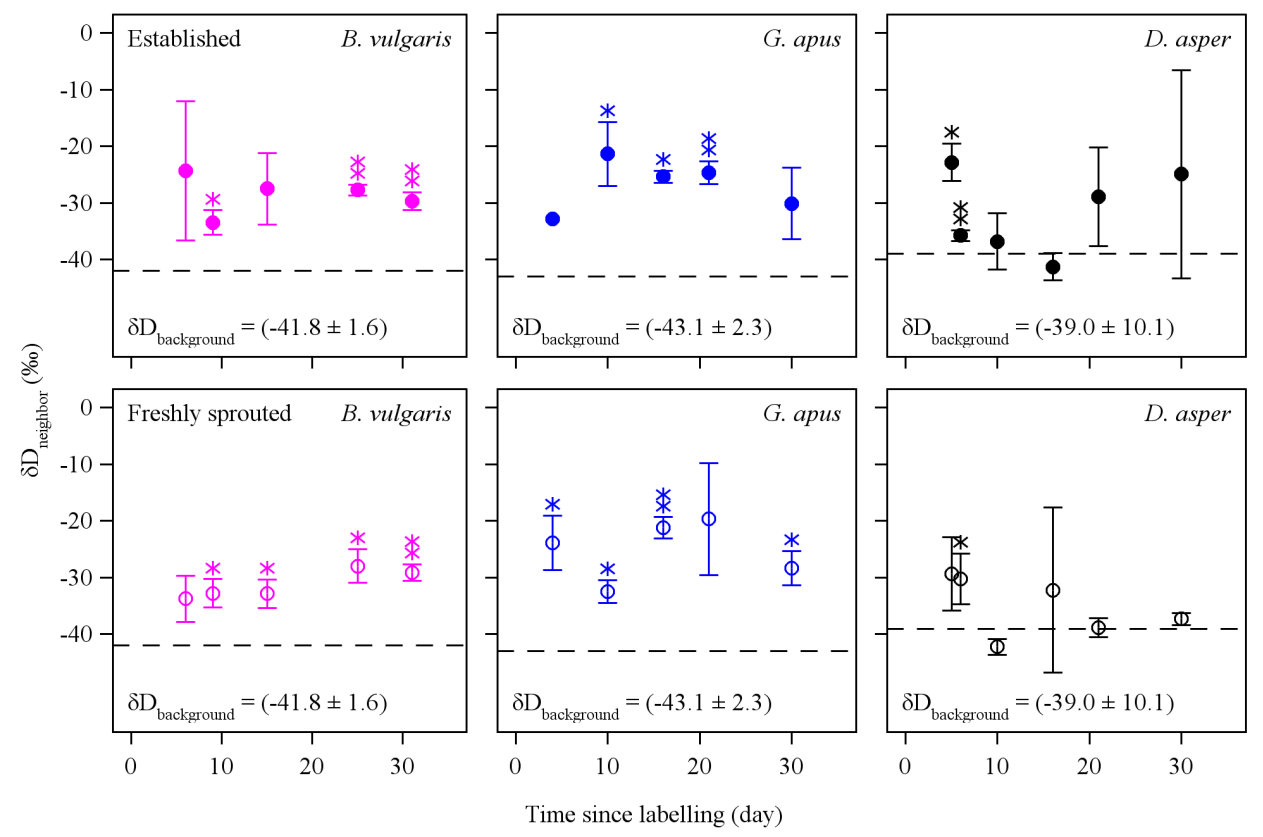

Fig. 4.6 Deuterium values $(\delta \mathrm{D}, \%)$ in different bamboo organs (leaf, branch, stem at 0,2, 6, $10 \mathrm{~m}$ height and rhizome) of the labeled bamboos which was harvested after about 40 days since labeling. Each dot (mean \pm SD) stands for the mean values from 4 culms of $B$. vulgaris and 3 culms of $D$. asper and $G$. apus.
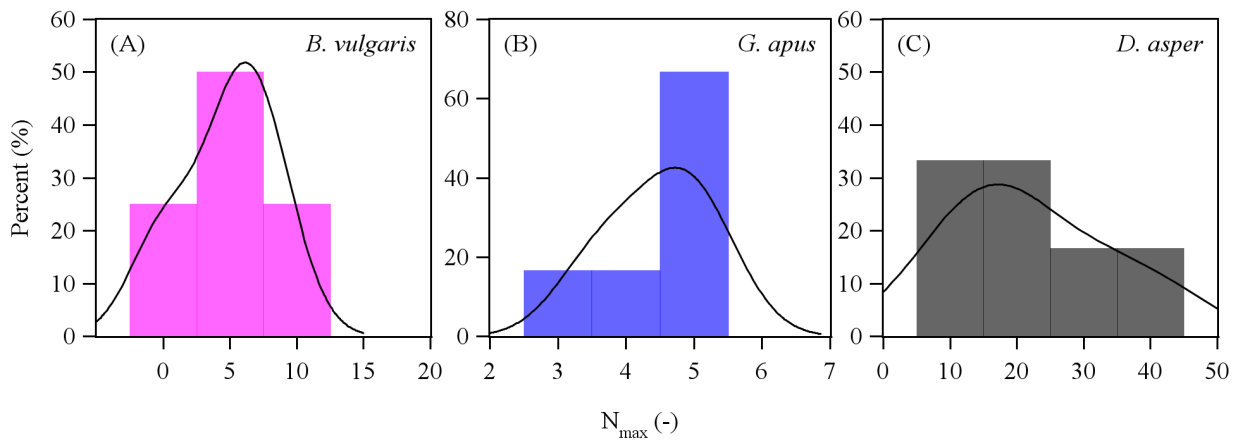

Fig. 4.7 The distribution of the maximal amount of neighboring culms $\left(N_{\max }\right)$ which may receive transferred water from the labeled culms (B. vulgaris, $G$. apus and D. asper). For each species, data of 3 established and 3 freshly sprouted culms were used. The black line represented fitted kernel distribution. The mode (at the most frequency) of the $N_{\max }$ was 5.1, 4.5 and 22.0 on $B$. vulgaris, G. apus and D. asper, and the mode was 6.7 when pooling the three species together. 
Compared with the background $\delta \mathrm{D}$ values, significant higher $\delta \mathrm{D}$ values were found in the transpiration stream of neighbor established and freshly sprouted bamboos almost over the 30 days on B. vulgaris and G. apus, while only in the first 6 days on $D$. asper $(P<0.05$ with t-test; Fig. 4.6). Such elevated $\delta \mathrm{D}$ values may be related to water transfer through rhizomes between the labelled bamboos and neighbor ones. Based on the assumption that the water transfer existed continuously during the experiment, the total transferred $\mathrm{D}_{2} \mathrm{O}$ on one neighbor culm varied between 0.36 to $0.93 \mathrm{~g}$, which accounted for $1.7-11.7 \%$ of the injected $\mathrm{D}_{2} \mathrm{O}$. As the $\mathrm{D}_{2} \mathrm{O}$ retention was negligible, the difference between $\mathrm{WU}_{\mathrm{D}_{2} \mathrm{O}}$ and $\mathrm{WU}$ TDP was assumed mainly relating to tracer loss by water transfer among culms. Under such assumption, the amount of culms that may receive $\mathrm{D}_{2} \mathrm{O}$ transfer from the labeled culms ranged from 0 to 41 culms with the mode of 6 culms (Fig. 4.7).

We assumed the incomplete mix of $\mathrm{D}_{2} \mathrm{O}$ in sap flow was another interference source of $\mathrm{WU}_{\mathrm{D}_{2} \mathrm{O}}$ estimation, which may be indicated by the different sap flux densities in different directions. Among the culms of each species, the averaged coefficients of variation of daily sap flux densities at breast height in three directions $\left(\mathrm{CV}_{\mathrm{J}_{\mathrm{s}}}\right)$ were $23 \%, 52 \%$ and $14 \%$ for B. vulgaris, D. asper and $G$. apus respectively. With the assumption that a labeled culm transferred $\mathrm{D}_{2} \mathrm{O}$ to 6 neighboring culms (Fig. 4.7), the calculated differences between the corrected $\mathrm{WU}_{\mathrm{D}_{2} \mathrm{O}}$ and $\mathrm{WU}$ TDP was found significantly correlated with $\mathrm{CV}_{\mathrm{J}_{\mathrm{S}}}$ (Fig. 4.8; $R^{2}=0.44, P<0.05$ ).

\subsection{Discussion}

\subsubsection{Sap velocity}

Compared to B. blumeana in Philippine (Dierick et al., 2010; Schwendenmann et al., 2010), the three bamboo species (B. vulgaris, G. apus and D. asper; Table 4.1) in our study showed much smaller $T_{\text {arrival }}(1.5,1.0,1.0$ vs. 3.1 days) and $T_{\max }(2.5,1.3,1.7$ vs. 4.8 days $)$ while larger $V_{\mathrm{D}_{2} \mathrm{O}}(12.5,13.3,16.1$ vs. 8.5 $\left.\mathrm{m} \mathrm{day}^{-1}\right)$ and $V_{\mathrm{TDP}}\left(3.6,3.2,1.3\right.$ vs. $\left.0.9 \mathrm{~m} \mathrm{day}^{-1}\right)$. Such differences among the bamboo species in the two studies may be attributed to the species-specific anatomical structures, different sampling methods or various environmental conditions in these sites. Bamboos had highly variable size and shape of vascular bundles among species (de Agrasar and Rodríguez, 2003) which may lead to different water transport velocities. Despite this, different sampling 
methods applied in our study and the study in Philippine might also contribute to the differences. In the Philippine study, leaves were collected twice a day (interval sampling) while we installed transparent bags on the branches to gather water for a whole day (Calder et al., 1986). The interval sampling may cause missing of the peak value that was used to derive the $T_{\text {arrival }}$ and $V_{\mathrm{D}_{2} \mathrm{O}}$.

The averaged $V_{\mathrm{D}_{2} \mathrm{O}}$ of the three bamboo species was 5.6 times higher than $V_{\text {TDP. }}$ Such large differences between $V_{\mathrm{D}_{2} \mathrm{O}}$ and $V_{\text {TDP }}$ were also found in other studies (Dierick et al., 2010; James et al., 2003; Meinzer et al., 2006). Compared with $V_{\mathrm{TDP}}$, higher $V_{\mathrm{D}_{2} \mathrm{O}}$ was found on one bamboo species (Bambusa blumeana) and five tropical tree species (Schwendenmann et al., 2010), and on temperate conifers (Meinzer et al., 2006). Meinzer et al. (2006) explained that sap velocity derived from sap flux density by the unit change were not the right sap velocity transported in the conduits and the fraction of the conduit area to the whole cross sectional area may influence the calculation. In an early study, Tatarinov et al. (2005) described sap flux density as the product of sap velocity, wood porosity, and water density. Therefore, following the work of Vandegehuchte and Steppe (2012), we calculated wood porosity from easily obtained factors such as dry wood density and fresh wood volume of a sample and got new $V_{\mathrm{TDP}}$, which reduced the relative deviation of $V_{\mathrm{D}_{2} \mathrm{O}}$ to $V_{\text {TDP }}$ from 5.6 times to 0.86 times higher. Despite the new $V_{\text {TDP }}$ calculated in such way may also introduce errors, it did reduce the differences and may be improved with the more accurate calculation on porosity. The different measurement scales of the two methodologies could be another reason for the difference between $V_{\mathrm{D}_{2} \mathrm{O}}$ and $V_{\text {TDP. }} V_{\text {TDP }}$ only stand for the velocity between the installation heights of the TDPs while $V_{\mathrm{D}_{2} \mathrm{O}}$ is a mean value along the hydraulic path from stem base to the crown until water left the leaves.

Despite $V_{\mathrm{D}_{2} \mathrm{O}}$ was higher in our study and also the other previous studies, $V_{\mathrm{D}_{2} \mathrm{O}}$ could even be larger when $\mathrm{D}_{2} \mathrm{O}$ sampling was done at a higher frequency. The arrival time ( $T_{\text {arrival }}, 1$ day for all but one) could be shorter if the tracer arrived at the crown within one day and strong water uptake occurred in daytime. The one-day sampling interval in the present study may be too coarse for a precise estimation of the arrival time. Therefore, $T_{\text {arrival }}$ was the maximal $\mathrm{D}_{2} \mathrm{O}$ transit time from base stem to canopy, and thus $V_{\mathrm{D}_{2} \mathrm{O}}$ derived with $T_{\text {arrival }}$ and the transport pathway was minimum estimates of maximum sap velocity (James et al., 2003; Meinzer et al., 2006). In future studies, one should probably sample water from leaves with shorter intervals, such as 4 hours over the initial days. 


\subsection{2 $\mathrm{D}_{2} \mathrm{O}$ residence time and water storage}

$T_{\text {residence varied between } 5.5 \text { and } 6.3 \text { days on average for the three studied }}$ bamboo species (Table 4.1), while 11.5 days on another bamboo species - $B$. blumeana and 4.7 days on the five reference tree species (Schwendenmann et al., 2010). However, $T_{\text {residence }}$ on these bamboo species was shorter than the $\approx 20$ days of two tropical tree species in Panama (James et al., 2003) and much shorter than the 36-79 days on two coniferous species in North America (Meinzer et al., 2006). $T_{\text {residence }}$ on trees was found positively correlating with the normalized maximum crown-base sap flow which implies the relative reliance of transpiration on water storage (James et al., 2003), and with sapwood capacitance which reflects the water exchange capacity between transporting lumens and surrounding tissues (Meinzer et al., 2006). Therefore, It was assumed that $T_{\text {residence }}$ could be an indicator of the relative reliance of transpiration on water storage (James et al., 2003). However, on the three studied bamboo species in our study, $T_{\text {residence }}$ was found not significantly related to the normalized maximum crown-base sap flow (data not show) nor with the daily $C_{\text {WS }}$ (Fig. 4.4.A). Such finding may be attributed to the limited support of the water storage to the relatively high daily transpiration, as the bamboo culms have much fewer volumes to store water than tree stems due to the thin culm wall and the hollow center. In the present study, during the experiment from $8^{\text {th }}$ March to $6^{\text {th }}$ April 2013 , daily $C_{\mathrm{WS}}$ were $15 \%, 9 \%$ and $9 \%$ on average for B. vulgaris, D. asper and G. apus, respectively. On contrast, on trees or palms, $10-50 \%$ of daily transpiration can be contributed by stem water storage (Carrasco et al., 2015; Goldstein et al., 1998; Holbrook et al., 1992; Scholz et al., 2008; Waring and Running, 1978). However, although $T_{\text {residence }}$ was not correlated with $C_{\text {WS }}$, it appeared to negatively correlate with $V_{\mathrm{D}_{2} \mathrm{O}}$ (Fig. 4.4.A). It may indicate that high axial water transport efficiency reduced the time of water staying in the bamboo culms. These findings seemed to verify the hypothesis that the trade-off of water transport efficiency and water storage capacity could contribute to a safe water status in the crown (Gleason et al., 2016; James et al., 2003). On bamboos, culm water storage may be less important than the relatively high water transport efficiency on maintaining leaf water status, which could be indicated by the higher maximum sap flux densities on bamboo species than on the neighbored trees (Ichihashi et al., 2015; Mei et al., 2016). 


\subsubsection{Water use derived with deuterium tracing method}

On most of the studied culms (90\%) in our study, water use was higher by deuterium tracing method compared to calibrated TDP method. On average, the deuterium tracing method gave $41 \pm 35 \%, 99 \pm 38 \%$ and $87 \pm 11 \%$ higher values on B. vulgaris, D. asper and G. apus respectively. Higher values (11-43\%) by $\mathrm{D}_{2} \mathrm{O}$ method was found on Eucalyptus grandis compared with Heat Pulse Method (Kalma et al., 1998), while lower values (7-26\%) was also found in the same species with the same reference method by Dye et al. (1992). On the only studied bamboo species (B. blumeana) applied with $\mathrm{D}_{2} \mathrm{O}$ method (Schwendenmann et al., 2010), on average $813 \%$ higher water use was found compared with TDP. The discrepancy between $\mathrm{D}_{2} \mathrm{O}$ method and the reference methods were supposed to come from both of the methods (Kalma et al., 1998; Schwendenmann et al., 2010). Errors could be raised if the reference method was used violating its application conditions (Lu et al., 2004; Smith and Allen, 1996). Lower estimation (by $66 \%$ on average on 4 bamboo species) by uncalibrated TDP was found in situ when compared with stem heat balance method (Mei et al., 2016). Considering the errors associated with $\mathrm{D}_{2} \mathrm{O}$ method, two primary sources presumed mostly related to $\mathrm{D}_{2} \mathrm{O}$ method were tracer loss (retention in labeled plants or redistribution to soil or neighbor plants) and incomplete mixing of $\mathrm{D}_{2} \mathrm{O}$ in the stem before flowing to different branches or crown levels. Both of them could break the underlying assumptions of applying the $\mathrm{D}_{2} \mathrm{O}$ method (Kalma et al., 1998; Kline et al., 1970; Schwendenmann et al., 2010).

\subsubsection{Deuterium retention and its influence on $\mathrm{WU}_{\mathrm{D}_{2} \mathrm{O}}$}

Residual $\mathrm{D}_{2} \mathrm{O}$ were found in the labeled bamboos after 40 days since $\mathrm{D}_{2} \mathrm{O}$ injection, but it was insignificant to affect the water use estimation. The total remaining $\mathrm{D}_{2} \mathrm{O}$ in each bamboo culm was merely $1 \%$ on average of the injected $\mathrm{D}_{2} \mathrm{O}$, which could correspondingly lead to $1 \%$ higher estimate of the $\mathrm{WU}_{\mathrm{D}_{2} \mathrm{O}}$. It was thought that the plants would retain too little tracer to change the water use rates estimate after sampling for enough long time (James et al., 2003; Kline et al., 1970; Schwendenmann et al., 2010). James et al. (2003) found prominent tracers from all portions of the Cordia alliodora tree after eight days of $\mathrm{D}_{2} \mathrm{O}$ labeling and Schwendenmann et al. (2010) found the absent of $\mathrm{D}_{2} \mathrm{O}$ in branches after three weeks of labeling. Therefore, to exclude the influence from retention of $\mathrm{D}_{2} \mathrm{O}$, the sampling period should be long enough, and the time may differ from different species. 
Although the remaining $\mathrm{D}_{2} \mathrm{O}$ was too little to influence water use estimated by $\mathrm{D}_{2} \mathrm{O}$ method, they showed arresting distribution within the labeled bamboos after the experiment. On B. vulgaris and G. apus, the remaining $\mathrm{D}_{2} \mathrm{O}$ were obviously more in leaves and roots than in stems, with smallest values appearing in $2 \mathrm{~m}$ height (Table1 4.2). This $\mathrm{D}_{2} \mathrm{O}$ distribution on the organs may indicate that the injected $\mathrm{D}_{2} \mathrm{O}$ was relocated upward and downward from the injected points. On leaves, the enrichment of $\mathrm{D}_{2} \mathrm{O}$ may be partly attributed to the element fractionation, which makes more $\mathrm{D}_{2} \mathrm{O}$ than hydrogen left in the leaves when water was transpired rapidly to the air during daytime (Roden and Ehleringer, 1999). While in roots, $\mathrm{D}_{2} \mathrm{O}$ could be transferred from injected points via phloem according to Münch flow-pressure theory (Münch, 1927). Inverse water flow through phloem was considered as a possible way to take tracers downwards (Choi and Aronoff, 1966; Dierick et al., 2010; Schwendenmann et al., 2010). On Eucalyptus saligna trees, $\mathrm{D}_{2} \mathrm{O}$ was observed exchanging between phloem and xylem through ray parenchyma (Pfautsch et al., 2015a,b). On bamboos, we assumed that the water exchange between phloem and xylem were much easier than trees, as the phloem and xylem stay closely to each other in vascular bundles (Grosser and Liese, 1971). Additionally, the inverse water flow may be more active when leaves were wet due to rain, fog or dew, as in this situation water potential gradient could be formed from leaves to roots (Goldsmith, 2013; Goldsmith et al., 2013). In our study, when rain occurred on the second day after $\mathrm{D}_{2} \mathrm{O}$ labeling, a clear drop of the $\mathrm{D}_{2} \mathrm{O}$ concentration was observed in most of the labeled bamboos (Fig. 4.2). The drop may also be possibly induced by the foliage water uptake that diluted $\mathrm{D}_{2} \mathrm{O}$ in the crown and stem.

\subsection{5 $\mathrm{D}_{2} \mathrm{O}$ transfer between culms and its influence on $\mathrm{WU}_{\mathrm{D}_{2} \mathrm{O}}$}

The water transported by inverse water flow may be released to soil from roots, or transferred to other trees or bamboo culms if the plants had connected rhizomes (Dierick et al., 2010; Kline et al., 1970; Marc and Robinson, 2004; Zhao et al., 2016). In this case, loss of $\mathrm{D}_{2} \mathrm{O}$ occurred and led to an overestimation of the water upward to the leaves. In the present study, water transfer was implied obviously on B. vulgaris and G. apus but slightly on D. asper by the elevated $\mathrm{D}_{2} \mathrm{O}$ concentration in the neighbor freshly sprouted and established bamboos (Fig. 4.6), and the water transfer may probably happen among five culms on B. vulgaris and G. apus (Fig. 4.7). These findings indicated the bamboo 


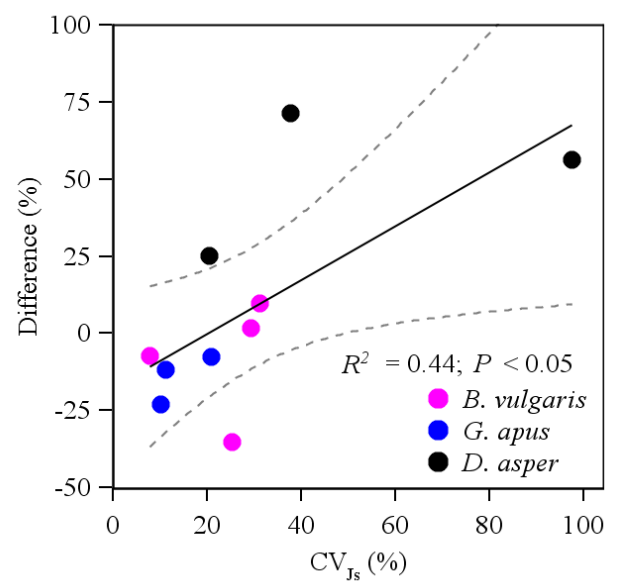

Fig. 4.8 The relative differences between the corrected $\mathrm{WU}_{\mathrm{D}_{2} \mathrm{O}}$ and $\mathrm{WU} \mathrm{TDP}_{\mathrm{T}}$, in relation to coefficients of variation of daily sap flux densities at breast height $\left(\mathrm{CV}_{\mathrm{J}_{\mathrm{s}}}\right)$. The corrected $\mathrm{WU}_{\mathrm{D}_{2} \mathrm{O}}$ was calculated based on the assumption that $\mathrm{D}_{2} \mathrm{O}$ transfer between one labeled culm and six neighboring culms, and the assumption was based on the mode of the distribution of the maximal amount of neighboring culms when pooling the three species together.

culms might transport water downward to the underground rhizome system, and further redistribute this water to the other culms in a clump. However, even among big clumpy bamboo species, water transfer might be different on different species. Additionally, the quantity of the transferred water was unclear. In another recent study on a running bamboo species (P. pubescens), the rhizome-cutting culms consumed $\approx 20 \%$ less water use than the intact culms and such difference was thought relating to water transfer through rhizomes from other culms or roots (Zhao et al., 2016). Furthermore, the reliance on the water transfer may differ upon the age of the culms. For example, freshly sprouted culms were thought more relied on rhizomes of mother culms than older ones (Liese and Köhl, 2015; Zhao et al., 2016). However, in our study on both freshly sprouted and established neighbor culms of the three studied bamboo species, significant higher $\delta$ D values were observed $(P<0.05$ with t-test; Fig. 4.6). This finding indicated that water transfer might be a typical water use characteristic at clump edges of bamboo culms regardless of their ages. The actual impact of water transfer from rhizomes may be more complex than our understanding due to the sophisticated rhizome system of bamboos (Stapleton, 1998). 


\subsubsection{Variability of sap flux and incomplete mixing of $\mathrm{D}_{2} \mathrm{O}$}

Besides the tracer loss due to retention and transfer, incomplete mixing of $\mathrm{D}_{2} \mathrm{O}$ may become another interference source to $\mathrm{WU}_{\mathrm{D}_{2} \mathrm{O}}$. Unlike the direct influence on water use estimation from tracer loss, influence from incomplete mixing of $\mathrm{D}_{2} \mathrm{O}$ was harder to detect and quantify. The injected $\mathrm{D}_{2} \mathrm{O}$ at the base of the culms could be transported axially and radially (James et al., 2003). Therefore, the $\mathrm{D}_{2} \mathrm{O}$ concentration in the leaves could be influenced by the speeds of the axial water transport and the radial water exchange between the xylem vessels and the surrounding tissues. In the present study, the $T_{\text {residence }}$ of the $\mathrm{D}_{2} \mathrm{O}$ appeared to correlate with $V_{\mathrm{D}_{2} \mathrm{O}}$ negatively. Such relationship may mean that if the water transport efficiency was different in the different

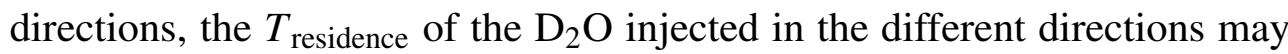
vary accordingly and furtherly the mixing extent of the $\mathrm{D}_{2} \mathrm{O}$ was different. In our study, the averaged $\mathrm{CV}_{\mathrm{J}_{\mathrm{s}}}$ at breast height were $14-52 \%$ on the three bamboo species, which may indicate incomplete $\mathrm{D}_{2} \mathrm{O}$ mixing according to the assumption mentioned above. Excluding the influence of water transfer on $\mathrm{WU}_{\mathrm{D}_{2} \mathrm{O}}$ with assuming six culms receiving transferred $\mathrm{D}_{2} \mathrm{O}$ (Fig. 4.7), the differences between $\mathrm{WU}_{\mathrm{D}_{2} \mathrm{O}}$ and $\mathrm{WU}_{\mathrm{TDP}}$ were correlated with the $\mathrm{CV}_{\mathrm{J}_{\mathrm{S}}}$ significantly (Fig. 4.8). These findings indicated that except avoiding $\mathrm{D}_{2} \mathrm{O}$ loss in any form, we should also try to eliminate the influence of incomplete $\mathrm{D}_{2} \mathrm{O}$ mixing when estimating water use rates with deuterium tracing method. Uniform sampling over the entire canopy could be a seemingly reasonable way. Additionally, drilling more holes around the culms for injecting $\mathrm{D}_{2} \mathrm{O}$ could be another way to reduce errors from incomplete mixing.

\subsection{Conclusions}

The deuterium tracing method was applied to three tropical bamboo species. Contrast to TDP method, deuterium tracing method showed its advantages on revealing water transfer among bamboo culms and estimating sap velocity. Water use estimated with deuterium tracing method was obviously influenced by water transfer and incomplete mixing indicated by the circumferential sap flux variety. Deuterium retention can be ignored if enough long time was satisfied to collect the $\mathrm{D}_{2} \mathrm{O}$ samples. Conclusively, the deuterium tracing is a good method to estimate sap velocity with short enough sampling intervals, but it is not so suitable to estimate quantitate water use of species that have 
strong water redistribution. However, the deuterium tracing has its obvious advantage on tracing water movement or transfer within or among bamboo culms, and such advantage makes the method to be a powerful way to explore water redistribution or exchange on plants. 


\section{Chapter 5}

\section{Synthesis}

\subsection{Bamboo water use and methods testing}

As monocots, woody bamboos have tree-like habits but differ from trees in many respects: relatively limited water conducting area due to the hollow culm, high parenchyma which provides a potential reservoir for water storage, and connected culms through rhizomes which may provide passages for water transfer (Liese and Köhl, 2015). These features may cause specific water use characteristics of bamboos and may influence sap flux measurement with the widely used thermal dissipation probe and water use estimation with deuterium tracing method. In our study, thermal dissipation probe (TDP) method was calibrated by comparing it to the stem heat balance (SHB) and gravimetric measurement on a bamboo species (Bambusa vulgaris). The calibrated TDP was thereafter applied in the field to monitor sap flow of four tropical bamboo species (B. vulgaris, Dendrocalamus asper, Gigantochloa atroviolacea, and G. apus) and three nearby tree species (Chapter 2). To explore the deviation of TDP measurement on bamboos due to the daily fluctuation of culm water content $\left(\theta_{\text {wood }}\right)$, we conducted a dehydration experiment on bamboo segments, a long-term monitoring of bamboo sap flux and soil moisture and a steady-state thermal model (Chapter 3). During long-term monitoring with TDP, deuterium tracing method was applied synchronously for about one month on the studied bamboos to explore sap velocity, water use rates and water transfer among culms (Chapter 4).

TDP was widely used to measure sap flux density $\left(J_{\mathrm{s}}\right)$ in trees (Granier, 1985), but the method should be calibrated before studying new species ( $\mathrm{Lu}$ et al., 2004; Wullschleger et al., 2011). In three studies conducting TDP calibration on bamboos, $J_{\mathrm{s}}$ derived with Granier's formula, was lower than 
that with reference gravimetric method on Moso bamboo (Kume et al., 2010; Zhao et al., 2016) and SHB method on B. blumeana (Dierick et al., 2010). In our study (Chapter 2), compared with SHB method, TDP underestimated $J_{\mathrm{S}}$ of the four bamboo species by on average 66 and $63 \%$ on the daily and 30 -min scales respectively $(P<0.01)$. The calibration parameters of TDP against SHB differed upon species and culms of same species. Confronting this insight with results from sap flux studies on other bamboo species (Dierick et al., 2010; Kume et al., 2010), differences among species become even more apparent. The observed differences may be related to highly heterogeneous wood anatomical properties among bamboo species (de Agrasar and Rodríguez, 2003; Saha et al., 2009). Differences in wood anatomical properties may lead to heterogeneous heat conductive properties, which potentially affects applicability and accuracy of sap flux measurements of the TDP method (Wullschleger et al., 2011). The differences among culms of same species may be attributed to culm ages. Over the ontogeny of a certain culm, events and processes such as conductive circuit failure (drought- or metabolism-related; Cochard et al., 1994; Liese and Weiner, 1996) and lignification (Lin et al., 2002) could result in overall reduced hydraulic conductivity and further influence the heat conductivity of the wood.

The underestimation of $J_{\mathrm{S}}$ by TDP was assumed partly due to the diurnal fluctuation of $\theta_{\text {wood }}$. On trees, $\theta_{\text {wood }}$ reached to peak values during the night when $J_{\mathrm{s}}$ was zero or minimum and dropped to minimum during daytime (Hao et al., 2013; Sperling et al., 2015). On a bamboo species (B. vulgaris), a similar pattern of bamboo culm circumference was observed (Yang et al., 2015). Although it's not the direct measurement on $\theta_{\text {wood }}$, the daily dynamic of culm circumference should reflect at least part of change on $\theta_{\text {wood }}$ as assumed on trees (Köcher et al., 2013; Scholz et al., 2008). In our study (Chapter 2), the bamboos reached peak values of $J_{\mathrm{s}}$ earlier than trees and also earlier than vapor pressure deficit (VPD). Consistent with this, the hysteresis between sap flow and VPD on bamboos were larger than on trees, indicating the decouple of transpiration and VPD. The observed early peak of $J_{\mathrm{S}}$ and the larger hysteresis implied that bamboos had a quick depletion of water storage in the morning despite the high percentage of parenchyma (50\%, Liese and Köhl, 2015). These findings and assumptions may mean that the water content in bamboo culms dropped to low values earlier than in trees. The large change of $\theta_{\text {wood }}$ between daytime and nighttime can change thermal conductivity of wood $\left(K_{\mathrm{wood}}\right)$ and the maximal temperature difference $\left(\Delta \mathrm{T}_{\max }\right)$ of TDP (Vergeynst et al., 2014; Wullschleger et al., 2011). $\Delta \mathrm{T}_{\max }$ is central to the calculation 
of $J_{\mathrm{s}}$, and it is measured at zero flow conditions usually at night (Granier, $1985,1987)$. Underestimation of $J_{\mathrm{s}}$ happened if selecting one $\Delta \mathrm{T}_{\max }$ at night to calculate $J_{\mathrm{s}}$ in the whole day with ignoring the different $K_{\text {wood }}$ between nighttime and daytime. Vergeynst et al. (2014) quantified the influence of $\theta_{\text {wood }}$ on $J_{\mathrm{s}}$ by setting possible temperature change that was assumed to relate to $\theta_{\text {wood }}$. However, the direct relationship between $\theta_{\text {wood }}$ and errors on $J_{\mathrm{s}}$ remained unclear.

The previously found negative correlation between $\theta_{\text {wood }}$ and $\Delta \mathrm{T}_{\max }$ on trees (Vergeynst et al., 2014) was verified on bamboo segments in our study with a dehydration experiment and a steady-state thermal model in ANSYS (Chapter 3). Based on the previous studies (Vergeynst et al., 2014; Wullschleger et al., 2011), we numerically simulated the influence of $\theta_{\text {wood }}$ on TDP-measured $J_{\mathrm{s}}$ and the results showed more direct and quantifiable relationship between $\theta_{\text {wood }}$ and errors on $J_{\mathrm{s}}$. By the simulation in the model, we found at any $J_{\mathrm{s}}$, more underestimation was introduced by larger decreasing of $\theta_{\text {wood }}$ from nighttime to daytime. Therefore, most significant underestimation of $J_{\mathrm{s}}$ would occur when $\theta_{\text {wood }}$ was lowest. According to the previous studies on bamboo (Yang et al., 2015) and palm (Sperling et al., 2015), $\theta_{\text {wood was }}$ decreasing gradually from sunrise until sunset. Therefore, in the afternoon especially at dusk, $J_{\mathrm{S}}$ may be influenced significantly by $\theta_{\text {wood }}$. Additionally, the magnitude of underestimation differed with $J_{\mathrm{s}}$. The relative error of $J_{\mathrm{s}}$ $(\%)$ was larger at lower $J_{\mathrm{s}}$, and it gradually became smaller and approached to a stable value with increasing $J_{\mathrm{s}}$. This finding may mean that on plants with low water consumption or when $J_{\mathrm{S}}$ was low, the TDP-measured $J_{\mathrm{S}}$ was influenced more obvious by the changing $\theta_{\text {wood }}$. In contrast, for the plants with high $J_{\mathrm{s}}$, the influence from $\theta_{\text {wood }}$ would be small. Despite relative small errors at higher daytime $J_{\mathrm{s}}$, they were responsible for most of the underestimation on daily water use. For example, relative error was only $9.4 \%$ at $30 \mathrm{~g} \mathrm{~cm}^{-2} \mathrm{~h}^{-1}$ (in contrast, $18.6 \%$ at $5 \mathrm{~g} \mathrm{~cm}^{-2} \mathrm{~h}^{-1}$ ), but it could lead to $64 \%$ of the underestimation on daily water use of a bamboo culm. Except varying with different $J_{\mathrm{s}}$, the influence of $\theta_{\text {wood }}$ on TDP-measured $J_{\mathrm{s}}$ may also differ with different water conditions due to weather or management, e.g. rainy or sunny days or irrigation. In the model, when $\theta_{\text {wood }}$ was reduced with same ratio (half) from nighttime to daytime, higher nighttime $\theta_{\text {wood }}$ caused larger underestimation of $J_{\mathrm{s}}$. High nighttime $\theta_{\text {wood }}$ may occur in a wet season. This may raise a problem when calibrating TDP with other methods in situ. It was reported that after calibrating with one-month data, about $10 \%$ of the TDP measurements still significantly differ from SHB measurements (Chapter 2). Therefore, the 
calibration conducted in a short period may not be suitable for a long period with dynamic $\theta_{\text {wood. }}$. With the same concern, calibration on segments with fully water supply may be also not applicable to the field measurement due to the varying water conditions. Therefore, if applying TDP through obvious dry and wet seasons, we recommended calibration with different water conditions or use the model to correct the possible bias of TDP.

Except for the widely used thermal methods (e.g. TDP), deuterium tracing method is another way to investigate water use of trees or bamboos (Calder et al., 1986; Schwendenmann et al., 2010). In our present study (Chapter 4), with TDP as a reference method, we applied deuterium tracing method to estimate sap velocities. $V_{\text {TDP }}$ was much lower than deuterium derived sap velocity $\left(V_{\mathrm{D}_{2} \mathrm{O}}\right)$ on the three studied bamboo species. The $V_{\mathrm{D}_{2} \mathrm{O}}$ was derived by dividing the tracing length $(\approx$ bamboo/tree height $)$ with the transit time from deuterium injection to when deuterium concentration in the leaves first reach $10 \%$ of the maximal of the deuterium concentration (Meinzer et al., 2006). In such straightforward way, $V_{\mathrm{D}_{2} \mathrm{O}}$ seemed more reliable. The further improvement on $V_{\mathrm{D}_{2} \mathrm{O}}$ may be estimating the deuterium transit time more precisely with shorter sampling intervals. We think $V_{\mathrm{D}_{2} \mathrm{O}}$ could even be larger when $\mathrm{D}_{2} \mathrm{O}$ sampling is done at a higher frequency. Additionally, we found that $V_{\text {TDP }}$ seem to have a negative relationship with $\mathrm{D}_{2} \mathrm{O}$ residence time in labeled culms, i.e. the deuterium residence time in labeled culms was shorter under high sap velocity. However, the residence time was not correlated to the culm water storage $\left(C_{\mathrm{WS}}\right)$ as found in other studies on trees (James et al., 2003; Meinzer et al., 2006). The insignificant correlation may be attributed to the limited contribution of stem water storage as estimated based on the TDP method. During the experiment from $8^{\text {th }}$ March to $6^{\text {th }}$ April 2013, $C_{\mathrm{WS}}$ were $15 \%, 9 \%$ and $9 \%$ on average for B. vulgaris, G. apus and D. asper, respectively. On our study bamboos, it was implied that culm water storage was quickly depleted in the morning due to high $J_{\mathrm{s}}$ (Chapter 2). Half-hourly maximal $J_{\mathrm{s}}$ in the four studied bamboo species ranged from 21.6 to $70.5 \mathrm{~g} \mathrm{~cm}^{-2} \mathrm{~h}^{-1}$ and were (on average) almost two times greater than in the studied tree species (Chapter $2)$. When applying deuterium tracing method to estimate water use, we found deuterium derived water use was $70 \%\left(R^{2}=0.9\right)$ higher than that derived from TDP on three bamboo species. Such high overestimation cannot fully be explained by TDP underestimation $(\approx 10 \%$, Chapter 2$)$, and the overestimation was attributed to tracer loss (deuterium retention and transfer) and incomplete mixing of tracers. Among these error sources, water transfer between bamboo culms through rhizome was proved to be the main cause of tracer loss. With 
deuterium tracing method, we found elevated deuterium concentration in the non-labeled culms near the deuterium labeled one. In conclusion, the deuterium tracing method is more suitable to trace water movement than to estimate water use in bamboos or other trees that characterized with water redistribution.

\subsection{Outlook}

In our study, we found the four studied bamboo species had higher and earlier maximal $J_{\mathrm{S}}$ than nearby tree species. However, the near maximal $J_{\mathrm{S}}$ cannot be maintained for a long time under increasing transpiration demand (e.g. larger VPD) in midday. These results implied the internal water storage supported transpiration in the morning but the contribution may be limited (c.a. 10\%). However, in another study on B. vulgaris (Yang et al., 2015), the culm water storage showed more important role in the afternoon. These different findings suggested more work on exploring the mechanisms of bamboo water storage. Additionally, water transfer was implied by the deuterium tracing method in the present study, and more direct and quantifiable measurement should be done in the future work. As an important part of this study, method testing and calibration was conducted on widely used TDP method. The calibration results and the modeling on the influence of $\theta_{\text {wood }}$ on TDP can help further studying bamboo water use and understanding dynamic of water storage. The future work may emphasize on testing the present model in the field with simultaneous measurement of $\theta_{\text {wood }}$ and $J_{\mathrm{S}}$ by TDP, or on improving and developing heat-based methods with considering $\theta_{\text {wood }}$. Regarding the deuterium tracing method, it was proved to be a good method to estimate sap velocity with short enough sampling intervals, but it is not so suitable to estimate quantitate water use of species that have strong water redistribution. However, the deuterium tracing has its obvious advantage on tracing water movement or transfer within or among bamboo culms, and such advantage makes the method to be a powerful way to explore water redistribution or exchange on plants. 



\section{Bibliography}

Adonsou, K. E., DesRochers, A., and Tremblay, F. (2016). Physiological integration of connected balsam poplar ramets. Tree Physiology, 36(7):797806.

Baker, J. and Bavel, C. v. (1987). Measurement of mass flow of water in the stems of herbaceous plants. Plant, Cell \& Environment, 10(9):777-782.

Bovard, B., Curtis, P., Vogel, C., Su, H.-B., and Schmid, H. (2005). Environmental controls on sap flow in a northern hardwood forest. Tree Physiology, 25(1):31-38.

BPG (2012). An updated tribal and subtribal classification of the bamboos (poaceae: Bambusoideae). The Journal of the American Bamboo Society, 24(1):1-10.

Burgess, S. S., Adams, M. A., Turner, N. C., Beverly, C. R., Ong, C. K., Khan, A. A., and Bleby, T. M. (2001a). An improved heat pulse method to measure low and reverse rates of sap flow in woody plants. Tree Physiology, 21(9):589-598.

Burgess, S. S., Adams, M. A., Turner, N. C., White, D. A., and Ong, C. K. (2001b). Tree roots: conduits for deep recharge of soil water. Oecologia, 126(2):158-165.

Bush, S. E., Hultine, K. R., Sperry, J. S., and Ehleringer, J. R. (2010). Calibration of thermal dissipation sap flow probes for ring-and diffuse-porous trees. Tree Physiology, 30(12):1545-1554.

Calder, I., Narayanswamy, M., Srinivasalu, N., Darling, W., and Lardner, A. (1986). Investigation into the use of deuterium as a tracer for measuring transpiration from eucalypts. Journal of Hydrology, 84(3-4):345-351.

Calder, I. R. (1991). Implications and assumptions in using the 'total counts' and convection-dispersion equations for tracer flow measurements-with particular reference to transpiration measurements in trees. Journal of Hydrology, 125(1):149-158.

Calder, I. R., Kariyappa, G., Srinivasalu, N., and Murty, K. S. (1992). Deuterium tracing for the estimation of transpiration from trees part 1. field calibration. Journal of Hydrology, 130(1-4):17-25.

Cao, K.-F., Yang, S.-J., Zhang, Y.-J., and Brodribb, T. J. (2012). The maximum height of grasses is determined by roots. Ecology Letters, 15(7):666-672. 
Carrasco, L. O., Bucci, S. J., Di Francescantonio, D., Lezcano, O. A., Campanello, P. I., Scholz, F. G., Rodríguez, S., Madanes, N., Cristiano, P. M., Hao, G.-Y., et al. (2015). Water storage dynamics in the main stem of subtropical tree species differing in wood density, growth rate and life history traits. Tree Physiology, 35(4):354-365.

Carslaw, H. S. and Jaeger, J. C. (1959). Conduction of heat in solids. Oxford: Clarendon Press.

Čermák, J., Kučera, J., Bauerle, W. L., Phillips, N., and Hinckley, T. M. (2007). Tree water storage and its diurnal dynamics related to sap flow and changes in stem volume in old-growth douglas-fir trees. Tree Physiology, 27(2):181-198.

Chen, X., Zhang, X., Zhang, Y., Booth, T., and He, X. (2009). Changes of carbon stocks in bamboo stands in china during 100 years. Forest Ecology and Management, 258(7):1489-1496.

Choi, I. C. and Aronoff, S. (1966). Photosynthate transport using tritiated water. Plant Physiology, 41(7):1119-1129.

Clearwater, M. J., Meinzer, F. C., Andrade, J. L., Goldstein, G., and Holbrook, N. M. (1999). Potential errors in measurement of nonuniform sap flow using heat dissipation probes. Tree Physiology, 19(10):681-687.

Cochard, H., Ewers, F., and Tyree, M. (1994). Water relations of a tropical vinelike bamboo (Rhipidocladum racemiflorum): root pressures, vulnerability to cavitation and seasonal changes in embolism. Journal of Experimental Botany, 45(8):1085-1089.

Constantz, J. and Murphy, F. (1990). Monitoring moisture storage in trees using time domain reflectometry. Journal of Hydrology, 119(1):31-42.

de Agrasar, Z. R. and Rodríguez, M. F. (2003). Culm anatomy of native woody bamboos in argentina and neighboring areas: cross section. Bamboo Science and Culture: Journal of the American Bamboo Society, 17:28-43.

Dierick, D. and Hölscher, D. (2009). Species-specific tree water use characteristics in reforestation stands in the philippines. Agricultural and Forest Meteorology, 149(8):1317-1326.

Dierick, D., Hölscher, D., and Schwendenmann, L. (2010). Water use characteristics of a bamboo species (Bambusa blumeana) in the philippines. Agricultural and Forest Meteorology, 150(12):1568-1578.

Do, F. and Rocheteau, A. (2002). Influence of natural temperature gradients on measurements of xylem sap flow with thermal dissipation probes. 1. field observations and possible remedies. Tree Physiology, 22(9):641-648.

Dransfield, S. and Widjaja, E. (1995). Bamboos-plant resources of southeast asia, no. 7. Prosea. Bogor, Indonesia. 
Durst, P. B., Ulrich, W., Kashio, M., Khan, S., Shi, K., Gupta, B., Silitonga, T., Yong, P. L., Khatri, D. B., and Iqbal Sial, M. (1994). Non-wood forest products in Asia. RAPA Publication (FAO).

Dye, P. and Olbrich, B. (1993). Estimating transpiration from 6-year-old Eucalyptus grandis trees: development of a canopy conductance model and comparison with independent sap flux measurements. Plant, Cell \& Environment, 16(1):45-53.

Dye, P., Olbrich, B., and Calder, I. (1992). A comparison of the heat pulse method and deuterium tracing method for measuring transpiration from Eucalyptus grandis trees. Journal of Experimental Botany, 43(3):337-343.

Edwards, W. and Warwick, N. (1984). Transpiration from a kiwifruit vine as estimated by the heat pulse technique and the penman-monteith equation. New Zealand Journal of Agricultural Research, 27(4):537-543.

Eller, C. B., Lima, A. L., and Oliveira, R. S. (2013). Foliar uptake of fog water and transport belowground alleviates drought effects in the cloud forest tree species, drimys brasiliensis (winteraceae). New Phytologist, 199(1):151-162.

FAO (2010). Global forest resources assessment 2010: main report, fao forestry paper, 0258-6150; 163.

Feng, Y., Lin, H., Ho, S., Yan, J., Dong, J., Fang, S., and Huang, Y. (2015). Overview of wind power generation in china: status and development. Renewable and Sustainable Energy Reviews, 50:847-858.

Forster, M. A. (2014). How significant is nocturnal sap flow? Tree Physiology, 34(7):757-765.

Gaines, K. P., Meinzer, F. C., Duffy, C. J., Thomas, E. M., and Eissenstat, D. M. (2016). Rapid tree water transport and residence times in a pennsylvania catchment. Ecohydrology, 9(8):1554-1565.

Gleason, S. M., Westoby, M., Jansen, S., Choat, B., Hacke, U. G., Pratt, R. B., Bhaskar, R., Brodribb, T. J., Bucci, S. J., Cao, K.-F., et al. (2016). Weak tradeoff between xylem safety and xylem-specific hydraulic efficiency across the world's woody plant species. New Phytologist, 209(1):123-136.

Goldsmith, G. R. (2013). Changing directions: the atmosphere-plant-soil continuum. New Phytologist, 199(1):4-6.

Goldsmith, G. R., Matzke, N. J., and Dawson, T. E. (2013). The incidence and implications of clouds for cloud forest plant water relations. Ecology Letters, 16(3):307-314.

Goldstein, G., Andrade, J., Meinzer, F., Holbrook, N., Cavelier, J., Jackson, P., and Celis, A. (1998). Stem water storage and diurnal patterns of water use in tropical forest canopy trees. Plant, Cell \& Environment, 21(4):397-406.

Granier, A. (1985). Une nouvelle méthode pour la mesure du flux de sève brute dans le tronc des arbres. Annales des Sciences forestières, 42(2):193-200. 
Granier, A. (1987). Evaluation of transpiration in a douglas-fir stand by means of sap flow measurements. Tree Physiology, 3(4):309-320.

Grime, V. and Sinclair, F. (1999). Sources of error in stem heat balance sap flow measurements. Agricultural and Forest Meteorology, 94(2):103-121.

Grosser, D. and Liese, W. (1971). On the anatomy of asian bamboos, with special reference to their vascular bundles. Wood Science and technology, 5(4):290-312.

Hao, G.-Y., Wheeler, J. K., Holbrook, N. M., and Goldstein, G. (2013). Investigating xylem embolism formation, refilling and water storage in tree trunks using frequency domain reflectometry. Journal of Experimental Botany, 64(8):2321-2332.

Hartung, W., Sauter, A., and Hose, E. (2002). Abscisic acid in the xylem: where does it come from, where does it go to? Journal of Experimental Botany, 53(366):27-32.

Hernández-Santana, V., David, T., and Martínez-Fernández, J. (2008). Environmental and plant-based controls of water use in a mediterranean oak stand. Forest Ecology and Management, 255(11):3707-3715.

Holbrook, N. M., Burns, M., and Sinclair, T. (1992). Frequency and timedomain dielectric measurements of stem water content in the arborescent palm, sabal palmetto. Journal of Experimental Botany, 43(1):111-119.

Hölttä, T., Linkosalo, T., Riikonen, A., Sevanto, S., and Nikinmaa, E. (2015). An analysis of granier sap flow method, its sensitivity to heat storage and a new approach to improve its time dynamics. Agricultural and Forest Meteorology, 211-212:2-12.

Horna, V., Schuldt, B., Brix, S., and Leuschner, C. (2011). Environment and tree size controlling stem sap flux in a perhumid tropical forest of central sulawesi, indonesia. Annals of forest science, 68(5):1027-1038.

Ichihashi, R., Komatsu, H., Kume, T., Onozawa, Y., Shinohara, Y., Tsuruta, K., and Otsuki, K. (2015). Stand-scale transpiration of two moso bamboo stands with different culm densities. Ecohydrology, 8(3):450-459.

Inagaki, T., Ahmed, B., Hartley, I. D., Tsuchikawa, S., and Reid, M. (2014). Simultaneous prediction of density and moisture content of wood by terahertz time domain spectroscopy. Journal of Infrared, Millimeter, and Terahertz Waves, 35(11):949-961.

INBAR (2014). International trade in bamboo and rattan 2012. beijing: International network for bamboo and rattan.

Ito, R., Miyafuji, H., and Kasuya, N. (2015). Rhizome and root anatomy of moso bamboo (Phyllostachys pubescens) observed with scanning electron microscopy. Journal of Wood Science, 61(4):431-437. 
James, S. A., Meinzer, F. C., Goldstein, G., Woodruff, D., Jones, T., Restom, T., Mejia, M., Clearwater, M., and Campanello, P. (2003). Axial and radial water transport and internal water storage in tropical forest canopy trees. Oecologia, 134(1):37-45.

Jarvis, N. (1989). A simple empirical model of root water uptake. Journal of Hydrology, 107(1-4):57-72.

Johnson, D., McCulloh, K., Meinzer, F., Woodruff, D., and Eissenstat, D. (2011). Hydraulic patterns and safety margins, from stem to stomata, in three eastern us tree species. Tree Physiology, 31(6):659-668.

Jung, E., Otieno, D., Lee, B., Lim, J., Kang, S., Schmidt, M., and Tenhunen, J. (2011). Up-scaling to stand transpiration of an asian temperate mixeddeciduous forest from single tree sapflow measurements. Plant Ecology, 212(3):383-395.

Kalma, S. J., Thorburn, P. J., and Dunn, G. M. (1998). A comparison of heat pulse and deuterium tracing techniques for estimating sap flow in Eucalyptus grandis trees. Tree Physiology, 18(10):697-705.

Kline, J., Martin, J., Jordan, C., and Koranda, J. (1970). Measurement of transpiration in tropical trees with tritiated water. Ecology, 51(6):10681073.

Köcher, P., Horna, V., and Leuschner, C. (2013). Stem water storage in five coexisting temperate broad-leaved tree species: significance, temporal dynamics and dependence on tree functional traits. Tree Physiology, 33(8):817-832.

Köhler, M., Dierick, D., Schwendenmann, L., and Hölscher, D. (2009). Water use characteristics of cacao and gliricidia trees in an agroforest in central sulawesi, indonesia. Ecohydrology, 2(4):520-529.

Köhler, M., Schwendenmann, L., and Hölscher, D. (2010). Throughfall reduction in a cacao agroforest: tree water use and soil water budgeting. Agricultural and Forest Meteorology, 150(7):1079-1089.

Kollman, F. F. and Côté, W. (1968). Principles of wood science and technology, vol i.

Komatsu, H., Onozawa, Y., Kume, T., Tsuruta, K., Kumagai, T., Shinohara, Y., and Otsuki, K. (2010). Stand-scale transpiration estimates in a moso bamboo forest: Ii. comparison with coniferous forests. Forest Ecology and Managemen, 260(8):1295-1302.

Kremer, T. A., LaSarre, B., Posto, A. L., and McKinlay, J. B. (2015). N2 gas is an effective fertilizer for bioethanol production by zymomonas mobilis. Proceedings of the National Academy of Sciences, 112(7):2222-2226.

Kubota, M., Tenhunen, J., Zimmermann, R., Schmidt, M., Adiku, S., and Kakubari, Y. (2005). Influences of environmental factors on the radial profile of sap flux density in fagus crenata growing at different elevations in the naeba mountains, japan. Tree Physiology, 25(5):545-556. 
Kume, T., Onozawa, Y., Komatsu, H., Tsuruta, K., Shinohara, Y., Umebayashi, T., and Otsuki, K. (2010). Stand-scale transpiration estimates in a moso bamboo forest: (i) applicability of sap flux measurements. Forest Ecology and Management, 260(8):1287-1294.

Kume, T., Takizawa, H., Yoshifuji, N., Tanaka, K., Tantasirin, C., Tanaka, N., and Suzuki, M. (2007). Impact of soil drought on sap flow and water status of evergreen trees in a tropical monsoon forest in northern thailand. Forest Ecology and Management, 238(1):220-230.

Liese, W. and Köhl, M. (2015). Bamboo: the plant and its uses, volume 10. Springer.

Liese, W. and Weiner, G. (1996). Ageing of bamboo culms. a review. Wood Science and Technology, 30(2):77-89.

Lin, J., He, X., Hu, Y., Kuang, T., and Ceulemans, R. (2002). Lignification and lignin heterogeneity for various age classes of bamboo (Phyllostachys pubescens) stems. Physiologia Plantarum, 114(2):296-302.

Lu, P., Urban, L., and Zhao, P. (2004). Granier's thermal dissipation probe (tdp) method for measuring sap flow in trees: theory and practice. Acta Botanica Sinica-English Edition-, 46(6):631-646.

Marc, V. and Robinson, M. (2004). Application of the deuterium tracing method for the estimation of tree sap flow and stand transpiration of a beech forest (Fagus silvatica L.) in a mountainous mediterranean region. Journal of Hydrology, 285(1):248-259.

Mathew, P. (1998). The bamboo economy of Kerala, India: an analysis of the production-to-consumption systems. Number 12. International Network for Bamboo and Rattan.

Mei, T.-T., Fang, D.-M., Röll, A., Niu, F.-R., Hendrayanto, and Hölscher, D. (2016). Water use patterns of four tropical bamboo species assessed with sap flux measurements. Frontiers in plant science, 6:1202.

Meinzer, F., Brooks, J., Domec, J.-C., Gartner, B., Warren, J., Woodruff, D., Bible, K., and Shaw, D. (2006). Dynamics of water transport and storage in conifers studied with deuterium and heat tracing techniques. Plant, Cell \& Environment, 29(1):105-114.

Meinzer, F., Goldstein, G., and Andrade, J. (2001). Regulation of water flux through tropical forest canopy trees: do universal rules apply? Tree Physiology, 21(1):19-26.

Mohmod, A. L. and Mustafa, M. T. (1992). Variation in anatomical properties of three malaysian bamboos from natural stands. Journal of Tropical Forest Science, 5(1):90-96.

Münch, E. (1927). Versuche über den saftkreislauf. Berichte der Deutschen Botanischen Gesellschaft, 45(6):340-356. 
Nadler, A., Raveh, E., Yermiyahu, U., Lado, M., Nasser, A., Barak, M., and Green, S. (2008). Detecting water stress in trees using stem electrical conductivity measurements. Soil Science Society of America Journal, 72(4):1014-1024.

Niu, F., Röll, A., Hardanto, A., Meijide, A., Köhler, M., Hölscher, D., et al. (2015). Oil palm water use: calibration of a sap flux method and a field measurement scheme. Tree Physiology, 35(5):563-573.

Numata, M. (1987). The ecology of bamboo forests-particularly on temperate bamboo forests. Bamb $J, 4: 118-131$.

O'Brien, J. J., Oberbauer, S. F., and Clark, D. B. (2004). Whole tree xylem sap flow responses to multiple environmental variables in a wet tropical forest. Plant, Cell \& Environment, 27(5):551-567.

Parr, J., Sullivan, L., Chen, B., Ye, G., and Zheng, W. (2010). Carbon biosequestration within the phytoliths of economic bamboo species. Global Change Biology, 16(10):2661-2667.

Pereira, H. and Hosegood, P. (1962). Comparative water-use of softwood plantations and bamboo forest. Journal of Soil Science, 13:299-313.

Peters, E. B., McFadden, J. P., and Montgomery, R. A. (2010). Biological and environmental controls on tree transpiration in a suburban landscape. Journal of Geophysical Research: Biogeosciences, 115(G4):2156-2202.

Petit, G., DeClerck, F. A., Carrer, M., and Anfodillo, T. (2014). Axial vessel widening in arborescent monocots. Tree Physiology, 34(2):137-145.

Pfautsch, S., Hölttä, T., and Mencuccini, M. (2015a). Hydraulic functioning of tree stems-fusing ray anatomy, radial transfer and capacitance. Tree Physiology, 35(7):706-722.

Pfautsch, S., Renard, J., Tjoelker, M. G., and Salih, A. (2015b). Phloem as capacitor: radial transfer of water into xylem of tree stems occurs via symplastic transport in ray parenchyma. Plant Physiology, 167(3):963-971.

Philip, J. R. (1966). Plant water relations: some physical aspects. Annual Review of Plant Physiology, 17(1):245-268.

Regalado, C. M. and Ritter, A. (2007). An alternative method to estimate zero flow temperature differences for granier's thermal dissipation technique. Tree Physiology, 27(8):1093-1102.

Renninger, H. J. and Phillips, N. (2010). Intrinsic and extrinsic hydraulic factors in varying sizes of two amazonian palm species (iriartea deltoidea and mauritia flexuosa) differing in development and growing environment. American journal of botany, 97(12):1926-1936.

Roden, J. S. and Ehleringer, J. R. (1999). Observations of hydrogen and oxygen isotopes in leaf water confirm the craig-gordon model under wide-ranging environmental conditions. Plant Physiology, 120(4):1165-1174. 
Roderick, M. L. and Berry, S. L. (2001). Linking wood density with tree growth and environment: a theoretical analysis based on the motion of water. New Phytologist, 149(3):473-485.

Röll, A., Niu, F., Meijide, A., Hardanto, A., Knohl, A., Hölscher, D., et al. (2015). Transpiration in an oil palm landscape: effects of palm age. Biogeosciences, 12(19):5619-5633.

Saha, S., Holbrook, N. M., Montti, L., Goldstein, G., and Cardinot, G. K. (2009). Water relations of chusquea ramosissima and merostachys claussenii in iguazu national park, argentina. Plant Physiology, 149(4):1992-1999.

Sakuratani, T. (1981). A heat balance method for measuring water flux in the stem of intact plants. Journal of Agricultural Meteorology, 37(1):9-17.

Sakuratani, T., Aoe, T., and Higuchi, H. (1999). Reverse flow in roots of sesbania rostrata measured using the constant power heat balance method. Plant, Cell \& Environment, 22(9):1153-1160.

Scholz, F. C., Bucci, S. J., Goldstein, G., Meinzer, F. C., Franco, A. C., and Miralles-Wilhelm, F. (2008). Temporal dynamics of stem expansion and contraction in savanna trees: withdrawal and recharge of stored water. Tree Physiology, 28(3):469-480.

Schwendenmann, L., Dierick, D., Köhler, M., and Hölscher, D. (2010). Can deuterium tracing be used for reliably estimating water use of tropical trees and bamboo? Tree Physiology, 30(7):886-900.

Smith, D. and Allen, S. (1996). Measurement of sap flow in plant stems. Journal of Experimental Botany, 47(12):1833-1844.

Smith, D., Jackson, N., Roberts, J., and Ong, C. (1999). Reverse flow of sap in tree roots and downward siphoning of water by Grevillea robusta. Functional Ecology, 13(2):256-264.

Song, X., Peng, C., Zhou, G., Gu, H., Li, Q., and Zhang, C. (2016). Dynamic allocation and transfer of non-structural carbohydrates, a possible mechanis$\mathrm{m}$ for the explosive growth of moso bamboo (Phyllostachys heterocycla). Scientific reports, 6.

Song, Z., Liu, H., Li, B., and Yang, X. (2013). The production of phytolithoccluded carbon in china's forests: implications to biogeochemical carbon sequestration. Global change biology, 19(9):2907-2915.

Sperling, O., Shapira, O., Schwartz, A., and Lazarovitch, N. (2015). Direct in vivo evidence of immense stem water exploitation in irrigated date palms. Journal of Experimental Botany, 66(1):333-338.

Stapleton, C. (1998). Form and function in the bamboo rhizome. Journal of American Bamboo Society, 12(1):21-29.

Steppe, K., De Pauw, D. J., Doody, T. M., and Teskey, R. O. (2010). A comparison of sap flux density using thermal dissipation, heat pulse velocity and heat field deformation methods. Agricultural and Forest Meteorology, 150(7):1046-1056. 
Studer, M., Siegwolf, R., Leuenberger, M., and Abiven, S. (2015). Multiisotope labelling of organic matter by diffusion of ${ }^{2} \mathrm{~h} /{ }^{18} \mathrm{O}-\mathrm{h}_{2} \mathrm{O}$ vapour and ${ }^{13}{\mathrm{C}-\mathrm{CO}_{2}}$ into the leaves and its distribution within the plant. Biogeosciences, 12(6):1865-1879.

Tang, J., Bolstad, P. V., Ewers, B. E., Desai, A. R., Davis, K. J., and Carey, E. V. (2006). Sap flux-upscaled canopy transpiration, stomatal conductance, and water use efficiency in an old growth forest in the great lakes region of the united states. Journal of Geophysical Research: Biogeosciences, 111(G2).

Tatarinov, F. A., Kučera, J., and Cienciala, E. (2005). The analysis of physical background of tree sap flow measurement based on thermal methods. Measurement Science and Technology, 16(5):1157.

Trcala, M. and Čermák, J. (2016). A new heat balance equation for sap flow calculation during continuous linear heating in tree sapwood. Applied Thermal Engineering, 102:532-538.

Tyree, M. T. and Sperry, J. S. (1988). Do woody plants operate near the point of catastrophic xylem dysfunction caused by dynamic water stress? answers from a model. Plant Physiology, 88(3):574-580.

Uchimura, E. (1994). Invitation to bamboos: Wonder of biology. Tokyo, Kenseisha, 188.

Van Den Besselaar, E. J., Klein Tank, A. M., Van Der Schrier, G., Abass, M. S., Baddour, O., Van Engelen, A. F., Freire, A., Hechler, P., Laksono, B. I., Jilderda, R., et al. (2015). International climate assessment \& dataset: climate services across borders. Bulletin of the American Meteorological Society, 96(1):16-21.

Vandegehuchte, M. W. and Steppe, K. (2012). Improving sap flux density measurements by correctly determining thermal diffusivity, differentiating between bound and unbound water. Tree Physiology, 32(7):930-942.

Vandegehuchte, M. W. and Steppe, K. (2013). Corrigendum to: Sap-flux density measurement methods: working principles and applicability. Functional Plant Biology, 40(10):1088-1088.

Vergeynst, L. L., Vandegehuchte, M. W., McGuire, M. A., Teskey, R. O., and Steppe, K. (2014). Changes in stem water content influence sap flux density measurements with thermal dissipation probes. Trees, 28(3):949-955.

Wang, B., Wei, W., Liu, C., You, W., Niu, X., and Man, R. (2013). Biomass and carbon stock in moso bamboo forests in subtropical china: characteristics and implications. Journal of Tropical Forest Science, 25(1):137-148.

Wang, H., Zhao, P., Hölscher, D., Wang, Q., Lu, P., Cai, X. A., and Zeng, X. P. (2012). Nighttime sap flow of acacia mangium and its implications for nighttime transpiration and stem water storage. Journal of Plant Ecology, 5(3):294-304. 
Waring, R. and Running, S. (1978). Sapwood water storage: its contribution to transpiration and effect upon water conductance through the stems of old-growth douglas-fir. Plant, Cell \& Environment, 1(2):131-140.

Wullschleger, S. D., Childs, K. W., King, A. W., and Hanson, P. J. (2011). A model of heat transfer in sapwood and implications for sap flux density measurements using thermal dissipation probes. Tree Physiology, 31(6):669679.

Wullschleger, S. D., Hanson, P. J., and Todd, D. E. (1996). Measuring stem water content in four deciduous hardwoods with a time-domain reflectometer. Tree Physiology, 16(10):809-815.

Wullschleger, S. D. and Norby, R. J. (2001). Sap velocity and canopy transpiration in a sweetgum stand exposed to free-air co2 enrichment (face). New Phytologist, 150(2):489-498.

Yang, S.-J., Zhang, Y.-J., Goldstein, G., Sun, M., Ma, R.-Y., and Cao, K.-F. (2015). Determinants of water circulation in a woody bamboo species: afternoon use and night-time recharge of culm water storage. Tree Physiology, 35(9):964-974.

Yang, S.-J., Zhang, Y.-J., Sun, M., Goldstein, G., and Cao, K.-F. (2012). Recovery of diurnal depression of leaf hydraulic conductance in a subtropical woody bamboo species: embolism refilling by nocturnal root pressure. Tree Physiology, 32(4):414-422.

Zhao, X.-H., Zhao, P., Zhang, Z.-Z., Zhu, L.-W., Niu, J.-F., Ni, G.-Y., Hu, Y.-T., and Ouyang, L. (2016). Sap flow-based transpiration in Phyllostachys pubescens: applicability of the tdp methodology, age effect and rhizome role. Trees, pages 1-15.

Zhuang, S., Ji, H., Zhang, H., and Sun, B. (2015). Carbon storage estimation of moso bamboo (Phyllostachys pubescens) forest stands in fujian, china. Tropical Ecology, 56(3):383-91.

Zimmermann, M. H. and Tomlinson, P. B. (1972). The vascular system of monocotyledonous stems. Botanical Gazette, 133(2):141-155. 


\section{List of figures}

2.1 Installation of thermal dissipation probe (TDP) and stem heat balance (SHB) sensors on bamboo culms for the calibration experiments on potted plants (A) and for field calibration (B).

2.2 Half-hourly sap flux density $\left(J_{\mathrm{S}}\right)$ measured with thermal dissipation probes (TDP) and stem heat balance (SHB) sensors on five potted Bambusa vulgaris culms plotted against GMderived reference sap flux densities $\left(J_{\mathrm{S}_{-} \mathrm{GM}}\right)$ before $(\mathrm{A}$; $J_{\text {S_TDP_cali_original }}: Y=0.44 X, R^{2}=0.84, P<0.01 ; J_{\text {S_SHB }}: Y$ $\left.=0.98 X, R^{2}=0.93, P<0.01\right)$ and $\operatorname{after}\left(\mathrm{B} ; J_{\text {S_TDP_cali_field }} Y\right.$ $=1.24 X, R^{2}=0.84, P<0.01 ; J_{\text {s_TDP_cali_pot }}: Y=1.01 X, R^{2}$ $=0.84, P<0.01)$ species-specific calibration and field calibrations of the TDP method. Pooled data from 2 to 5 days of simultaneous TDP, SHB, and gravimetric measurements (GM). 19

2.3 Relationship between diameter at breast height (DBH) of bamboo culms and maximum observed sap flux density $\left(J_{\text {S_max }}\right)$ in four bamboo species. Horizontal error bars indicate DBH standard errors, vertical bars standard errors of $J_{\text {s_max }}$. Data of five culms pooled per species, average of the highest $10 \%$ of daily $J_{\mathrm{s}_{-} \max }$ values of each culm used for the analysis. . . . . 21

2.4 Normallized daily accumulated sap flux density $\left(J_{\mathrm{S}}\right)$ plotted against absolute values of (A) intergrated daily radiation and (B) average daily vapor pressure deficit (VPD). Daily values of four bamboo (upper row) and three tree species (lower row); data from 7 months of measurements (July 2012-January 2013) encompassing both wet (filled circles) and dry (open circles) periods (except for Dendrocalamus asper and Gmelina arborea, mainly dry period). Daily averages derived from measurements of five culms per species. . . . . . . . . . 22 
2.5 Normalized daily accumulated sap flux density $\left(J_{\mathrm{S}}\right)$ of four bamboo species (A) and three tree species (B) in the 'dry period' (characterized with mean daily VPD $>0.74 \mathrm{kPa}$ ) plotted against normalized mean daily soil moisture content (SM). There was a significant linear relationship between $J_{\mathrm{S}}$ and SM $(P<0.05)$ for all species except $D$. asper and G. arborea. Normalized values do not reach 1.0 for all species in the figure as the normalization was performed by setting the maximum value of the full measurement period of each species (including wet period) to one, while the figure displays only values in dry period. Daily averages derived from measurements on five culms per species, data of at least 10 dry period days per species. ...................... 23

2.6 Normalized hourly sap flux density $\left(J_{\mathrm{s}}\right)$ plotted against $(\mathrm{A})$ normalized hourly radiation and (B) VPD. Data of four bamboo (upper row) and three tree species (lower row). Hourly averages derived from simultaneous measurements on five culms per species and by averaging the values of three sunny days to minimize influences of weather. The numbers in the sub-figures indicate the respective time of the day. . . . . . . 24

3.1 The maximum temperature difference between the probes of $\operatorname{TDP}\left(\Delta \mathrm{T}_{\max }\right)$ in relation to the water content in culm segments of freshly sprouted G. apus in a dehydration experiment. Different symbols indicate different segments. The unit of culm water content $\left(\mathrm{kg} \mathrm{kg}^{-1}\right)$ indicates $\mathrm{kg}$ water in the culm per $\mathrm{kg}$ dry weight. . . . . . . . . . . . . . . . 40

3.2 The daily maximum temperature difference between the probes of TDP $\left(\Delta \mathrm{T}_{\max }\right)$ in relation to daily mean soil moisture for three bamboo species (B. vulgaris: $Y=-3.55 X+10.54, R^{2}=$ $0.63, P<0.01 ; D$. asper: $Y=-1.91 X+9.21, R^{2}=0.54, P<0.01$; G. apus: $\left.Y=-2.14 X+11.10, R^{2}=0.37, P<0.01\right) . \ldots . . .40$

3.3 The simulated maximum temperature difference between the probes of TDP $\left(\Delta \mathrm{T}_{\max }\right)$ with the ANSYS model in relation to culm water content. The unit of culm water content $\left(\mathrm{kg} \mathrm{kg}^{-1}\right)$ indicates $\mathrm{kg}$ water in the culm per $\mathrm{kg}$ dry weight. . . . . . . 
3.4 The relationship between the ratio of thermal conductivity in the axial direction to culm dry density and the culm water content. . . . . . . . . . . . . . . 4 4

3.5 The simulated relative change of daytime sap flux density $\left(J_{\mathrm{s}}\right)$ in percentage $(\%)$ at different absolute $J_{\mathrm{s}}\left(\mathrm{g} \mathrm{cm}^{-2} \mathrm{~h}^{-1}\right)$. Relationships are provided for different reductions of stem water content in daytime $\left(-0.1,-0.3,-0.7\right.$ and $\left.-0.9 \mathrm{~kg} \mathrm{~kg}^{-1}\right)$ from $1 \mathrm{~kg} \mathrm{~kg}^{-1}$ in the nighttime, which results in different degrees of change of stem thermal conductivity. Provided data based on numerical simulations with the ANSYS model. . . . 43

3.6 The corrected sap flux density $\left(J_{\mathrm{s}}\right)$ for different levels of $\theta_{\text {wood }}$ reduction (\%) during the daytime. Simulations based on field monitoring data of a B. vulgaris on 17 September 2012. Numerical simulations with the ANSYS model for reductions of daytime $\theta_{\text {wood }}$ by $0.1,0.3,0.7$ and $0.9 \mathrm{~kg} \mathrm{~kg}^{-1}$ from a 1 $\mathrm{kg} \mathrm{kg}^{-1}$ nighttime $\theta_{\text {wood }}$ result in underestimation of daily accumulated $J_{\mathrm{s}}$ by $2 \%, 10 \%, 19 \%$ and $28 \%$, respectively. . . .

3.7 The simulated relative change of daytime sap flux density $\left(J_{\mathrm{s}}\right)$ in $\%$ at different absolute $J_{\mathrm{s}}\left(\mathrm{g} \mathrm{cm}^{-2} \mathrm{~h}^{-1}\right)$. Relationships are provided for different nighttime stem water contents ( $\theta_{\text {wood }}$, $0.3,0.6$ and $0.9 \mathrm{~kg} \mathrm{~kg}^{-1}$ ), assuming a constant reduction (i.e. by half) in the ratio between nighttime and daytime $\theta_{\text {wood }}$. Provided data based on numerical simulations with the ANSYS model. . . . . . . . . . . . . . . . . . . . 44

4.1 Scheme of applying deuterium tracing and TDP methods. . . . 54

4.2 Deuterium concentration $\left(\mathrm{D}_{2} \mathrm{O} \mathrm{g} \mathrm{kg}{ }^{-1}\right.$ above background level) in transpired water of B. vulgaris, G. apus and D. asper over the course of the experiment. Day 0 is the day of deuterium injection. . . . . . . . . . . . . . 59

4.3 Sap velocities $\left(\mathrm{m} \mathrm{day}^{-1}\right)$ derived from deuterium tracing method $\left(V_{\mathrm{D}_{2} \mathrm{O}}\right)$ in relation to the sap velocities obtained from TDP method ( $\left.V_{\mathrm{TDP}}\right)$. The two grey dot lines represent $95 \%$ confidence limits for the expected values. The black line accounts for a regression line. . . . . . . . . . . . . . . 60

4.4 Residence time in relation to (A) the sap velocity derived from thermal dissipation probe $\left(V_{\mathrm{TDP}}, \mathrm{m} \mathrm{day}^{-1}\right)$ and (B) the contribution of culm water storage to daily water use $\left(C_{\mathrm{WS}}, \%\right) .60$ 
4.5 Water use estimated by the TDP method ( $\mathrm{WU}_{\mathrm{TDP}}, \mathrm{kg}_{\mathrm{day}}{ }^{-1}$ ) versus water use determined by deuterium tracing $\left(\mathrm{WU}_{\mathrm{D}_{2} \mathrm{O}}, \mathrm{kg}\right.$ day $^{-1}$ ) on bamboos. The solid line represents regression of all values of the three bamboo species. The dash lines represent species-specific regressions: B. vulgaris: $Y=1.4 X, R^{2}=0.95$, $P<0.01 ; D$. asper: $Y=2.0 X, R^{2}=0.97, P<0.01 ; G$. apus: $Y$ $=1.9 X, R^{2}=0.99, P<0.01 \ldots \ldots \ldots \ldots \ldots$

4.6 Deuterium values $(\delta \mathrm{D}, \% 0)$ in different bamboo organs (leaf, branch, stem at $0,2,6,10 \mathrm{~m}$ height and rhizome) of the labeled bamboos which was harvested after about 40 days since labeling. Each dot (mean \pm SD) stands for the mean values from 4 culms of $B$. vulgaris and 3 culms of $D$. asper and G. apus. . . . . . . . . . . . . . . . . . 62

4.7 The distribution of the maximal amount of neighboring culms $\left(N_{\max }\right)$ which may receive transferred water from the labeled culms (B. vulgaris, G. apus and D. asper). For each species, data of 3 established and 3 freshly sprouted culms were used. The black line represented fitted kernel distribution. The mode (at the most frequency) of the $N_{\max }$ was 5.1, 4.5 and 22.0 on B. vulgaris, G. apus and D. asper, and the mode was 6.7 when pooling the three species together.

4.8 The relative differences between the corrected $\mathrm{WU}_{\mathrm{D}_{2} \mathrm{O}}$ and $\mathrm{WU}_{\mathrm{TDP}}$, in relation to coefficients of variation of daily sap flux densities at breast height $\left(\mathrm{CV}_{\mathrm{J}_{\mathrm{s}}}\right)$. The corrected $\mathrm{WU}_{\mathrm{D}_{2} \mathrm{O}}$ was calculated based on the assumption that $\mathrm{D}_{2} \mathrm{O}$ transfer between one labeled culm and six neighboring culms, and the assumption was based on the mode of the distribution of the maximal amount of neighboring culms when pooling the three species together. . . . . . . . . . . . . . . . . . 68 
1 The temperature contours around the heating probe under zero sap flow conditions. The simulated bamboo segments had different water contents of 0.1 (A), 0.5 (B) and $1 \mathrm{~kg} \mathrm{~kg}^{-1}$ (C), respectively. The ambient temperature in the model was set to $300 \mathrm{~K}$. The legend shows the increase of temperature after reaching steady-state thermal conditions. The geometry and physical properties applied in the model were based on a mature culm segment of $B$. vulgaris, extracted from a culm at breast height. . . . . . . . . . . . . . . . 99 



\section{List of tables}

2.1 Structural characteristics of the studied bamboo and tree species $(\mathrm{n}=5$ per species; mean \pm SD). . . . . . . . . . . . . . . 14

2.2 Values of the parameter $\mathrm{c}$ of different bamboo calibrations (species-specific/common) for TDP sap flux estimates. . . . . 20

2.3 Time lags between diurnal peaks of radiation and VPD and peaks of $J_{\mathrm{s}}$ in studied bamboos and trees. . . . . . . . . 25

3.1 Parameters for the ANSYS numerical simulation . . . . . 38

4.1 The information of studied bamboos and trees ( 3 culms per species but 4 culms of $B$. vulgaris used). The adjusted $\mathrm{WU}_{\mathrm{D}_{2} \mathrm{O}}$ was $\mathrm{WU}_{\mathrm{D}_{2} \mathrm{O}}$ adjusted with deuterium transfer on bamboos. The values were represented as the means(SD) which were in parenthesis. .................... 55

4.2 Deuterium signature $(\delta \mathrm{D}, \% 0)$ in different bamboo organs (leaf, branch, stem at 0,2,6,10 m height and rhizome) of the labelled bamboos ( 4 culms of $B$. vulgaris and 3 culms of $D$. asper and $G$. apus) which was harvested after about 40 days since labelling. The values were represented as the means (standard deviation). 59

1 The influence of the three factors formula type, time step and formula specificity on the performance of the linear calibration model. Results of multi-ANOVA of the three factors against normalized Root-Mean-Square Error (nRMSE). . . . . . . . . 96 
2 Performance of culm-specific vs. species-specific vs. common linear formulas for a simple linear field calibration of the thermal dissipation probe (TDP) method with the stem heat balance (SHB) method on four bamboo species Normalized Root-Mean-Square Errors (nRMSE) and passing rates of the Wilcoxon Signed-Rank test for each species and formula specificity type. . . . . . . . . . . . . . . . 96 
Appendix Chapter 3 
Table 1 The influence of the three factors formula type, time step and formula specificity on the performance of the linear calibration model. Results of multi-ANOVA of the three factors against normalized Root-Mean-Square Error (nRMSE).

\begin{tabular}{cccccc}
\hline Source & DF & Type SS & Mean Square & F value & $P$ \\
\hline Formula type & 1 & 0.0046 & 0.0046 & 0.68 & 0.4093 \\
Time step & 3 & 0.0046 & 0.0015 & 0.23 & 0.8777 \\
Formula specificity & 2 & 7.7675 & 3.8838 & 577.54 & $<0.0001$ \\
\hline
\end{tabular}

Note: nRMSE, calculated by normalizing the RMSE with the observed range of sap flux densities from stem heat balance (SHB) measurements; RMSE derived from SHB measurements vs. model-predicted values of each day. Data of 63 days were used. $P<0.01$ indicates significant difference.

Table 2 Performance of culm-specific vs. species-specific vs. common linear formulas for a simple linear field calibration of the thermal dissipation probe (TDP) method with the stem heat balance (SHB) method on four bamboo species Normalized Root-Mean-Square Errors (nRMSE) and passing rates of the Wilcoxon Signed-Rank test for each species and formula specificity type.

\begin{tabular}{cccc}
\hline Species & Formula specificity & nRMSE & Passing rate (\%) \\
\hline B. vulgaris & common & $0.11^{a}$ & $83^{a}$ \\
& culm & $0.04^{a}$ & $94^{a}$ \\
G. apus & species & $0.10^{a}$ & $84^{a}$ \\
& common & $0.12^{a}$ & $77^{a}$ \\
D. asper & culm & $0.06^{a}$ & $90^{a}$ \\
& species & $0.10^{a}$ & $81^{a}$ \\
G. atroviolacea & common & $0.18^{a}$ & $74^{a}$ \\
& culm & $0.04^{a}$ & $94^{a}$ \\
& species & $0.18^{a}$ & $70^{a}$ \\
& common & $0.13^{a}$ & $74^{a}$ \\
& culm & $0.06^{a}$ & $89^{a}$ \\
\hline
\end{tabular}

Note: Superscripted letters indicate significant differences between nRMSEs and passing rates, respectively, within each species (Tukey's test, $P<0.05)$. 


\section{Appendix Chapter 4}

The thermal conductivity of the sample segments was calculated following the work of Vandegehuchte and Steppe (2013) who introduced a corrected thermal conductivity on the axial direction $\left(K_{\mathrm{a}}, \mathrm{W} \mathrm{m} \mathrm{m}^{-1} \mathrm{~K}^{-1}\right)$ as shown in the following equation (Eq. 1).

$$
K_{a}=K_{w}\left(\theta_{\text {wood }}-\theta_{\text {wood }-F S P}\right) \frac{\rho_{d r y}}{\rho_{w}}+0.04186 \times\left(21.0-20.0 \times F_{v-F S P}\right)
$$

Where $K_{\mathrm{w}}$ is thermal conductivity of water $\left(0.6 \mathrm{~W} \mathrm{~m}^{-1} \mathrm{~K}^{-1}\right), \theta_{\text {wood-FSP }}$ is $\theta_{\text {wood }}$ at fiber saturation point, $\rho_{\text {dry }}$ and $\rho_{\mathrm{w}}$ are the density of dry wood and water $\left(1000 \mathrm{~kg} \mathrm{~m}^{-3}\right), F_{\mathrm{v}-\mathrm{FSP}}$ is a void fraction of wood at fiber saturation point (Eq. 2) according to Vandegehuchte and Steppe (2013):

$$
F_{v-F S P}=1-G_{b}\left(\rho_{w} \rho_{c w}^{-1}+\theta_{w o o d-F S P}\right)
$$

Where $F_{\mathrm{v}-\mathrm{FSP}}$ is void fraction of the wood at fiber moisture saturation point, $\rho_{\mathrm{cw}}$ is the density of cell wall $\left(1530 \mathrm{~kg} \mathrm{~m}^{-3}\right.$, Kollman and Côté, 1968; Vandegehuchte and Steppe, 2013), $G_{\mathrm{b}}$ is the basic specific gravity as the function of weight of dry mass per fresh volume divided by the density of water. $\theta_{\text {wood-FSP }}$ (Eq. 3) refers to (Roderick and Berry, 2001):

$$
\theta_{\text {wood }-F S P}=0.2\left(\rho_{d} \rho_{w}^{-1}\right)^{-\frac{1}{2}}
$$

Where $\rho_{\text {ovend }}$ is the density of oven dried wood (Eq. 4) refers to $\left(\mathrm{kg} \mathrm{m}^{-3}\right.$, Inagaki et al., 2014):

$$
\rho_{d}=\rho_{\text {air }}\left(1-F_{\text {ovencw }}\right)+\rho_{\text {ovencw }} F_{\text {ovencw }}
$$

Where $\rho_{\text {air }}$ is the density of air at $20^{\circ} \mathrm{C}\left(1.2 \mathrm{~kg} \mathrm{~m}^{-3}\right), \rho_{\text {ovencw }}$ is the density of oven dried cell wall $\left(1400 \mathrm{~kg} \mathrm{~m}^{-3}\right)$. $F_{\text {ovencw }}$ is the volume fraction of the oven dried cell wall (Eq. 5).

$$
F_{\text {ovencw }}=w_{\text {ovencw }} \rho_{\text {ovencw }}^{-1} v_{\text {fresh }}^{-1}
$$

Where $w_{\text {ovencw }}$ is the weight of oven-dried cell wall $(\mathrm{kg})$. In this study, we assumed $w_{\text {ovencw }}$ approximately equal to the weight of oven-dried wood. $v_{\text {fresh }}$ is the volume of the fresh wood $\left(\mathrm{m}^{3}\right)$. The specific heat capacity of the fresh 
wood was calculated following (Burgess et al., 2001a) as shown below (Eq. 6).

$$
c=\frac{w_{d r y} c_{d r y}+c_{w}\left(w_{f r e s h}-w_{d r y}\right)}{w_{\text {fresh }}}
$$

Where $c$ is heat capacity of fresh wood $\left(\mathrm{J} \mathrm{kg}^{-1} \mathrm{~K}^{-1}\right) . c_{\text {dry }}$ and $c_{\mathrm{w}}$ are heat capacity of dry wood $\left(1200 \mathrm{~J} \mathrm{~kg}^{-1} \mathrm{~K}^{-1}\right)$ and water $\left(4186 \mathrm{~J} \mathrm{~kg}^{-1} \mathrm{~K}^{-1}\right)$ at 20 ${ }^{\circ} \mathrm{C}$ (Edwards and Warwick, 1984), and $w_{\text {fresh }}$ and $w_{\text {dry }}$ are weights of fresh and dry wood. Because the wood domain contains wood matrix and sap (approximately equal to water in physical properties), heat transfer in such porous media directly depends on the contact surface between the two phases. Such heat transfer is characterized by interfacial area density (IFA, Eq. 7) which is defined as the surface area per unit volume $\left(\mathrm{m}^{-1}\right)$.

$$
I F A=\frac{\sqrt{4 \pi P F_{v-F S P}}}{100}
$$

Where $P$ is the number of conduits in $1 \mathrm{~cm}^{2}$ of the wood which is approximately 250 for bamboos according to Mohmod and Mustafa (1992). 


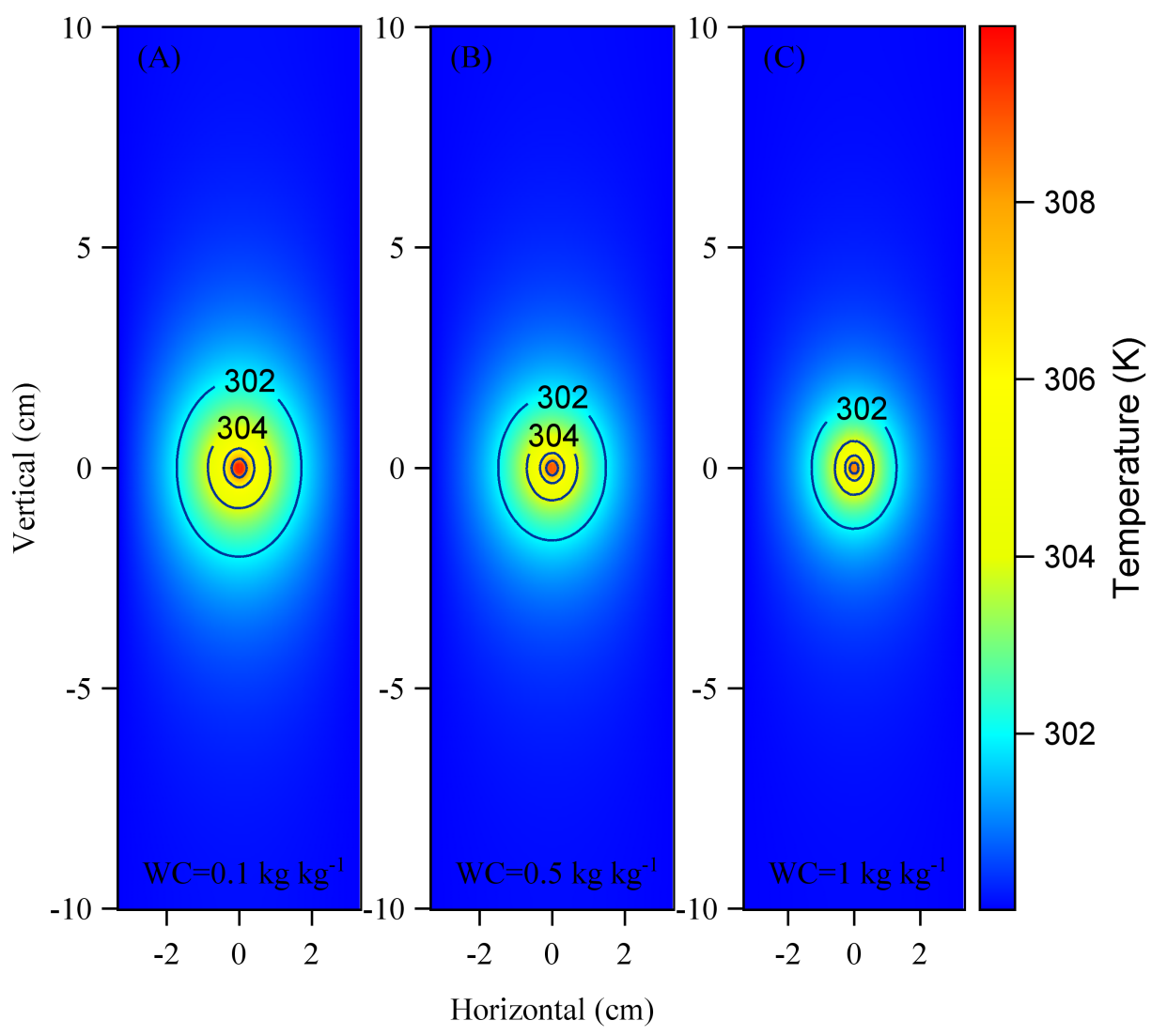

Fig. 1 The temperature contours around the heating probe under zero sap flow conditions. The simulated bamboo segments had different water contents of 0.1 (A), 0.5 (B) and $1 \mathrm{~kg} \mathrm{~kg}^{-1}(\mathrm{C})$, respectively. The ambient temperature in the model was set to $300 \mathrm{~K}$. The legend shows the increase of temperature after reaching steady-state thermal conditions. The geometry and physical properties applied in the model were based on a mature culm segment of $B$. vulgaris, extracted from a culm at breast height. 



\section{Declaration}

I hereby declare that I am the sole author of this dissertation entitled "MEASUREMENTS OF TROPICAL BAMBOO WATER USE". All the references and data sources that were used in this dissertation have been acknowledged. I further declare that this work has never been submitted in any forms as part of any other dissertation procedure.

Göttingen, January 2017

submitted by Ting-Ting Mei

April 2017 



\section{Acknowledgements}

First and foremost, I'd like to thank my supervisor Prof. Dr. Dirk Hölscher for his greatest support and guidance over my $\mathrm{PhD}$ study. Without his innovative idea and persistent endeavor, I would not go through the field work in China and Indonesia, and the data interpreting and publication work in Göttingen. I believe what I learn from him will enormously benefit my following career.

I also want to thank Prof. Dr. Hendrayanto from Faculty of Forestry in Bogor Agriculture University, for his passionate support and close cooperation during my staying in Indonesia.

Many thanks to our department secretary Eva Siegelkow for her patient and considerate help on each administrative things. Thanks to all the colleagues in the department of Tropical Silviculture and Forest Ecology for all the help. Especially thanks to Alex Röll and Furong Niu for their close cooperation in bamboo project. Also thanks to former stuffs: Diego Dierick, Michael Köhler and Luitgard Schwendenmann, for their kindly help on my research.

Thanks to all the people who ever helped in my field work. Especially thanks to Wahyu Iskandar who accompanied me from the beginning to the end of the experiment.

Thanks to all my friends in Göttingen for their help and encourage, especially thanks to Manli She, Hong Huang, Yuanheng Li, Qiong Bai. Thanks to Manli She from German Aerospace Center (DLR) for sharing her insight on ANSYS model and passionately discussing with us.

Thanks to my sister and my parents who always encourage and care for me. At last, I want to give my heartfelt gratefulness to my beloved husband, also my closest project cooperator, Dongming Fang. 



\title{
Curriculum vitae
}

\author{
Ting-Ting Mei
}

\section{Basic information}

$\begin{array}{ll}\text { Gender } & \text { Female } \\ \text { Email } & \text { ttmei84@126.com } \\ \text { Date of birth } & \text { 10 Aug. 1984 } \\ \text { Place of birth } & \text { Zhejiang, China } \\ \text { Citizenship } & \text { Chinese }\end{array}$

\section{High educations}

PhD (2011.10-) Plant Ecophysiology, Department of Tropical Silviculture and Forest Ecology, Georg-August-Universität Göttingen.

Master (2008.09-2011.07) Ecosystem physiology, South China Botanical Garden, Chinese Academy of Sciences, Guangzhou, China.

Bachelor (2004.09-2008.07) Forestry, College of Forestry, Northeast Forestry University, Harbin, China.

\section{Publications (As the main contribution)}

Ting-Ting Mei, Dong-Ming Fang, Alexander Röll, Fu-Rong Niu, Hendrayanto, Dirk Hölscher (2016) Water Use Patterns of Four Tropical Bamboo Species Assessed with Sap Flux Measurements. Frontiers in plant science 6, 1202.

Ting-Ting Mei, Ping Zhao, Guang-Yan Ni, Quan Wang, Xiao-Ping Zeng, Cui-Ming Zhou, Xi-An Cai, Meng-Hao Yu, Qing-Ping Cao, 2012. Effect of 
stem diameter at breast height on skewness of sap flow pattern and time lag. Acta Ecologica Sinica 32, 7018-7026. (In Chinese)

Ting-Ting Mei, Ping Zhao, Quan Wang, Xi-An Cai, Meng-Hao Yu, Li-Wei Zhu, Lv-Liu Zou, Xiao-Ping Zeng, 2010. Effects of tree diameter at breast height and soil moisture on transpiration of Schima superba based on sap flow pattern and normalization. Chinese Journal of Applied Ecology 21. (In Chinese)

Ting-Ting Mei, Chuan-Kuan Wang, Ping Zhao, Xi-An Cai, Xiao-Jing Liu, Quan-Zhi Zhang, 2010. Dynamics of trunk sap flux Density of Schima superba. Scientia Silvae Sinicae 40-47. (In Chinese)

Ping Zhao, Ting-Ting Mei, Li-Wei Zhu, Jun-Feng Niu, Guang-Yan Ni, 2014. Difference of measured sap flows of Bambusa chungii using thermal dissipation probes at different lengths and their in situ validation. Chinese Journal of Ecology 33, 1420-1428. (In Chinese)

Ping Zhao, Ting-Ting Mei, Guang-Yan Ni, Xiao-Ping Zeng, 2012. Application of thermal dissipation sap flow measuring system in investigating bamboo transpiration: Problems and solutions. Chinese Journal of Ecology 31, 187-193. (In Chinese)

Ping Zhao, Ting-Ting Mei, Guang-Yan Ni, Meng-Hao Yu, Xiao-Ping Zeng, 2012. Application of thermal dissipation probe in the study of Bambusa chungii sap flow. Chinese Journal of Applied Ecology 23, 979-984. (In Chinese)

\section{Other publications}

Xi-An Cai, Ping Zhao, Xiao-Ping Zeng, Li-Wei Zhu, Lv-Liu Zou, Ting-Ting Mei, Meng-Hao Yu, 2012. Dynamics of xylem sap flow of two Magnoliaceae tree species in relation to environmental factors. Chinese Journal of Ecology 31. (In Chinese)

Li-Wei Zhu, Ping Zhao, Xi-An Cai, Xiao-Ping Zeng, Guang-Yan Ni, Jun-Yan Zhang, Lv-Liu Zou, Ting-Ting Mei, Meng-Hao Yu, 2012. Effects of sap velocity on the daytime increase of stem $\mathrm{CO} 2$ efflux from stems of Schima 
superba trees. Trees 26, 535-542.

Cui-Ming Zhou, Ping Zhao, Guang-Yan Ni, Li-Wei Zhu, Quan Wang, TingTing Mei, Jun-Yan Zhang, Xi-An Cai, 2011. Whole-tree water use characteristics of Schima superba in wet and dry seasons based on sap flow and soil-leaf water potential gradient analysis. Chinese Journal of Ecology 30. (In Chinese)

Li-Wei Zhu, Ping Zhao, Guang-Yan Ni, Xi-An Cai, Xiao-Ping Zeng, Lv-Liu Zou, Ting-Ting Mei, Meng-Hao Yu, 2011. Differences of stem CO2 efflux among individual trees of Schima superba and effects of sap flow. Chinese Journal of Applied Environmental Biology 17, 447-452. (In Chinese)

\section{Conference presentations}

Ting-Ting Mei, Dong-Ming Fang, Michael Köhler, Hendrayanto, Dirk Hölscher: Water use of bamboos: methods test and first results. Poster presentation. Annual Conference of the Society for Tropical Ecology (gtö). Freising, Germany, 25-28 February 2014.

Ting-Ting Mei, Dong-Ming Fang, Alexander Röll, Hendrayanto, Dirk Hölscher: Water transfer between bamboo culms indicated by deuterium tracing. Poster presentation. $46^{\text {th }}$ Annual Meeting of the Ecological Society of Germany, Austria and Switzerland (gfö). Marburg, Germany, 05-09 September 2016.

\section{$\underline{\text { Academic awards }}$}

Di’Ao Scholarship in Chinese Academy of Sciences 2010 